\title{
Abbreviated Sampling and Analysis Plan for Planning Decontamination and Decommissioning at Test Reactor Area (TRA) Facilities
}

Published October 1994

SCIENTECH, Inc.

Idaho Falls, ID 83402

Prepared for Lockheed Idaho Under Subcontract and for the U.S. Department of Énergy

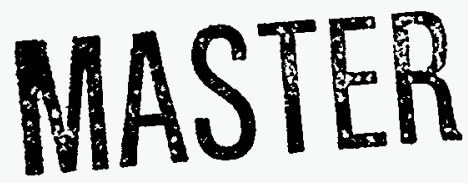

Assistant Secretary for Environmental Management Under DOE Idaho Field Office Contract DE-AC07-94ID13223 


\section{DISCLAIMER}

This report was prepared as an account of work sponsored by an agency of the United States Government. Neither the United States Government nor any agency thereof, nor any of their employees, makes any warranty, express or implied, or assumes any legal liability or responsibility for the accuracy, completeness, or usefulness of any information, apparatus, product, or process disclosed, or represents that its use would not infringe privately owned rights. Reference herein to any specific commercial product, process, or service by trade name, trademark, manufacturer, or otherwise does not necessarily constitute or imply its endorsement, recommendation, or favoring by the United States Government or any agency thereof. The views and opinions of authors expressed herein do not necessarily state or reflect those of the United States Government or any agency thereof. 


\section{DISCLAIMER}

Portions of this document may be illegible in electronic image products. Images are produced from the best available original document. 
Prepared for

ENVIRONMENTAL SUPPORT GROUP

\section{ABBREVIATED SAMPLING AND ANALYSIS PLAN FOR PLANNING DECONTAMINATION AND DECOMMISSIONING AT TEST REACTOR AREA (TRA) FACILITIES}

October 1994

\section{APPROVED BY}
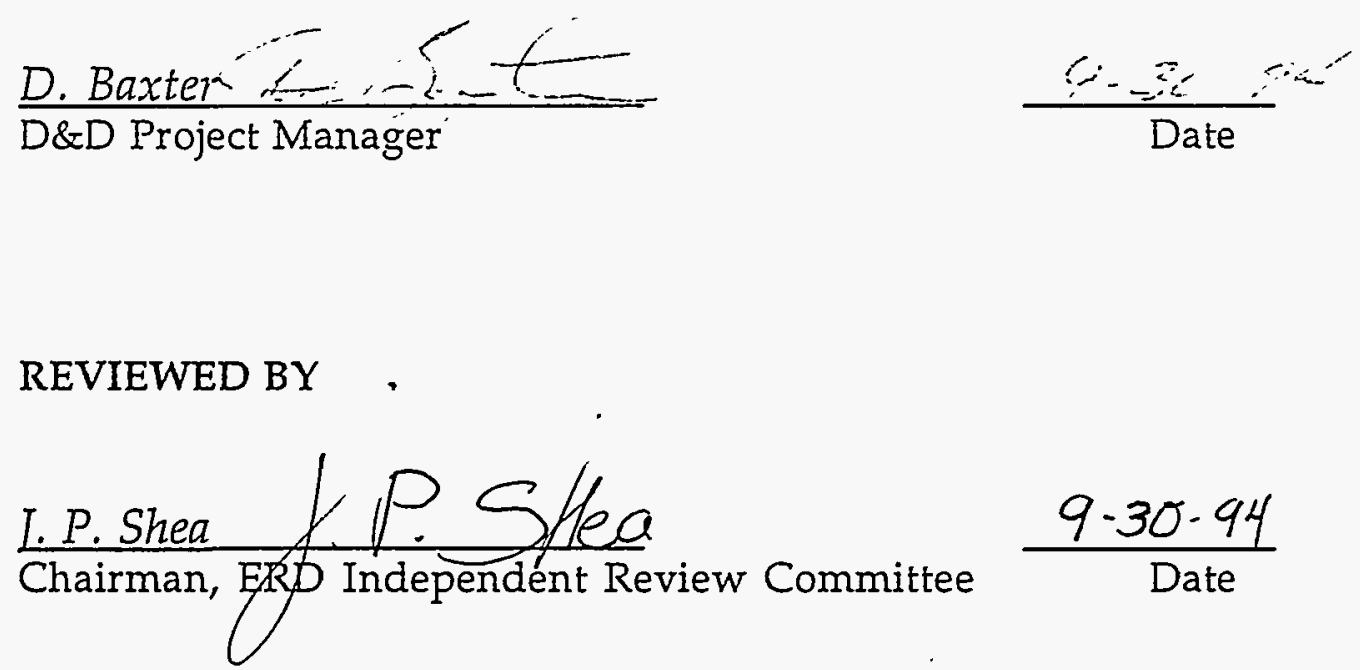


\section{TABLE OF CONTENTS}

ABSTRACT $x \mathrm{i}$

ACRONYMS xii

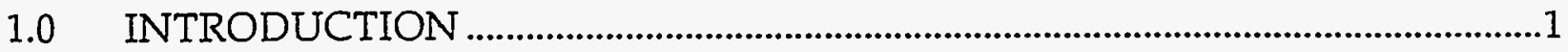

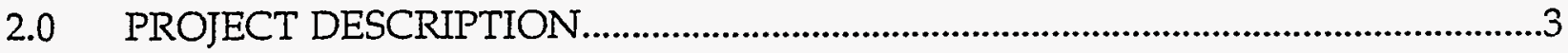

2.1 Background ............................................................................................

2.1.1 Sampling Areas...................................................................................6

2.1.2 Summary of Sampling Safety Issues .................................................14

2.2 Objectives and Scope..................................................................................15

2.3 Area Description ..................................................................................16

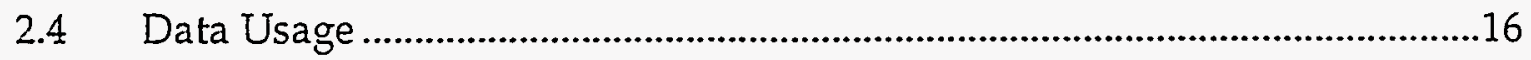

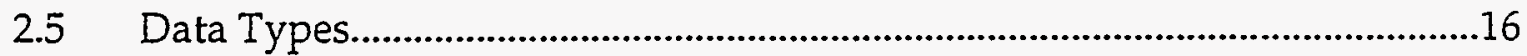

2.6 Personnel Safety and Health Precautions...................................................17

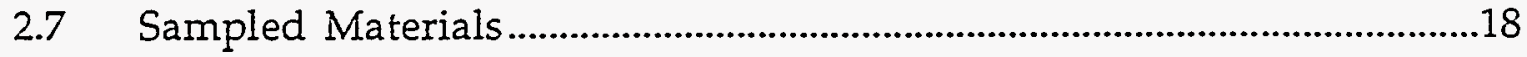

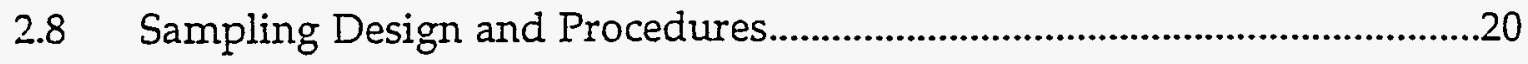

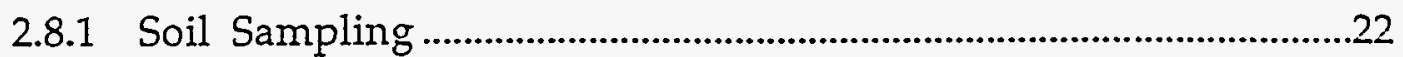

2.8.2 Aqueous Liquid Samples in Sumps .................................................23

2.8.3 Aqueous Liquid Samples from Tanks...............................................24

2.8.4 Concrete and Brick Samples..............................................................25

2.8.5 Drain Traps....................................................................................26

2.8.6 Piping and Drains Serving Reactor Experimental Loops...............27

2.8.7 Oil Reservoirs in Equipment.............................................................28

2.8.8 Ventilation System Filter Media.........................................................29

2.8.9 Paint from Walls in Radioactively Contaminated Areas..............29

2.8.10 Ion Exchange Resins...............................................................................30

2.9 Sample Identification and Locations............................................................31

2.10 Radiological Considerations.............................................................................39

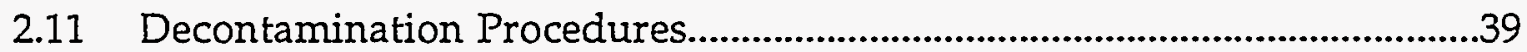

2.11.1 Disposal of Contaminated Materials .......................................................39

3.0 DATA QUALITY OBJECTIVES AND REQUIREMENTS ......................................40

3.1 Completeness and Critical Samples...................................................................40

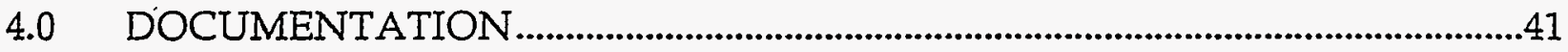


DATA VALIDATION AND REPORTING.....................................................42

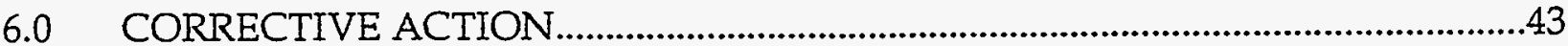

6.1 Field Corrective Action ..................................................................................43

6.2 Laboratory Corrective Action...................................................................43

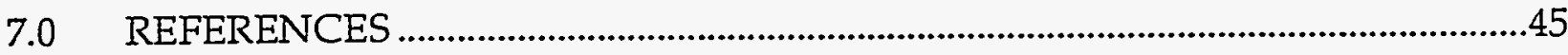



\section{FIGURES}

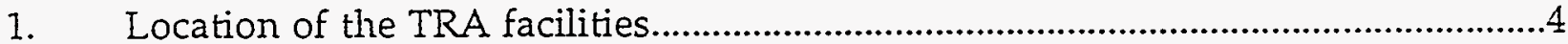

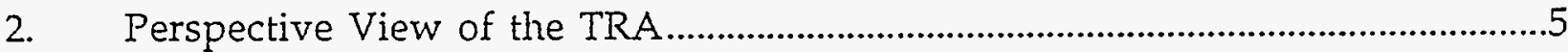

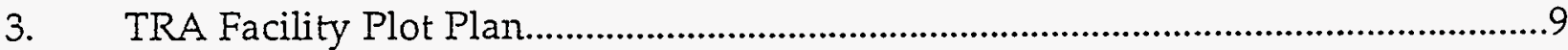

Figure A-1: Sample Label ..........................................................................................118

Figure A-2: Chain-of-Custody (COC) Form ...............................................................119

Figure A-3: Sample Log Sheets (Page 1 of 2)..................................................................120

Figure A-3: Sample Log Sheets (Page 2 of 2)..................................................................121

\section{TABLES}

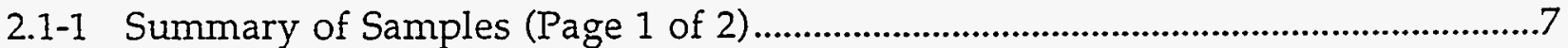

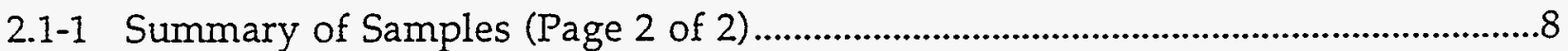

2.9-2 Sampling Parameters by Location................................................................................33

2.9-3 Listing of Sample Numbers Assigned by the INEL SMO.......................................34

2.9-4 Environmental Monitoring Target Radionuclide List...........................................37

2.9-5 Typical Requirements — Soils/Sediments/Sludges/Biota (DOE, 1989a)..........38

\section{EXHIBITS}

Exhibit 1.1: Location Drawing for Sample Group 1:

TRA -611 Plug Storage Facility: Soil Sampling Required Below Plug Storage

Channels (\#1)

Exhibit 1.2: Location Drawing for Sample Group 2:

TRA -612 MTR Retention Basin Sump Pumphouse: Liquid and Sludge

Sampling Required in Sump (\#2) 
Exhibit 1.3: Location Drawing for Sample Groups 3 and 4 ( 1 of 2):

TRA -644 ETR Heat Exchanger Building: Concrete Sampling Required in Resin Transfer Area (\#3) and in Degasifier Tank, Roof of Building (\#4)

Exhibit 1.4.: Location Drawing for Sample Groups 3 and 4 (2 of 2):

TRA -644 ETR Heat Exchanger Building: Concrete Sampling Required in Resin Transfer Area (\#3), and in Degasifier Tank, Roof of Building (\#4)

Exhibit 1.5: Location Drawing for Sample Groups 5 through 8:

TRA -645 ETR Secondary Coolant Pump House:

Samples Required in Pit Area (\#5 and \#6)

Samples of Drain and Brick Required (\#7)

Soil Samples Required (\#8)

Exhibit 1.6: Location Drawing for Sample Groups 9 through 13:

TRA -647 ETR Office Building

Room 104, Sink Drain Samples Required ( $\$ 9)$

Shop, Sink Drain Samples Required (\#10)

Basement HVAC Room

Sump Pit with Tank in Pit, Samples Required for Tank and Pit (\#11)

Samples Required of Hydraulic Oil in Dash Pots ("\#12)

Air Intake Filters, Filter Media Samples Required for Lead (\#13)

Exhibit 1.7: Location Drawing for Sample Groups 14 through 18:

TRA -642 ETR Reactor Building Basement,

Sub Pile Room, Sump Samples Required (\#14)

Sub Pile Room, Paint Samples Required Inside and Outside of Room (

Cubicle No. M-3,

Resin Samples Required from Inside M-3 (\#16)

Warm Waste Tanks Below Floor, Tank Samples Required (\#17)

Cold Waste Pit Below Floor, Pit Interior Samples Required to Verify

Cleanliness (\#18)

Exhibit 1.8: Location Drawing for Sample Group 19:

TRA -642 ETR Reactor Building Basement Decontamination Station, Oil Residue Samples Required for PCB Analysis (\#19)

Exhibit 1.9: Location Drawing for Sample Groups 20 through 23:

TRA -642 ETR Reactor Building Basement, South Console Floor

Pipe Trench Adjacent to Reactor Containment, Samples Required from Trench ( $\# 20, \# 21$ )

Hot Experiment Drain, Representative Drain Sample Required from One Drain (\#22)

Warm Drain Around Storage Canal, Sample Required from Drain and Trench Drain (\#23) 
Exhibit 1.10: Location Drawing for Sample Groups 24 through 32:

TRA -643 ETR Compressor Building

Gate Valve Motor Operators, Representative Oil Sample Required (\#24)

Primary Coolant Pump Motor, 460V, Representative Oil Reservoir Sample

Required (\#25)

Pipe Trench, Pit and Trench Samples Required (\#26)

Compressors, Representative Oil Sample Required (\#27)

Compressor Actuators, Representative Oil Sample Required (\#28)

Trench Below Compressors, Trench Sample Required (\#29)

Compressor Motor Drive, Oil Reservoir Sample Required (\#30)

Decon Restroom, Samples from Shower Drain and Sinks Required (\#31)

Chemistry Laboratory, Samples from Sink and Trench Required (\#32)

Exhibit 1.11: Location Drawing for Sample Groups 33 through 35:

TRA -648 ETR Electrical Building

Diesel Generator Room Pit, Pit Samples Required (\#33)

Battery Room, Samples of Drain and Floor Spill Areas Required (\#34)

TRA -663 ETR Superior Diesel Building (Adjacent to TRA-648, to SW, not shown)

Fuel Injector Cleaning Station, Residue Samples Required (\#35)

Exhibit 2.1: Photograph of TRA -611 Plug Storage Facility.

Soil Sampling Required Below Channels, (View to East)

Exhibit 2.2: Photograph of TRA -612 MTR Retention Basin Sump Pumphouse Liquid and Sludge Sampling Required from Floor, 40 feet down (View to Northwest)

Exhibit 2.3: Photograph of TRA -644 ETR Heat Exchanger Building Concrete Samples Required Outside of Building, in Resin Handling Area (View to Northwest)

Exhibit 2.4: Photograph of TRA -644 ETR Heat Exchanger Building Sampling Required in Degasifier Tank Room, Roof of Building (View to Northwest)

Exhibit 2.5: Photograph of TRA -645 ETR Secondary Coolant Pump House Samples Required in Pit Area

(View to West)

Exhibit 2.6: Photograph of TRA -645 ETR Secondary Coolant Pump House Top-- Closeup of Coolant Pit Bottom-- West Side of Coolant Pump House Samples Required in Pit Area 
Exhibit 2.7: Photograph of TRA -645 ETR Secondary Coolant Pump House Top -- Acid Pit Area Drain (View to South) Bottom -- Acid Pit Area Samples of Drain and Brick Required

Exhibit 2.8: Photograph of TRA -645 ETR Secondary Coolant Pump House South Side of Building Three Soil Samples Required (View to West)

Exhibit 2.9: Photograph of TRA -647 ETR Office Building, Room 104 Sink Drain Samples Required (View to East)

Exhibit 2.10: Photograph of TRA -647 ETR Office Building, Shop Sink Drain Samples Required (View to North)

Exhibit 2.11: Photograph of TRA -647 ETR Office Building Basement HVAC Room Sump Pit with Tank in Pit Samples Required for Tank and Pit (View to North)

Exhibit 2.12: Photograph of TRA -647 ETR Office Building Basement HVAC Room Closeup of Sump Pit Area Samples Required of Hydraulic Oil in Dash Pots (View to East)

Exhibit 2.13: Photograph of TRA -647 ETR Office Building Basement HVAC Room Air Intake Filters Filter Media Samples Required for Lead (View to East)

Exhibit 2.14: Photograph of TRA -642 ETR Reactor Building Basement Stairs to Rod Access Room Sump Samples Required (View to West)

Exhibit 2.15: Photograph of TRA -642 ETR Reactor Building Basement Sub Pile Room Paint Samples Required Inside and Outside of Room (View to West) 
Exhibit 2.16: Photograph of TRA -642 ETR Reactor Building Basement Cubicle No. M-3, Resin Samples Required from Inside M-3 (View to South)

Exhibit 2.17: Photograph of TRA -642 ETR Reactor Building Basement Cubicle No. M-3, Warm Waste Tanks Below Floor Tank Samples Required

(View to West)

Exhibit 2.18: Photograph of TRA -642 ETR Reactor Building Basement Cubicle No. M-3, Cold Waste Pit Below Floor Pit Interior Samples Required to Verify Cleanliness (View to Northeast)

Exhibit 2.19: Photograph of TRA -642 ETR Reactor Building Basement Decontamination Station Oil Residue Samples Required for PCB Analysis (View to South)

Exhibit 2.20: Photograph of TRA -642 ETR Reactor Building Basement South Console Floor, Pipe Trench Adjacent to Reactor Containment Samples Required from Trench

(View to Northwest)

Exhibit 2.21: Photograph of TRA -642 ETR Reactor Building Basement South Console Floor, Pipe Trench Adjacent to Reactor Containment Samples Required from this End of Trench (View to Northeast)

Exhibit 2.22: Photograph of TRA -642 ETR Reactor Building Basement South Console Floor, Hot Experiment Drain Representative Drain Sample Required from One Drain (View to South)

Exhibit 2.23: Photograph of TRA -642 ETR Reactor Building Basement South Console Floor, Warm Drain Around Storage Canal Sample Required from Drain and Trench Drain (View to West)

Exhibit 2.24: Photograph of TRA -643 ETR Compressor Building Gate Valve Motor Operators Representative Oil Sample Required (View to East) 
Exhibit 2.25: Photograph of TRA -643 ETR Compressor Building Primary Coolant Pump Motor, 460V

Representative Oil Reservoir Sample Required

(View to North)

Exhibit 2.26: Photograph of TRA -643 ETR Compressor Building Pipe Trench

Pit and Trench Samples Required

(View to East)

Exhibit 2.27: Photograph of TRA -643 ETR Compressor Building Compressors Representative Oil Sample Required

(View to South)

Exhibit 2.28: Photograph of TRA -643 ETR Compressor Building Compressor Actuators

Representative Oil Sample Required

(View to North)

Exhibit 2.29: Photograph of TRA -643 ETR Compressor Building Trench Below Compressors

Trench Sample Required

Exhibit 2.30: Photograph of TRA -643 ETR Compressor Building - Compressor Motor Drive

Oil Reservoir Sample Required

(View to North)

Exhibit 2.31: Photograph of TRA -643 ETR Compressor Building Decon Restroom

Samples from Shower Drain and Sinks Required

(View to West)

Exhibit 2.32: Photograph of TRA -643 ETR Compressor Building Chemistry Laboratory

Samples from Sink and Trench Required

(View to South)

Exhibit 2.33: Photograph of TRA -648 ETR Electrical Building

Diesel Generator Room Pit

Pit Samples Required

(View to West) 
Exhibit 2.34: Photograph of TRA -648 ETR Electrical Building

Battery Room

Samples of Drain and Floor Spill Areas Required

(View to Northeast)

Exhibit 2.35: Photograph of TRA -663 ETR Superior Diesel Building

Fuel Injector Cleaning Station

Residue Samples Required 


\begin{abstract}
This Abbreviated Sampling and Analysis Plan (ASAP) supports the EG\&G Idaho, Inc., Decontamination and Decommissioning (D\&D) Program at the U.S. Department of Energy's Idaho National Engineering Laboratory (INEL) in Southeastern Idaho. The objective is to sample and analyze for the presence of gamma emitting isotopes and hazardous constituents within certain areas of the Test Reactor Area (TRA), prior to D\&D activities.

The TRA, located approximately 4.5 miles northwest of the Central Facilities Area (CFA), is composed of three major reactor facilities and three smaller reactors built in support of programs studying the performance of reactor materials and components under high neutron flux conditions. The Materials Testing Reactor (MTR) and Engineering Test Reactor (ETR) facilities are currently pending Decontamination and Decommissioning. ATR continues to operate.
\end{abstract}

Work encompassed in this ASAP consists of pre-D\&D sampling of designated TRA (primarily ETR) process areas. This ASAP addresses only a limited subset of the samples which will eventually be required to characterize MTR and ETR and plan their D\&D. Sampling which is addressed in this document is intended to support planned $D \& D$ work which is funded at the present time. Biased samples, based on process knowledge and plant configuration, are to be performed. The multiple process areas which may be potentially sampled will be initially characterized by obtaining data for upstream source areas which, based on facility configuration, would affect downstream and as yet unsampled, process areas. Sampling and analysis will be conducted to determine the level of gamma emitting isotopes and hazardous constituents present in designated areas within buildings TRA-612, 642, 643, 644, 645, 647, 648, 663; and in the soils surrounding Facility TRA611. These data will be used to plan the D\&D and help determine disposition of material by D\&D personnel. Both MTR and ETR facilities will eventually be decommissioned by total dismantlement so that the area can be restored to its original condition.

This document also functions as a Quality Plan during site sampling and analysis to ensure that all data collected are valid, reliable, and defensible. The ASAP outlines organization, objectives, and quality assurance/quality control activities to achieve the desired data quality goals. 


\section{ACRONYMS}

ARA

ASAP

CFA

$\mathrm{COC}$.

$\mathrm{C} / \mathrm{P}$ or $\mathrm{CPM}$

D\&D

DMS

DOE

DQOs

EG\&G

EM

EMSP

EPA

ESG

ETR

FTL

HAZMAT

HEPA

HMTM

HPLC

HSP

ICP

IH

INEL

LDPE

LLW

$\mathrm{mg}$

$\mathrm{ml}$

MS/MSD

MTR

$\mathrm{MW}(\mathrm{t})$

NIOSH
Auxiliary Reactor Area

Abbreviated Sampling and Analysis Plan

Central Facilities Area

Chain of Custody

counts per minute

decontamination and decommissioning

data management system

U.S. Department of Energy

data quality objectives

EG\&G Idaho

environmental monitoring

environmental monitoring standard practices

U. S. Environmental Protection Agency

Environmental Support Group

Engineering Test Reactor

Field Team Leader

hazardous material

high-efficiency particulate air

EG\&G Hazardous Materials Transportation Manual

high-performance liquid chromatography

Health and Safety Plan

inductively coupled plasma

Industrial Hygienist

Idaho National Engineering Laboratory

Low Density Polyethylene

Low Level Radioactive Waste

milligram

milliliter

matrix spike and matrix spike duplicate

Materials Testing Reactor

Megawatts, thermal

National Institute for Occupational Safety and

Health 
OMP

OSHA

PPE

QA/QC

QAPjP

RADCON

RAM

RCRA

$R C T$

RML

RRWAC

RSD

RTV

RWMC

RWP

SMO

SOP

SW -846

TCLP

TLV

TRA

TRU

$\mu \mathrm{g}$

VOA

VOCs
Occupational Medical Program

Occupational Safety and Health Administration personal protective equipment

quality assurance and quality control

quality assurance project plàn

Radiation Control

radiation area monitor

Resource Conservation and Recovery Act

Radiological Control Technician

Radiation Measurements Laboratory

Reusable Property, Recyclable Material Waste

Acceptance Criteria

relative standard deviation

reactor temperature vulcanizing

Radioactive Waste Management Complex

Radiological Work Permit

Sample Management Office

standard operating procedure

EPA publication SW-846: Test Methods for

Evaluating Solid Waste

toxicity characteristic leaching procedure

threshold limit value

Test Reactor Area

transuranic radioactive waste

microgram

volatile organic analysis

volatile organic compounds 


\section{ABBREVIATED SAMPLING AND ANALYSIS PLAN FOR PLANNING DECONTAMINATION AND DECOMMISSIONING AT TEST REACTOR AREA (TRA) FACILITIES}

\section{1:0 INTRODUCTION}

This abbreviated sampling and analysis plan (ASAP) was prepared for the Decontamination and Decommissioning (D\&D) Program, which is responsible for the total dismantlement of the Materials Testing Reactor (MTR) and the Engineering Test Reactor (ETR).

\section{Scope}

This ASAP addresses only a portion of the samples which will eventually be required to characterize the entire MTR and EIR and plan their D\&D. Sampling, addressed in this document is intended to support planned D\&D work. For the areas addressed, the document outlines the approach for gathering sufficient and appropriate data to plan the D\&D of designated TRA facilities, and ensure proper characterization of materials from the planned work areas for proper disposal. Wast: materials will be disposed of in accordance with the RRWAC, DOE/ID-10381. Resource Conservation and Recovery Act (RCRA) hazardous waste and Class I nonhazardous waste will be transported to a RCRA-approved landfill. Unregulated waste does not require special handling for removal.

\section{Correlated Data}

The document is organized to allow cross-referencing (See Table 1.1) the planned samples, sampling methodology, media, planned analytes, and sampling locations. Location drawings and photographs of the sites to be sampled are provided as exhibits at the back of the document.

\section{Quality Plan}

This ASAP also functions as a Quality Assurance Project Plan (QAPjP). A QÀPjP serves as a controlling mechanism during sampling and analysis to ensure that all data collected are valid, reliable, defensible, and meet the identified data quality objectives. This document outlines the organization, objectives, and quality assurance/quality control (QA/QC) activities needed to achieve the desired data quality objectives.

\section{Key Personnel}

The Abbreviated Sampling and Analysis Plan and the Health and Safety Plan for the preliminary sampling assessment of the MTR and ETR work areas was requested by 
Don Baxter in June, 1994. The following are key project personnel and responsibilities:

Prepared By:

Field Team Leader:

Sampling Operations:

IH/Safety:

Quality Assurance:

Laboratory:

Validation:

Radiological Engineer:
N. R. Ricks, SCIENTECH

TBD

TBD

TBD

TBD

To be contracted by the EG\&G Idaho Sample

Management Office (SMO)

SMO

TBD 


\subsection{PROJECT DESCRIPTION}

\section{$2.1 \quad$ Background}

The TRA, located approximately 4.5 miles northwest of the Central Facilities Area (CFA) of the INEL (see Figure 1), is composed of three major reactor facilities and three smaller reactors built in support of programs studying the performance of reactor materials and components under high neutron flux conditions. The MTR and ETR facilities are currently pending Decontamination and Decommissioning. ATR continues to operate.

This ASAP is intended to address D\&D work which can be accommodated by currently approved budgets, and is restricted primarily to areas at ETR.

Materials Testing Reactor

The Materials Testing Reactor (MTR) was the second reactor operating at INEL, and was first operated on March 31, 1952, at a power level of $30 \mathrm{MW}(\mathrm{t})$, (see Figure 2). MTR was used until April 23, 1970, when it was placed in standby status. MTR consists of a building containing the reactor structure, extensive experimental facilities, and a storage canal. Waste systems at MTR are still operable.

Engineering Test Reactor

The Engineering Test Reactor (ETR) became operational in 1957, at an operating power level of $175 \mathrm{MW}(t)$. It provided more high-flux testing space, more stable flux, and a greater variety of flux levels than the MTR could provide, (see Figure 2). ETR was used until 1981.

ETR is housed in a three-story building with two complete floors below grade. The first basement houses experimental control panels, (identified in drawings as the "Console"); the second basement contains experimental equipment, housed in heavily-shielded concrete cubicles (identified in drawings as the "Basement").

The reactor main floor is relatively clear of plant and experimental equipment, and provides access to the T-shaped storage canal.

Much of the proposed sampling activity is adjacent to the experimental facilities areas at ETR, which consist of high pressure water loops. The loops pumped as much as 100 gallons per minute of high temperature, high pressure water past experimental fuel assemblies located in special facilities passing through the reactor core. 


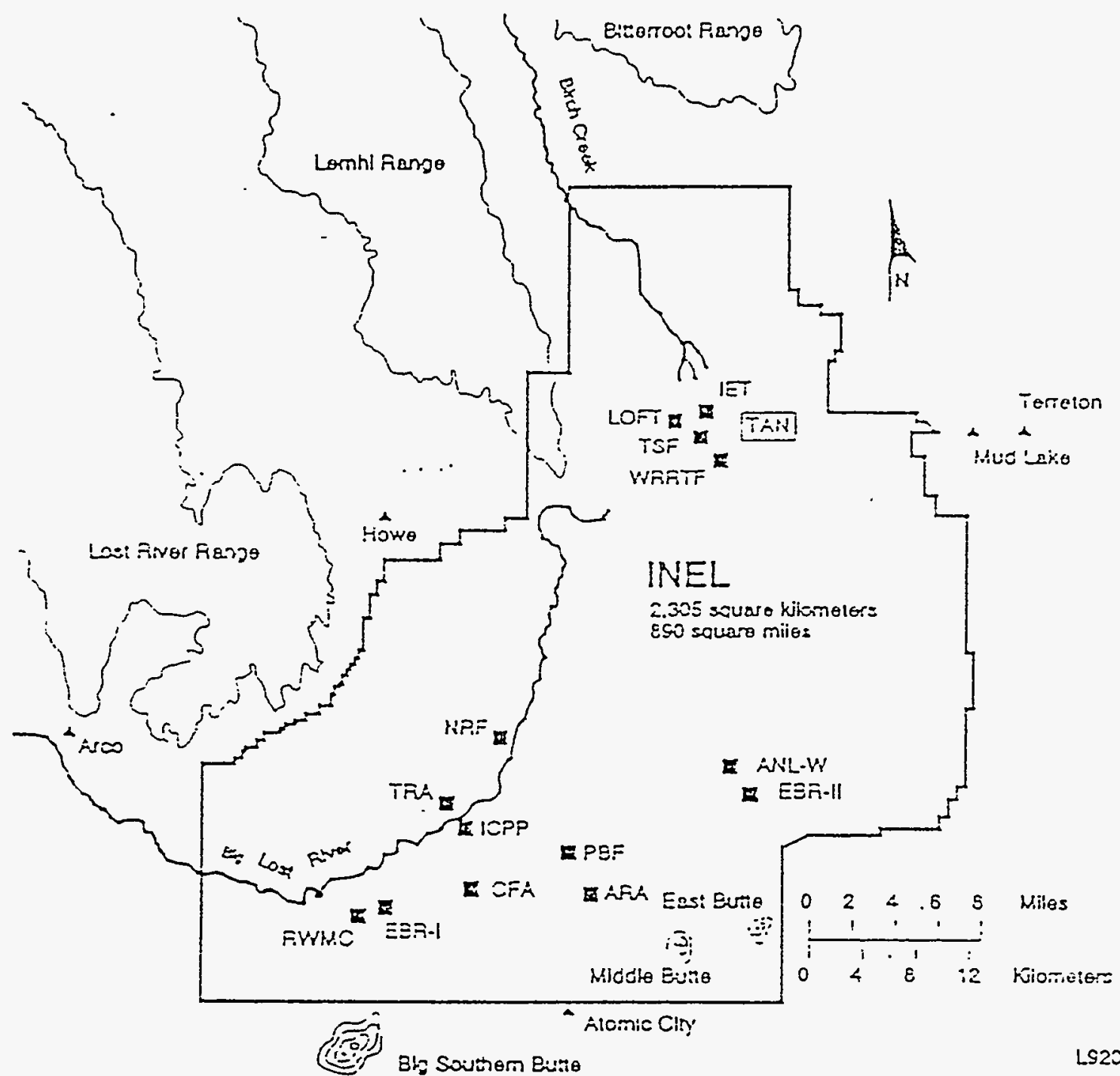

LS200391

Auxitiay Foecos Anes

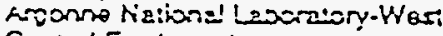

Cöritel Fentres Nos

Experitibaila E Ratar Racal

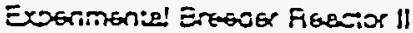

lawn Chernics' Piocosing Piart

Ireal Engine Tar.

Less-o.Filuid Tos. Factury

Neva Fas $=0$ : Facility

Fowor Eu=i Focility

Fatioscro Wevto haneganent Fazthy

ior. hroe Nors

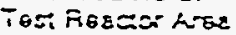

Tor: Suppor: Foctity

Waler Fios=0: Fieseares Tost Facilly

Figure 1. Location of the TRA facilities 


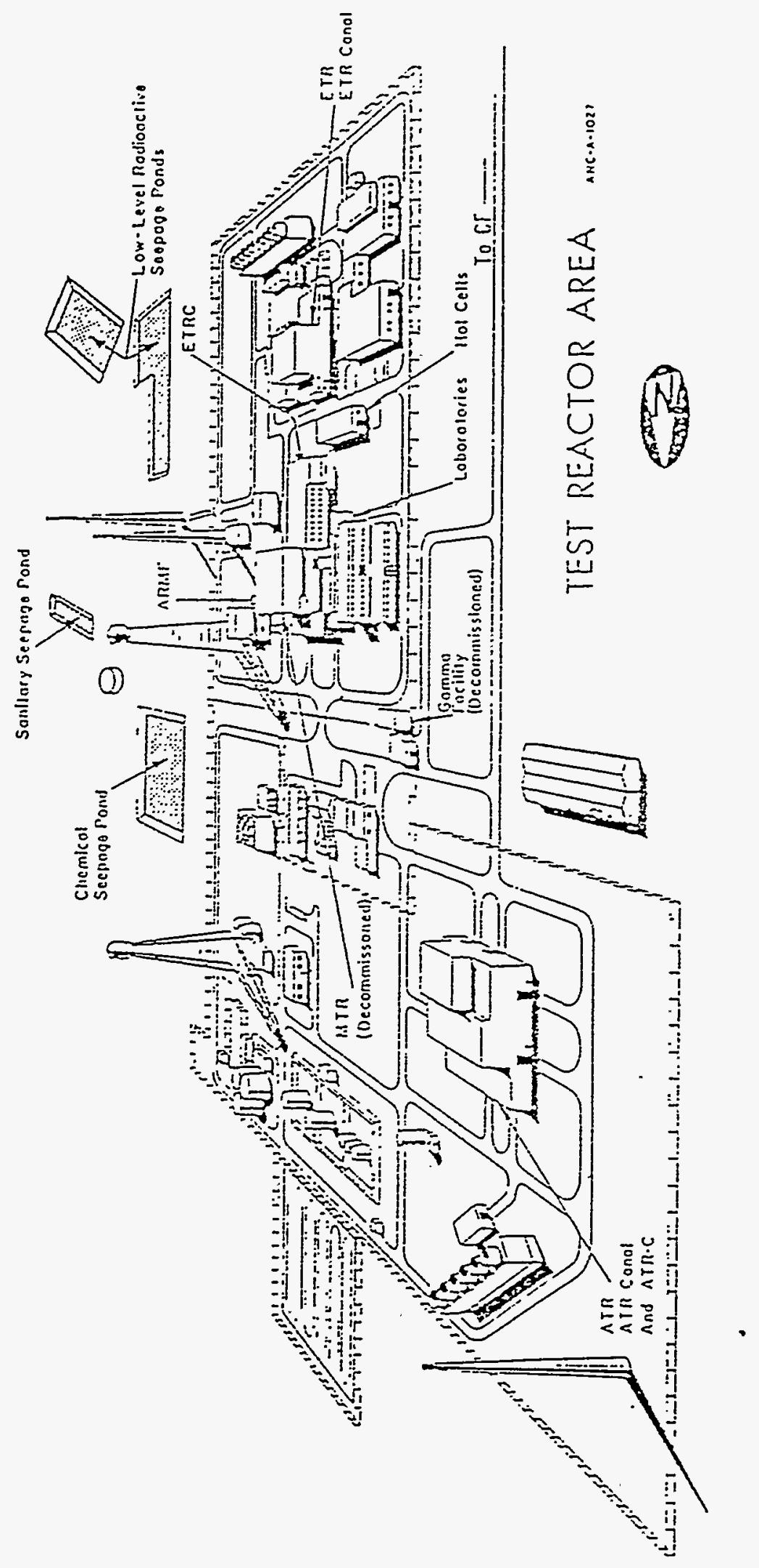

Figure 2. Perspective View of the TRA 


\section{Adranced Test Reactor}

The Advanced Test Reactor (ATR), the wrorld's largest test reactor, became operational in July, 1967, and has operated since that time at near its operating power level of $250 \mathrm{MW}(\mathrm{t}$ ), (see Figure 2). Because ATR continues in use today, it is not considered for D\&D at the present time, and is not addressed in this ASAP.

\subsubsection{Sampling Areas}

The facility locations targeted for this characterization are listed in Table 2.1-1, together with references to their associated location drawings and photographs, which are presented as Exhibits in the rear of this document. The spatial relationship of the facilities to one another is shown in Figure 3. A general description of the processes and waste streams associated with these areas is identified below:

\section{TRA-611 Plug Storage Facility}

The Plug Storage Facility is an ancillary structure supporting MTR experiment nandiling. It consists of a series of 14 horizontal east-west parallel channels accessible from their east end (inside the building), the west portions of which extend outside the building through a wall, and are covered with a soil covering to a depth of approximately eight feet. The soil covering the channels is posted as a radiation area. The soil is to be sampled at locations near--and below--the channels to confirm the presence of gamma emitting isotopes, as a prerequisite to its proper handling and disposai. No process knowiledge has been identified to indicate a creciible potential of chemical contamination to the soils; therefore no chemical sampling is to be performed.

\section{IRA-612 Retention Basin Pumphouse Sump}

The MIR primary coolant circuit includes a set of large concrete underground retention basins which are designed to be able to receive all of the primary coolant in the event of an accident, and retain it until such time as the short-lived isotopes have decayed sufficiently to allow the water to be released to a surface pond. The IRA-612 building is the pumphouse associated with these retention basins. It is located well southeast of MTR, and consists of a walled structure approximately 15 feet square by 10 feet deep within which the pump risers and inlet/outlet piping to the :etention basins are located. Tha liquid which has accumulated in the bottom of the pumphouse sump, will be sampled. During the active life of the facility, the retention basins did receive primary coolant liquids which were transferred to the - hârm waste pond. No process knowledge has been identified to indicate a credible potential of chemical contamination to the sump liquid; therefore no chemical sampling is to be performed. If sludge is present, a sample will be obtained and analyzed for gamma emitting isotopes and TCLP metals. 


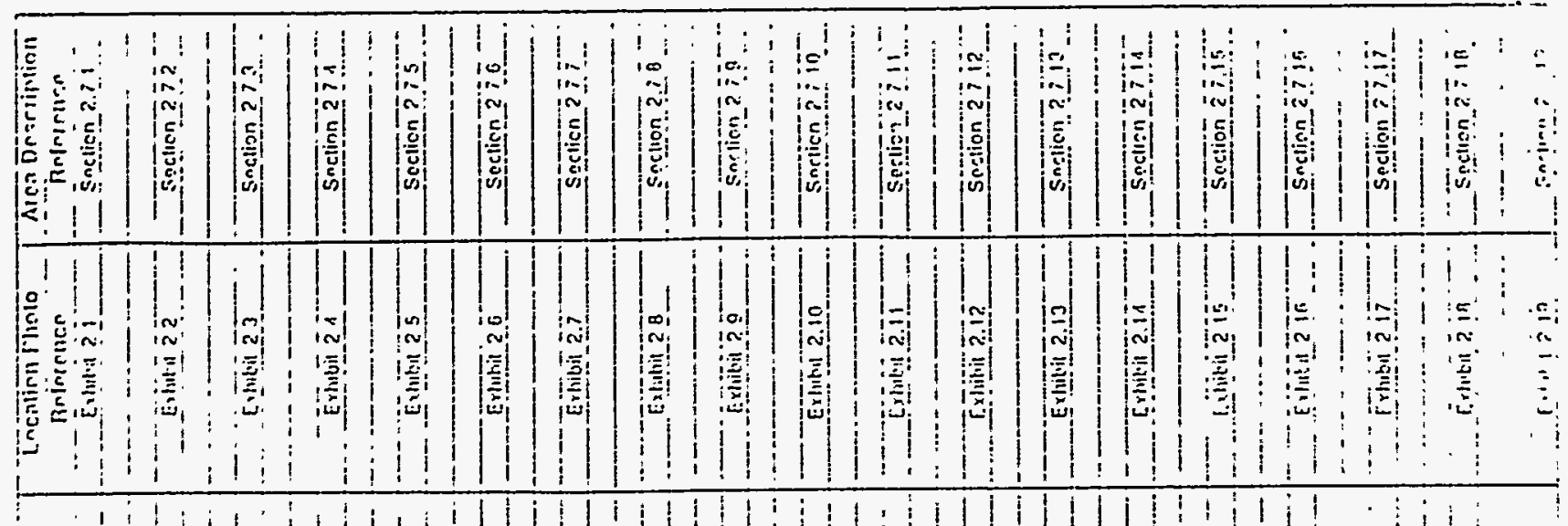

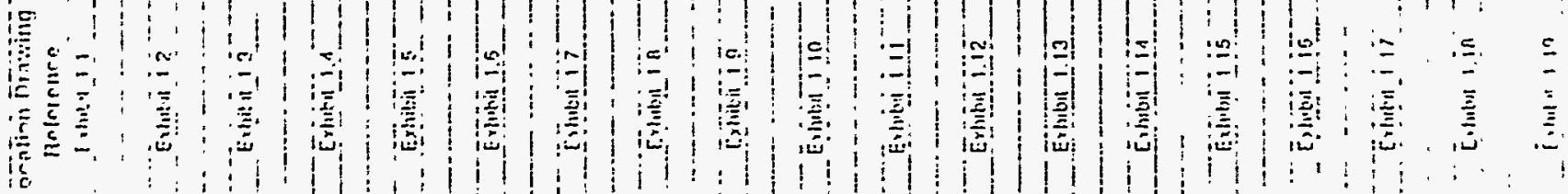

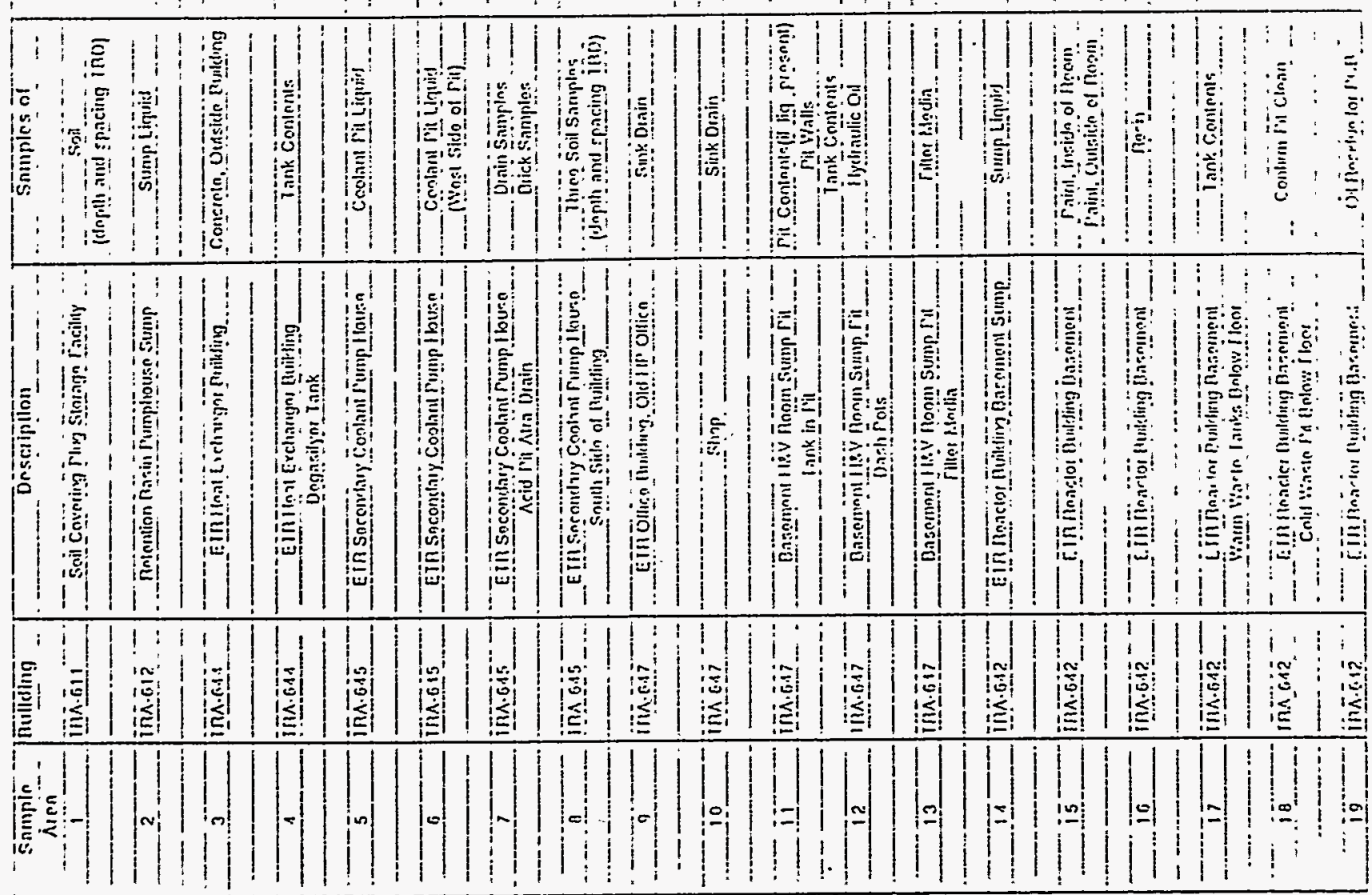

Table 2.1-1. Summary of Samples (Pàge 1 of 2) 


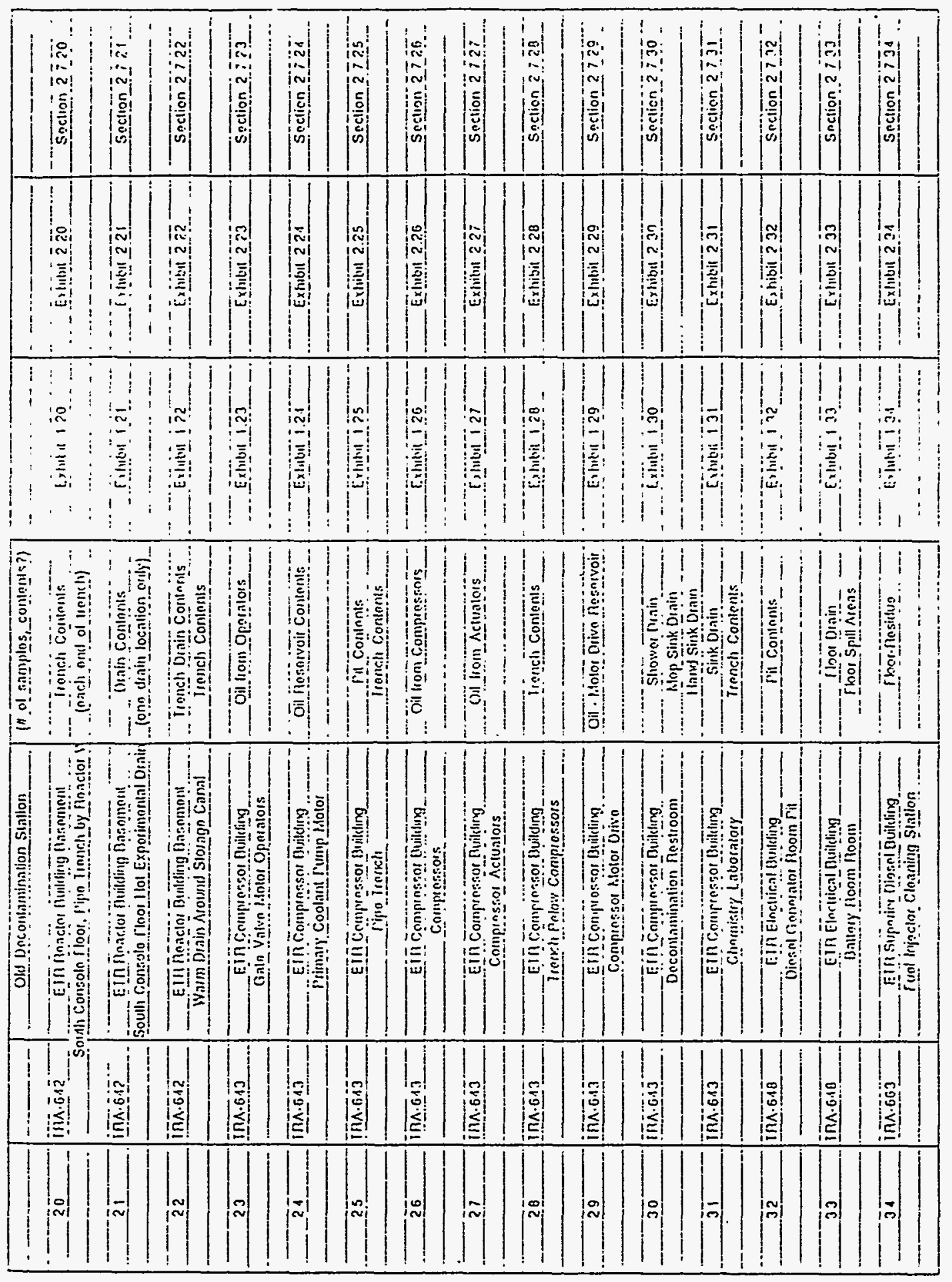

Table 2.1-1. Summary of Samples (Page 2 of 2) 


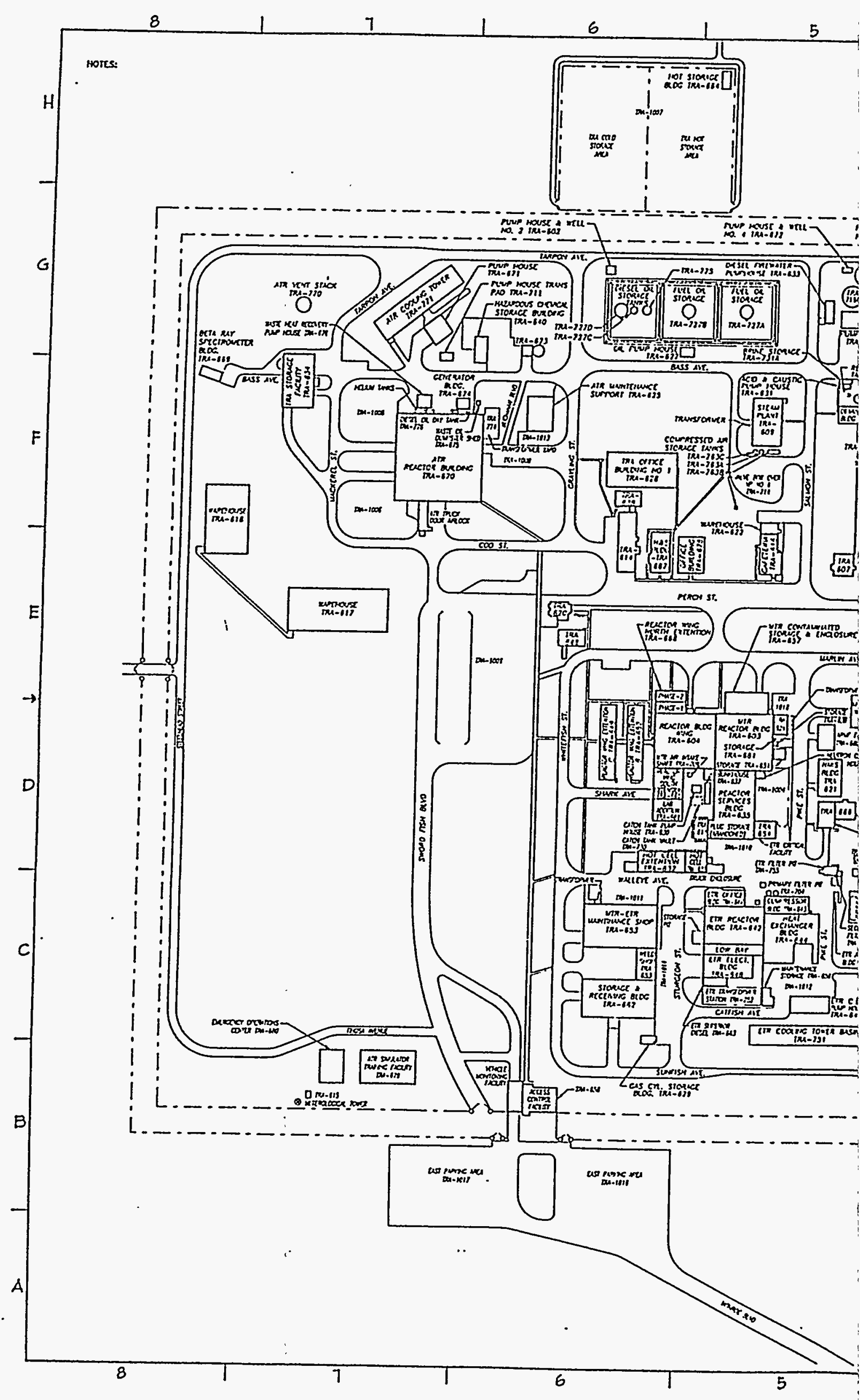


The TRA-612 structure is a confined space as defined by OSHA, and special access and egress precautions will apply to the sampling crew. Access is gained through a manhole in the surface cover.

\section{TRA-644 ETR Heat Exchanger Building}

The ETR Heat Exchanger building is located east of the ETR, and houses the pumps, and heat exchangers which transfer the heat from the primary coolant circuit flowing through the reactor (demineralized water) to the secondary coolant circuit which releases the heat through the cooling towers to the atmosphere. It also contains water treatment facilities and their associated piping and tankage. This sampling plan addresses only sampling associated with the concrete on the building east-side exterior (where ion-exchange resins were transferred), and with a 20-foot diameter, 10-foot high steel degassing tank located on the roof. Resins were designed to remove metals from the water, so any spillage would present a potential for heavy metal contamination of the concrete. Analyses for TCLP metals and radionuclides are to be performed in this area.

The degassing tank located on the roof is a confined space as defined by OSHA, and special access and egress precautions will apply to the sampling crew. Access is gained through a manhole in the tank top.

\section{TRA-645 ETR Secondarv Coolant Pump House}

The ETR Secondary Coolant Pump House is located immediately north of the ETR Cooling Tower, and houses the pumps, piping, tankage and water treatment appliances for the secondary cooling system. Samples are required of any residues or sludges present in the sump below the pipe trench which enclosed the coolant supply pipe and provides the area needed to manifold the output from the four secondary coolant pumps, the two utility pumps, and the emergency pump. Samples of the acid-resistant brick and of the drain serving the acid-handling area are also required. At least three soil samples are required from the south exterior of the building, through the wall from the area formerly occupied by the chemical mixing tanks.

It should be noted that the return water from the cooling tower entered a cold well from which the pumps drew water reentering the heat exchangers. This cold well also has a sump which might be sampled. Both the pipe trench and the cold well are confined spaces as defined by OSHA, and special access and egress precautions will apply to the sampling crew. Access is gained through a removable metal grate above each area, respectively.

TRA-647 ETR Office Building

The ETR office building is a three-story service building immediately north of the ETR. It is constructed of concrete, consisting of offices with adjacent restrooms on the first and second floors, and shops and mechanical rooms in the basement. 
Samples are required in the sink drains of the Health Physicist's Office and the Shop (for gamma emitting isotopes and for metals), and of pits, tanks and mechanical equipment in the basement.

The sump in the basement contains a tank, both of which will be sampled for - gamma emitting isotopes and for metals in any liquid sludge, or residue which may be present. If no liquid is present, the walls of the pit and tank will be sampled for those same analytes using a smear.

Oil in the dash pots serving the ventilation louvres will be sampled for PCBs.

Filter media in the basement will be sampled for gamma emitting isotopes and for lead.

\section{ETR-642 ETR Reactor Building Basement}

ETR Reactor Building areas addressed in this ASAP are primarily in the basement and console floors of the building; main floor areas to be sampled consist only of high density concrete used for reactor shielding. The basement, as defined on ETR drawings, is the subbasement which provided access to the experimental test loops, as distinguished from the first underground "console" level which was used for associated instrumentation.

\section{ETR-642 Basement}

A sump is located in the flooring of the basement rad-access room (directly below the sub-pile room) which will be sampled for gamma emitting isotopes and for metals in any liquid which may be present. If no liquid is present, the walls of the sump will be sampled for those same analytes using a smear.

Paint in the vicinity of both the inside and the outside of the sub-pile room will be sampled to characterize its radiochemistry.

The sub-pile room is surrounded by experimental cells which surround the circumference of the reactor. One of these cells, $M-3$, will be entered to obtain samples of the ion-exchange resin which remains at that location. Resins were designed to remove metals from the water, so remaining resin material would present a potential for heavy metal contamination. Analyses for TCLP metals and radionuclides are therefore to be performed.

A warm-waste tank area is located in a pit on the north side of this subbasement floor, and is covered with a set of high-density concrete covers. The tank contents will be sampled for radionuclides and for TCLP metals. The warm-waste tank pit is a confined space as defined by OSHA, and special access and egress precautions will apply to the sampling crew. Access is gained through an adjacent manhole, or by removing the concrete covers. 
In addition to the warm-waste tank, a cold-waste tank is located in a pit west of the warm-waste tank, which is also covered with a high-density concrete cover. The cold-waste tank is believed to be clean, but any contents will be sampled as a confirmatory action for radionuclides and for TCLP metals. The cold-waste tank pit is also a confined space as defined by OSHA, and special access and egress precautions will likewise apply to the sampling crew at that location. Access is gained by removing the concrete covers.

A decontamination station is located on the extreme south side of the reactor building basement floor, near the southeast stairwell. Oil residue on the floor at this location will be sampled for PCBs, to provide guidance for its cleanup.

\section{ETR-642 Console Floor}

On the south-center console floor of the ETR Building, a pipe trench extends from the east wall eastward toward the reactor. Samples are desired from this trench at both ends, one near the east wall of the console floor, the other at a point where the trench meets the southeast reactor shielding wall. Radionuclides and metal contamination are possible in this area, given the processes involved, so radiochemistry and TCLP metals analyses are to be performed.

The console floor also contains a number of access points to the hot experiment drain system. Samples for radionuclides, metals, and volatile organic compounds will be obtained from at least one drain in this system. Based on system configuration, the drain access immediately south of the reactor, near the center of the floor has been chosen as the sampling point.

Access points to the warm drain system likewise exist on the console floor, for which samples are required. Samples for radionuclides and metals are desired from at least one access point in this system. Based on system configuration, the drain access adjacent to the exterior wall of the reactor canal has been chosen as the sampling point.

\section{ETR-642 Main Floor}

Shielding blocks composed of high-density concrete have the potential to be classified as hazardous material, based on their composition. For this reason, small diameter core samples obtained with a diamond hollow-core drill will be taken . from shielding blocks surrounding the reactor core and analyzed for TCLP metals. The selection of shielding blocks for sampling has not been finalized at the time of this writing.

\section{EIR-643 ETR Compressor Building}

The ETR Compressor Building is located east of the ETR, and shares a wall with the Heat Exchanger Building which lies immediately to its south as well as the reactive building on its west side. The compressor equipment provides service air for the ETR complex, including power for the pneumatically-operated valves and controls serving both the reactor and its primary cooling system. The building houses two 
large compressors with their associated motor drives, and all associated piping and appliances.

The first area to be sampled in the Compressor Building is a set of motors which operate the gate valves of the primary coolant system. Oil in each of these operators is to be sampled to determine whether PCBs are present. The motors are aligned in an east-west line paralleling a grating-covered trench in the south-center portion of the building, which will also be sampled. If liquid exists in the trench, it will be sampled for radionuclides, metals, and for PCBs.

Four primary coolant pump motors are located in the Compressor Building which must also be sampled for PCBs. The oil reservoir in each motor will be sampled.

The Clark air compressors and their associated compressor actuators will be sampled for PCBs, by mean of access to the oil reservoirs in each separate unit, if necessary. The compressors are believed to still contain their initial complement of oil. A metal grate-covered trench is located below and surrounding each of the compressors. Samples for radiochemistry, metals, and PCB contamination will be obtained from each of these trench areas. If liquid exists in the trench, it will be sampled for radionuclides, metals, and for PCBs.

Two large Clark air compressor drive motors located in the Compressor Building will be sampled for PCBs. The oil reservoir in each motor will be sampled.

A restroom used by the decontamination staff, and a chemistry laboratory which are both part of the Compressor Building will be sampled to characterize the shower drain and sink traps, and the lab sink and trench, respectively. Radionuclides and metals are the target analytes, given the process history of those rooms. Additional sampling of the chemistry laboratory may be required, based on the results of the screening samples.

\section{TRA-648 ETR Electrical Building}

The ETR Electrical Building is located immediately south of the ETR. It contains a large diesel engine-powered generator, together with its fuel system, and a large array of high-capacity switchgear and power conditioning equipment, including space for two lead-acid batteries which were part of the uninterruptable power supply for the plant. The diesel-generator remains in place, however one of the batteries and some of the switchgear have been previously removed.

In the generator room, samples will be obtained from the metal-grate-covered trench which surrounds the generator unit. Analysis will be made for radioisotopes, metals, and $\mathrm{PCBs}$. 
Although the batteries have been removed from one of the battery rooms, evidence of residual contamination is visible in both the drain and in staining on the concrete floor of the in-service battery room. Both areas will be sampled for radioisotopes and metals.

TRA-663 ETR Superior Diesel Building.

The ETR Superior Diesel Building adjoins the ETR Electrical Building on its southwest side, and performs a similar function to the Electrical Building, having housed a large diesel-powered plant generator. Samples are required in the maintenance area of the building, at a point where fuel injectors were cleaned and serviced, and where spillage is known to have occurred. The concrete and surface areas in this part of the building will be sampled to identify metals or PCBs which may be present.

\subsubsection{Summary of Sampling Safety Issues}

Thirty-five separate sampling areas are identified in this ASAP. With few exceptions, they are located within existing buildings in areas without unusual physical hazards associated with access. A detailed analysis of the health and safety considerations associated with this project is present in a separate document.

Several sampling locations are in pits, tanks, sumps, and trenches which are confined spaces. Personnel entering these spaces will adhere to applicable requirements for entry (such as permits, training and atmospheric testing of the spaces). Specific direction and requirements will be provided by the on-site health and safety professionals.

Radiological contamination is likely to be present in many of the sampling areas, especially those associated with the primary reactor cooling circuit and the reactor experiment loops. The main areas of radiological and chemical contamination concern for the scope addressed in this ASAP are the reactor experiment cubicles located on the basement floor of TRA-642. A detailed radiological characterization of these areas will be made prior to sampling as part of the Radiological Work Permit process. The existing radiological characterization identifies Cubicle $\mathrm{M}-3$ as having the highest leveis of radionuclides present in areas proposed for sampling (general body field in TRA-642, Cubicle M-3, is in excess of $500 \mathrm{mrem} / \mathrm{hr}$ ). Job specific work control documents will be prepared in support of sampling activities. All radiological work will be in accordance with Rad Con requirements.

There are suspected chemical contaminants in almost all of the proposed sampling areas. Metals are the primary target analytes; solvents are a much smaller concern. Pesticides are not expected, based on TRA process history. Samples collected for this project will be analyzed for TCLP metals, notably chromium (from the cooling tower) and lead. PCB contamination is possible in the oils used as motor and compressor lubricants. 
Floor drains and sink traps identified for sampling are located in laboratory and Health Physics Decontamination areas, and have had some radiological contamination identified.

Waste types identified are as follows:

- Rádioisotopes: Reactor-produced uranium fission products (e.g., Cesium, Strontium, Cobalt) expected in TRA-611, TRA-612, TRA-643, TRA-644, TRA647, and TRA-642.

- RCRA: Heavy metal contamination from chrome-based water conditioners used in the secondary cooling circuit, and lead-containing fuel handling areas associated with engine-driven generators, and in former lead-acid battery areas, are expected in TRA-644, TRA-645, TRA-647, TRA-642, TRA-643, TRA-648, and TRA-663. Water conditioning chemicals may be present in the laboratory area of TRA-643.

- TSCA: PCBs are likely in many of the oils used as motor and compressor lubricants, in TRA-647, TRA-642, TRA-643, TRA-648, and TRA-663.

- NESHAPS: Asbestos from acid brick mastic in TRA-645.

NOTE: There are asbestos floor tiles and asbestos insulation on piping and associated equipment in the Compressor Building, the Heat Exchanger Building, and the Electrical Building, as well as in the window and door seals of the office building. EG\&G Idaho's Asbestos Team will address asbestos removal and sampling which may be associated with the D\&D of areas addressed in this document.

\section{$2.2 \quad$ Objectives and Scope}

The TRA D\&D project area has not been completely characterized to evaluate the presence, type, and extent of chemical and/or radioactive contamination. The purpose of the proposed sampling is to determine the presence, extent, and concentrations of chemical and radioactive constituents inside the structures for which D\&D funding has been approved. In addition, soil surrounding an experimental plug storage area (TRA-611), and the ETR Cooling Tower Pumphouse (TRA-645) will be sampled to determine its contents. This data will be used to characterize the structures that will be removed.

Analytical Level III will be used for all chemical analyses and analytical Level V will be used for radiological analyses (SMO-SOP-12.1.1). The information gained from this sampling effort will be used as a preliminary assessment. This data will be used as an aid in planning the D\&D activities. Compounds detected in sludges, sump liquids, and tank residues will be compared to regulatory levels to determine disposition of these materials. 
For the sampling areas identified, this ASAP addresses criteria for documenting the hazardous nature of the potential waste sources and obtaining representative samples and maintaining sample quality, as well as outlining safety considerations for field personnel. The $\mathrm{QA} / \mathrm{QC}$ requirements for this project follow the guidelines as detailed in Quality Program Plan for D\&D, QPP-149.

\subsection{Area Description}

The areas addressed in this plan for sampling are primarily indoors, in unheated industrial support buildings in which most operational activity has been suspended. Except for $D \& D$ activities, no occupancy by office workers or crafts personnel occurs.

Physical conditions at the sampling areas may be inferred by reference to the photographs of each sampling area which are included as Exhibits 2.1 through 2.35 at the rear of this document. These photographs may be compared to the locations of the sampling by reference to the corresponding facility plot plans, presented in Exhibits 1.1 through 1.11, also at the rear of this document.

\subsection{Data Usage}

The samples collected as part of this preliminary assessment will be analyzed to characterize the potential hazardous nature of the waste. This characterization will be based on the concentration of hazardous constituents found in the samples. The data will also be evaluated to determine hazardous waste exposure to personnel during planned $D \& D$ activities at the sites identified and to determine the final disposition of materials generated by planned D\&D activities at TRA. This will be accomplished by comparing the data to the limits for TCLP metals, volatile organic compounds (VOCs), semi-VOCs, and to the D\&D release limits for radionuclides. In addition, radiation measurements and analyses results will also be used to plan the $D \& D$ of the listed structures.

\section{$2.5 \quad$ Data Types}

Samples collected in support of this project are intended to be submitted to a SMO sub-contracted laboratory for Toxicity Characteristic Leaching Procedure (TCLP) metals analysis, limited volatile organic analysis (VOA), and PCB analysis. Samples for gamma analysis will be sent to the Radiation Measurement Laboratory (RML), located on-site at TRA.

All samples collected for this project will be surveyed by a Radiological Control Technician (RCT) before being transported. Any samples that cannot be released based on sample container surface contact readings will be shipped to the laboratories by à qualified INEL shipper.

Packaging and shipping will be done in accordance with ER PD 5.7, Chain of Custody Sample Handling and Packaging. Samples will be transported as soon as possible to 
the designated laboratory accompanied by chain-of-custody $(\mathrm{COC})$ documentation. Upon receipt of the samples, the laboratory will check for damage to the sample containers and check for discrepancies between the COC and the sample label information. The laboratory sample receiving person will sign the COC indicating receipt and transfer of custody of the samples.

This characterization is intended to only characterize materials as typical of those found in the candidate sampling areas, therefore defining boundaries of any contamination is not applicable.

Logbooks will be maintained per ER PD 4.2, "Logbooks." During execution of the work, any deviations from this plan will be in accordance with ER PD 4.1, "Document Control." The ASAP may also be revised at the completion of the sampling activity to reflect any changes or deviations that were made in the field.

\subsection{Personnel Safety and Health Precautions}

Health and Safety requirements for this sampling effort are specified in the Health and Safety Plan for TRA Facility Sampling.

In order to provide for the health and safety of the samplers, field activities will be performed in close consultation with site operations management, radiological control, and safety representatives. A pre-sampling briefing will be held to ensure all safety and radiological matters are addressed and communicated to the samplers prior to sampling in any individual sampling area.

Process knowledge and results of previous sampling and surveys by $\mathrm{IH}$ and RADCON personnel have been used to make a preliminary indication of PPE requirements. TCLP metals encountered are expected to be chromium and lead at some multiples of ambient soil background levels. PCBs may be present in oils which are to be sampled. VOAs in the form of carbon tetrachloride, trichloroethylene, and chloroform may be present in trace amounts in some of the laboratory drains and reactor experimental drains. Radioactive contamination is anticipated in the majority of the sampling areas, and will be precisely specified in the Radiation Work Permits prepared to support the sampling campaign.

Samplers shall be trained as per 29 CFR Part 1910.120 and wear appropriate protective clothing and equipment (see section 2.7). Skin contact, aspiration or ingestion of particulate matter from dry tanks and drains, or concrete, is anticipated to be the primary health and safety risk. Additional protective equipment will be determined by the on-site RADCON and health and safety representatives, based on actual sampling conditions.

Eating, drinking, smoking or chewing will not be permitted in the sampling area.

Any contact with potentially contaminated surfaces will be avoided. Team 
members will avoid sitting, leaning, or placing equipment on areas that are potentially contaminated. Sample collection operations will be stopped in the event of an accident or if any personnel determine conditions are unsafe.

A Radiological Work Permit and Safe Work Permit may be initiated by the requester and the field team leader prior to sampling, as appropriate.

\section{-2.7 Sampled Materials}

The samples included in this ASAP consists of the following types of materials:

- Soil samples obtained at depths extending from the surface to a depth of approximately eight feet.

- Aqueous Liquid Samples obtained from inflow to sumps which are up to 40 feet below plant grade. Sludge, if present, will be sampled.

- Aqueous Liquid Samples obtained from residuals in tanks which range from approximately 2 feet to 20 feet in diameter. Sludges, if present, will be sampled.

- Concrete, brick, and steel tank-wall smears of areas exposed to aqueous liquids, oils, acids, and to ion exchange resins, pits and trenches, and exterior concrete pads.

- Drain traps in floor drains, showers and sinks, and lab hoods

- Piping and drains serving reactor experimental loops

- Oil reservoirs in dash pots, valve operators, motors, compressors, and compressor actuators

- Building ventilation system filter media

- Paint from walls and floors in radioactively contaminated areas

- Ion Exchange Resins and oils in bulk and as a concrete contaminant 
Necessary materials to support this sampling include the following:

Sample Containers: $\quad$ 500-ml LDPE plastic quart jars (alpha, beta, and gamma analysis)

250-ml glass jars (TCLP metals)

$125-\mathrm{ml}$ glass jars (PCBs)

$125-\mathrm{ml}$ glass vials (VOCs)

Equipment List:

Field logbooks
Parafilm
Type II water
Latex gloves
Sample Splitter Box
Hand tools
Trip blanks
TLD Badges,
Hand Augers

Level-C protection

Teriwipe ${ }^{\text {TM }}$

Coolers with blue ice

Stainless Steel pans

Stainless steel spoons

Garbage bags

Safety Glasses

Air Hammer with Chisels

At TRA, it is anticipated that PPE will be provided by the RCTs.

Type II and/or deionized water will be used for trip blanks, rinsates, and field blanks.

Sampling Equipment Decontamination:

Wash pan, nonphosphate detergent

Tap water

Deionized water

Air dry rack

Aluminum foil for cleaned equipment

Sampling Documentation and Shipping Supplies:

Field logbooks and waterproof pens

RML Radiochemistry analysis request forms

U.S. DOE Hazardous Material-Shipping Record (IDF 5480.3A) (if required)

Abbreviated Sampling and Analysis Plan

Sample labels

Chain of Custody Forms

Shipping labels

Custody seals .

Clear tape

Strapping Tape

Packing material (i.e., bubble wrap)

EGG Form 176, "Request for Shipment of Materials" 


\section{EGG Form 253, "Requisition for Purchase of Materials and Services" \\ Blue ice \\ Coolers}

\subsection{Sampling Design and Procedures}

Data validation and laboratories to be utilized will be determined by the Sample Management Office (SMO). Sample preservation will be according to the specific method and analysis being conducted.

Quality assurance/quality control (QA/QC) samples will be collected during TRA D\&D sampling and analysis. Rinsates (equipment blanks), field blanks and trip blanks will be collected. The number of field blanks, trip blanks, replicates, and rinsates were selected to meet $5 \%$ of the total number of samples to be collected. The $5 \%$ criterion is commonly accepted for a minimum number of QA samples (DOE, 1989a). The types and frequency of collection for field quality control samples are provided below:

- Field Blanks - defined as samples of ASTM Type II (or other high purity) water from the same source as water used for decontamination. One fieid blank will be prepared for each method type and will be analyzed for the same analytes as the samples collected that day. Field blanks are prepared and preserved using sample containers from the same lot as the other samples collected that day. Results of the field blank analysis will help determine the level of contamination introduced into the sample due to sampling technique and as a check of the water used for decontamination.

- Rinsates (equipment blanks) - defined as the final analyte-free water rinse from equipment cleaning, collected during a sampling event. The sample is analyzed for the same analytes as the samples collected that day. The results of the rinsate analysis will be used to flag or assess the level of analytes in the samples, which enables contaminant evaluation of the decontamination process, the final rinse water, and the sample containers.

Biased sampling locations were chosen to determine the presence and concentration of chemical and radiological contaminants at locations that have the highest probability of containing contaminants. The specific locations were determined as a result of process knowledge and, to a limited extent, of previous sampling activities. Biased samples will be collected to investigate the presence and the extent of contamination in the structures scheduled for $D \& D$ removal. The Field Team Leader will document in the appropriate logbook the sample collection procedure used.

Radiological samples collected for gamma analysis from all sampling locations will be placed in $500-\mathrm{ml}$ plastic bottles. Material will also be collected for analysis by 
scraping (e.g., floor drains, pit interiors, and painted walls) with precleaned stainless steel spoons, chisels, or other appropriate sampling tools. Collected material will be surveyed with radiation survey instruments and placed in the $500-\mathrm{ml}$ plastic bottles and sealed. Samples collected for TCLP metals (250-ml glass jars), and PCB (125 ml glass jars) analyses will be placed in their appropriate containers.

Samples collected from drains, pipes, and tank interiors will be collected using precleaned stainless steel spoons. If the sample material cannot be collected with a spoon, the Field Team Leader will determine a different collection procedure. Any asbestos present will not be disturbed. Any tools used to collect samples will be decontaminated after use. Any deviation from the ASAP will be documented in the logbook by the FTL.

In addition to radiological characterization described above, general radiological surveys including direct beta-gamma radiation measurements and smears for removable contamination will be performed by RCTs in rooms for which current, reliable radiological characterization is not available.

In some areas, the absence of liquid material may necessitate using smears to obtain radiochemistry data. Smears shall be taken by firmly wiping a piece of dry smear material (Whatman 50 filter paper or equivalent) over approximately $100 \mathrm{~cm}^{2}$ (an area about $4 \times 4$ in.) of the surface being monitored. Smears shall be counted with an alpha, beta-gamma proportional counting system or a system with equivalent sensitivity. Calibration, performance checks, and operation of the counting system shall be performed in accordance with RCT procedures. The counting system shall have sufficient sensitivity to detect contamination below $20 \mathrm{dpm} / 100 \mathrm{~cm}^{2}$ alpha and $200 \mathrm{dpm} / 100 \mathrm{~cm}^{2}$ beta-gamma above background. Smear samples, where used to define chemical contamination, will be analyzed by the RML.

Fixed radiological contamination shall be measured with a portable survey meter for beta-gamma contamination. When searching for contamination, or when trying to find the most highly-contaminated portion of contaminated materials or areas, audible instrument response shall be used, when provided, rather than visual meter response.

Crafts personnel will assist in gaining access to the desired sampling locations (e.g., tank access below high density concrete lids in the basement of TRA-642 which must be removed by crane), where required.

Representative samples will be collected from floor drains, shower drains, sink traps, and drain pipes. If sufficient sample material is present, sample bottle sizes noted above will be used. All samples will be collected using stainless steel spoons or similar devices. It is not known whether adequate amounts of material will be present in all the locations described, but every attempt will be made to collect samples from locations of possible high radionuclide concentration or source of RCRA waste. If there is not enough material, radiological analyses will be the first 
priority followed by TCLP metals, VOCs, and PCBs (in that order). Environmental Standard Operating Procedures (ESOPs) will be followed for obtaining samples, when possible.

Analytical methods used shall consist of the following SW-846 protocols, as appropriate:

$\begin{array}{ll}\text { TCLP metals } & \text { EPA } 1311 / 6010 / 7470 \\ \text { TCLP VOAs } & \text { EPA } 1311 / 8240 \text { or } 8260 \\ \text { Isotopic Gamma } & \text { EPA } 901.1 \text { or equivalent } \\ \text { PCBs } & \text { EPA } 8080\end{array}$

Site Specific Sampling Design and Procedures

\subsubsection{Soil Sampling}

Sample Areas 1 and 8 consist of soil samples obtained at depths extending from the surface to a depth of approximately eight feet, in the vicinity of TRA-611, and TRA-645, respectively.

The TRA-611 and TRA-645 cover soils are disturbed fill materials; a wide variation in analyte concentrations as a function of sampling location is possible. Published INEL TRA soil sample background concentrations will be compared to levels of analytes detected in the soil samples.

Because this characterization is intended to provide indications of typical TRA soil cover conditions and to provide characterization for disposal, composites of soil samples will be taken.

Within each of the areas where soils are sampled, subsamples will be collected from different areas throughout the sample location using a stainless steel scoop and hand auger. The subsamples at TRA-61I and at TRA-645 will be separately composited into a stainless steel pan during the collection process. After compositing, the-material will be transferred to the proper sample containers. The RCT will perform contamination surveys while the samples are being collected.

Immediately after compositing, the RCT will survey samples prior to material being placed in the containers, the sampling times will be recorded for the samples and the sample containers labeled, parafilmed, and placed into a cooler with blue ice. The chain of custody will then be filled out, recording all pertinent information. The samples will be surveyed by a RCT before the samples are shipped to the analytical laboratory.

After the samples have been surveyed by the RCT, proper shipping papers and documentation will be produced as per ER PD 5.7, Chain of Custody, Sample 
Handling, and Packaging, and the EG\&G Idaho HMTM in order for the samples to be shipped to the analytical laboratory for analysis.

Two composite samples each will be obtained for TCLP metals and Gamma Spectrometry at each sampled area.

Except for cooling to $4^{\circ} \mathrm{C}$, no sample preservatives will be required.

\subsubsection{Aqueous Liquid Samples in Sumps}

Sample Areas 2 (TRA-612 Retention Basin Pumphouse Sump), 5 (TRA-645 ETR Secondary Coolant Pumphouse Sump), 6 (TRA-645 ETR Secondary Coolant Pumphouse Sump West Side), 11 (TRA-647 Heating and Ventilating Room Sump Pit), 14 (TRA-642 Reactor Building Rad-Access Room Sump), 20 (TRA-642 South Console Floor Pipe Trench), 25 (TRA-643 Compressor Building Pipe Trench), 28 (TRA-643 Trench Below Compressors), 31(TRA-643 Chemistry Lab Trench), and 32 (ETR Electrical Building Diesel Generator Room Pit) have the potential for aqueous materials in their floors which will be sampled. All are easily accessed except the TRA-612 sampling area, which is up to 40 feet below plant grade.

Areas 11,14 , and 20 are associated with the reactor primary cooling circuit, in which radioactive contamination is expected. Areas 5, 6, 11, 25, 28, 31, and 32 are in areas in which metal contamination is expected. Additionally, Areas 25, 28, and 32 have the potential for $\mathrm{PCB}$ contamination. A wide variation in analyte concentrations as a function of sampling location is possible. Published regulatory action levels and risk-based action levels will compared to levels of analytes detected in the samples.

Because this characterization is intended to provide indications of site-specific conditions and to provide characterization for disposal, composites of aqueous samples will be taken at each individual sampling area. Sludges/sediments layers will also be sampled, if present.

Within each of the areas where aqueous liquids are sampled, subsamples will be collected from different areas throughout the sample location using a coliwasa sampler, where possible. After compositing, the aqueous liquid will be transferred to the proper sample containers. The RCT will perform contamination surveys while the samples are being collected.

Immediately after compositing, the RCT will survey samples prior to aqueous liquid being placed in the containers, the sampling times will be recorded for the samples and the sample containers labeled, parafilmed, and placed into a cooler with blue ice. The chain of custody will then be filled out, recording all pertinent information. The samples will be surveyed by a RCT before the samples are shipped to the analytical laboratory. 
After the samples have been surveyed by the RCT, proper shipping papers and documentation will be produced as per ER PD 5.7, Chain of Custody, Sample Handling, and Packaging, and the EG\&G Idaho HMTM in order for the samples to be shipped to the analytical laboratory for analysis.

Two composite samples each will be obtained for TCLP metals, Gamma Spectrometry, and PCBs at each sampled area, as listed in Table 2.1-1.

Except for cooling to $4^{\circ} \mathrm{C}$, no sample preservatives will be required.

\subsubsection{Aqueous Liquid Samples from Tanks}

Sample Areas 11 (TRA-647 H\&V Room Tank in Floor Pit), 17 (TRA-642 Basement Warm Waste Tanks Below Floor), and 18 (TRA-642 Basement Cold Waste Tank Below Floor) have the potential for containing aqueous materials, which will be sampled if present. All are accessed with difficulty except the TRA-647 sampling area, which is accessible by removing a metal floor grate.

Area 17 is associated with the reactor experimental channels, in which significant radioactive contamination is expected. All areas are areas in which metal contamination is expected. Area 11 may have PCB contamination. A wide variation in analyte concentrations as a function of sampling location is expected. Published regulatory action levels and risk-based actions levels will be compared to levels of analytes detected in the samples.

Because this characterization is intended to provide indications of site-specific conditions and to provide characterization for disposal, composites of aqueous samples will be taken at each individual sampling area.

Within each of the areas containing a large tank or multiple tanks where aqueous liquids are sampled, subsamples will be collected from different areas throughout the sample location using a Coliwasa sampler, where possible. After compositing, the aqueous liquid will be transferred to the proper sample containers. The RCT will perform contamination surveys while the samples are being collected.

Immediately after compositing, the RCT will survey samples prior to aqueous liquid being placed in the containers, the sampling times will be recorded for the samples and the sample containers labeled, parafilmed, and placed into a cooler with blue ice. The chain of custody will then be filled out, recording all pertinent information. The samples will be surveyed by a RCT before the samples are shipped to the analytical laboratory.

After the samples have been surveyed by the RCT, proper shipping papers and documentation will be produced as per ER PD 5.7, Chain of Custody, Sample 
Handling, and Packaging, and the EG\&G Idaho HMTM in order for the samples to be shipped to the analytical laboratory for analysis.

Two composite samples each will be obtained for TCLP metals, TCLP VOAs, Gamma Spectrometry, and PCBs at each sampled area, as listed in Table 2.1-1.

Except for cooling to $4^{\circ} \mathrm{C}$, no sample preservatives will be required.

\subsubsection{Concrete and Brick Samples}

Sample Areas 2 (TRA-612 Retention Basin Pumphouse Sump), 3 (TRA-644 Concrete Pad where resin was transferred), 5 (TRA-645 ETR Secondary Coolant Pumphouse Sump), 6 (TRA-645 ETR Secondary Coolant Pumphouse Sump West Side), 7 (TRA645 Acid Pit Area Drain), 11 (TRA-647 Heating and Ventilating Room Sump Pit) , 14 (TRA-642 Reactor Building Sub Pile Room Sump), 19 (TRA-642 Decontamination Station), 20 (TRA-642 South Console Floor Pipe Trench), 22 (TRA-642 Warm Drain around Storage Canal), 25 (TRA-643 Compressor Building Pipe Trench), 28 (TRA-643 Trench Below Compressors), 31(TRA-643 Chemistry Lab Trench), 32 (ETR Electrical Building Diesel Generator Room Pit), 33 (ETR Electrical Building Battery Room Floor), and 34 (TRA-633 Superior Diesel Building injector Maintenance Station Floor) have the potential for residues or absorbed hazardous materials in their floors and walls. When present, solids that remain will be sampled. Porous surfaces, such as brick or concrete, will also be sampled. All are easily accessed except the TRA-612 sampling area, which is up to 40 feet below plant grade, and the TRA644 Degasifier Tank, another confined space with a potential for a hazardous atmosphere.

Areas 2, 4, 14, 19,20,22, and 31 are associated with the reactor primary cooling system, in which radioactive contamination is expected. All areas are areas in which metal contamination is possible. Areas 19,25, 28, 32, 33, and 34 may have PCB contamination. Area 31 may have a wide variety of chemicals present. Published regulatory action levels and risk-based actions levels will be compared to levels of analytes detected in the samples.

Because this characterization is intended to provide indications of site-specific conditions and to provide characterization for disposal, composites of concrete and pit wall samples may be taken at each individual sampling area. Steel/metal tank walls will not be sampled; residues or aqueous contents are the objective for solid samples in those locations. Smears may be obtained for gamma analysis.

Within each of the areas where multiple pits, tanks or trenches are sampled, subsamples will be collected from different areas throughout the sample location using a scoop, power chisel or other appropriate tool. After compositing, the 
material obtained will be transferred to the proper sample containers. The RCT will perform contamination surveys while the samples are being collected. Smears may be obtained inside "empty" locations for gamma analysis.

Immediately after compositing, the RCT will survey samples prior to material being placed in the containers, the sampling times will be recorded for the samples and the sample containers labeled, parafilmed, and placed into a cooler with blue ice. The chain of custody will then be filled out, recording all pertinent information. The samples will be surveyed by a RCT before the samples are shipped to the analytical laboratory.

After the samples have been surveyed by the RCT, proper shipping papers and documentation will be produced as per ER PD 5.7, Chain of Custody, Sample Handling, and Packaging, and the EG\&G Idaho HMTM in order for the samples to be shipped to the analytical laboratory for analysis.

Two composite samples each will be obtained for TCLP metals, Gamma Spectrometry, and PCBs at each sampled area, as listed in Table 2.1-1.

Except for cooling to $4^{\circ} \mathrm{C}$, no sample preservatives will be required.

\subsubsection{Drain Traps}

Sample Areas 7 (TRA-645 Acid Pit Area Drain), 9 (TRA-647 Health Physicists' Office Drain), 10 (TRA-647 Shop Drain), 30 (ETR-643 Compressor Building Decon Restroom), 31(TRA-643 Chemistry Lab Hood Drain), and 33 (ETR Electrical Building Battery Room Floor Drain) have the potential for hazardous materials in their drain traps which will be sampled. All are easily accessed.

Areas 7 and 33 are associated with the sulfuric acid handling, in which acid or metal salt contamination is expected. Areas 9,30 , and 31 are areas in which radioactive contamination is possible. Area 31 may have a variety of chemicals present. Published regulatory action levels and risk-based actions levels will be used to indicate levels of significance for analytes detected in the specified aqueous liquid samples.

Because this characterization is intended to provide indications of site-specific conditions and to provide characterization for disposal and the individual nature of the drains, individual samples will be taken at each separate sampling area.

Within each of the areas to be sampled, samples will be collected using a scoop, power chisel, power brush, or other appropriate tool. After sampling, the material obtained will be transferred to the proper sample containers. The RCT will perform contamination surveys while the samples are being collected.

Immediately after sampling, the RCT will survey samples prior to their being placed 
in the containers, the sampling times will be recorded for the samples and the sample containers labeled, parafilmed, and placed into a cooler with blue ice. The chain of custody will then be filled out, recording all pertinent information. The samples will be surveyed by a RCT before the samples are shipped to the analytical laboratory.

After the samples have been surveyed by the RCT, proper shipping papers and documentation will be produced as per ER PD 5.7, Chain of Custody, Sample Handling, and Packaging, and the EG\&G Idaho HMTM in order for the samples to be shipped to the analytical laboratory for analysis.

Two samples each will be obtained for TCLP metals and Gamma Spectrometry at each sampled area, as listed in Table 2.1-1.

Except for cooling to $4^{\circ} \mathrm{C}$, no sample preservatives will be required.

\subsubsection{Piping and Drains Serving Reactor Experimental Loops}

Sample Areas 21 (TRA-642 South Console Floor Hot Experiment Drain) and 22 (TRA-642 South Console Floor Warm Drain Around Storage Canal) have the potential for both radioactive and hazardous materials in their piping and drains which will be sampled. Both are easily accessed.

Both areas may have a variety of chemicals present; therefore a variation in analyte concentrations as a function of sampling location is expected. Published regulatory action levels and risk-based actions levels will be used to indicate levels of significance for analytes detected in the specified aqueous liquid samples.

Because this characterization is intended to provide indications of site-specific conditions and to provide characterization for disposal and the individual nature of the piping and drain system, individual samples will be taken at each separate sampling area.

Within each of the areas to be sampled, samples will be collected using a scoop, power chisel, power brush, or other appropriate tool. After sampling, the material obtained will be transferred to the proper sample containers. The RCT will perform contamination surveys while the samples are being collected.

Immediately after sampling, the RCT will survey samples prior to their being placed in the containers, the sampling times will be recorded for the samples and the sample containers labeled, parafilmed, and placed into a cooler with blue ice. The chain of custody will then be filled out, recording all pertinent information. The samples will be surveyed by a RCT before the samples are shipped to the analytical laboratory.

After the samples have been surveyed by the $\mathrm{RCT}$, proper shipping papers and 
documentation will be produced as per ER PD 5.7, Chain of Custody, Sample Handling, and Packaging, and the EG\&G Idaho HMTM in order for the samples to be shipped to the analytical laboratory for analysis.

Two samples each will be obtained for TCLP metals and Gamma Spectrometry at each sampled area, as listed in T.able 2.1-1.

Except for cooling to $4^{\circ} \mathrm{C}$, no sample preservatives will be required.

\subsubsection{Oil Reservoirs in Equipment}

Sample Areas 12 (TRA-647 ETR Office Building Heating and Ventilating Room Louver Dash Pots), 23 (TRA-643 ETR Compressor Building Gate Valve Motor Operators), 24 (TRA-643 ETR Compressor Building Primary Coolant Pump \intor), 26 (TRA-643 ETR Compressor Building Compressors), 27 (TRA-643 ETR Conipressor Building Compressor Actuators), and 29 (TRA-613 ETR Compressor Building Compressor Motor Drives) have the potential for oil containing PCBs in their oil reservoirs which will be sampled. All will require mechanical disassembly of some portions of the equipment to obtain a sample.

None of these areas are expected to be associated with hazardous levels of heary metals or of radioactive :ontamination. Published regulatory action levels and riskbased action levels will be compared to levels of PCBs which are detected in the oil samples.

Because this characterization is intended to provide indications of site-specific conditions and to provide characterization for disposal, individual samples will be taken at each separate sampling area.

Witinin each of the areas to be sampled, samples will be collected by pouring the material directly into the sampling container, where possible. The RCI will perform contamination surveys while the samples are being collected.

Immediately after sampling, the RCT will survey samples prior to their being placed in the shipping containers, the sampling times will be recorded for the samples and the sample containers labeled, parafilmed, and placed into a cooler with blue ice. The chain of custody will then be filled out, recording all pertinent information. The samples will be surveyed by a RCT before the samples are shipped to the analytical laboratory.

After the samples have been surveved by the RCT, proper shipping papers and documentation will be produced as per ER PD 5.7, Chain of Custody, Sample Handling, and Packaging, and the EG\&G Idaho HMTM in order for the samples to be sinipped to the analytical laboratory for analysis.

Two samples each will be obtained for PCBs at each sampled area, as listed in 
Table 2.1-1.

Except for cooling to $4^{\circ} \mathrm{C}$, no sample preservatives will be required.

\subsubsection{Ventilation System Filter Media}

Sample Area 13 (TRA-643 Heating and Ventilating Filters) has the potential for radiological and lead contamination in the filter media which will be sampled. No complex mechanical disassembly is anticipated.

The sample media may have dust containing hazardous levels of heavy metals or of other hazardous materials. Published regulatory action levels and risk-based actions levels will be compared to levels of lead detected in the filter media samples.

Because this characterization is intended to provide indications of site-specific conditions and to provide characterization for disposal, composites of material taken from several filters will be made.

Samples will be collected by cutting the filter material directly into the sampling container, where possible. The RCT will perform contamination surveys prior to and during sample collection.

Immediately after sampling, the RCT will survey samples prior to their being placed in the shipping containers, the sampling times will be recorded for the samples and the sample containers labeled, parafilmed, and placed into a cooler with blue ice. The chain of custody will then be filled out, recording all pertinent information.

After the samples have been surveyed by the RCT, proper shipping papers and documentation will be produced as per ER PD 5.7, Chain of Custody, Sample Handling, and Packaging, and the EG\&G Idaho HMTM in order for the samples to be shipped to the analytical laboratory for analysis.

Two composite samples will be obtained for lead in the filter media, as listed in Table 2.1-1. The samples will be analyzed according to SW-846.

Except for cooling to $4^{\circ} \mathrm{C}$, no sample preservatives will be required.

\subsubsection{Paint from Walls in Radioactively Contaminated Areas}

Sample Area 15 (TRA-642 Sub Pile Room Entrance) has the potential for significant radioactive contamination bonded in the paint on both the interior and exterior areas of the Sub Pile Room Entrance which will be sampled. No complex 
mechanical disassembly is anticipated to obtain access to the paint, howerer the strength of the epoxy based paint may make it necessary to chisel the samples from the walls.

The paint may cover areas of contamination, since it was commonly used as a fixative. Published regulatory action levels and risk-based actions levels will be compared to levels of radioactive contamination which are detected in the paint samples.

Because this characterization is intended to provide indications of site-specific conditions and to limited characterization for disposal, composites will be taken from several areas of paint.

Samples will be collected using a power chisel by chiseling the paint material directly on to the plastic sheet from which it can be collected. The RCT will perform contamination surveys while the samples are being collected.

Immediately after sampling, the RCT will survey samples prior to their being placed in the shipping containers, the sampling times will be recorded for the samples and the sample containers labeled, parafilmed, and placed into a cooler with biue ice. The chain of custody will then be filled out, recording all pertinent information. The samples will be surveyed by a RCT before the samples are shipped to the analytical laboratory.

After the samples have been surveyed by the RCT, proper shipping papers and documentation will be produced as per ER PD 5.7, Chain of Cusiody, Sample Handling, and Packaging, and the EG\&G Idaho HMTM in order for the samples to be shipped to the analytical laboratory for analysis.

Two composite samples will be obtained for the paint material, as listed in Table 2.1-1. The samples will be analyzed according to SW-846.

Except for cooling to $4^{\circ} \mathrm{C}$, no sample preservatives will be required.

\subsubsection{Ion Exchange Resins}

Sample Area 16 (TRA-642 Experimental Cubicle M-3) has remaining ion-exchange resin which will be bulk-sampled. The mechanical disassembly required to obtain access to the resin is unknown at this time, however the high radiation field within the cubicle may make it necessary to do a mock-up of this sampling to minimize exposure to radiation in conformance with ALARA.

Published regulatory action levels and risk-based actions levels will be compared to levels of radioactive and chemical (primarily metals) contamination detected in the resin. 
Because this characterization is intended to provide incications of site-specific conditions and to provide characterization for disposal, direct samples of resin material will be taken.

Samples will be collected using a scoop to transfer the material from the housing from which it is collected directly to the sample bottle. The RCT will perform contamination surveys while the samples are being collected.

Immediately after sampling, the RCT will survey samples prior to their being placed in the shipping containers, the sampling times will be recorded for the samples and the sample containers labeled, parafilmed, and placed into a cooler with blue ice. The chain of custody will then be filled out, recording all pertinent information. The samples will be surveyed by a RCT before the samples are shipped to the analytical laboratory.

After the samples have been surveyed by the RCT, proper shipping papers and documentation will be produced as per ER PD 5.7, Chain of Custody, Sample Handling, and Packaging, and the EG\&G Idaho HMTM in order for the samples to be shipped to the analytical laboratory for analysis.

Two separate samples will be obtained for the resin material, as listed in Table 2.1-1.

Except for cooling to $4^{\circ} \mathrm{C}$, no sample preservatives will be required.

\subsection{Sample Identification and Locations}

A systematic character code will be used to number the samples. The Sample ID codes will be generated by the INEL Sample Management Office (SMO).

Table 2.9-2 presents the relationship between the sampling locations and the numbers of samples projected at each location. The final sample numbers used on sample labels which are prepared by SMO for the project, will be presented in Table 2.9-3 [Pending].

The building location and location of sampling will be recorded in the field logbook. Candidate sampling locations, based on a walk-through with the Facility $D \& D$ Manager, are identified in Exhibits 1.1 through 1.11, at the rear of this document.

Figures A-1, A-2, and A $=3$ in Appendix A present examples of sample labels, chainof-custody forms, and sample log sheets that will be used for the sampling excursion.

Sample labels will identify the analysis desired, for each radiochemistry and hazardous waste sample. Analytes identified in the radiochemistry analyses will be consistent with those listed on the Environmental Monitoring Target Radionuclide List, presented in Table 2.9-4. 
The sample label will also indicate the time of sample acquisition and the type of sample, so that holding times may be readily identified. The sample bottles and preservatives used, together with associated holding times and minimum sample volumes are presented in Table 2.9-5, Typical Requirements Soils/Sediments/Sludges/Biota, from (DOE, 1989a). 
Table 2.9-2 . Sampling Parameters by Location

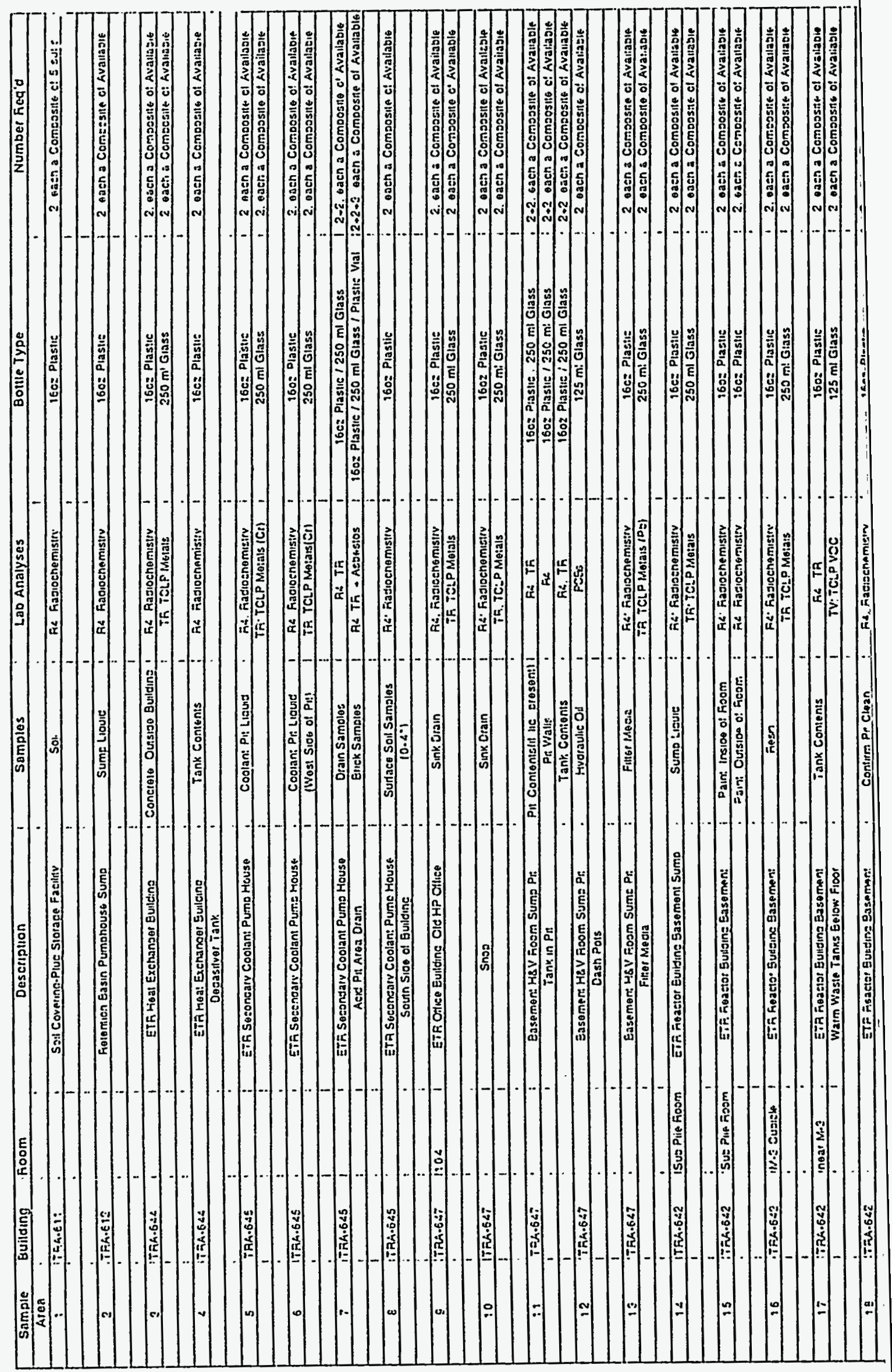




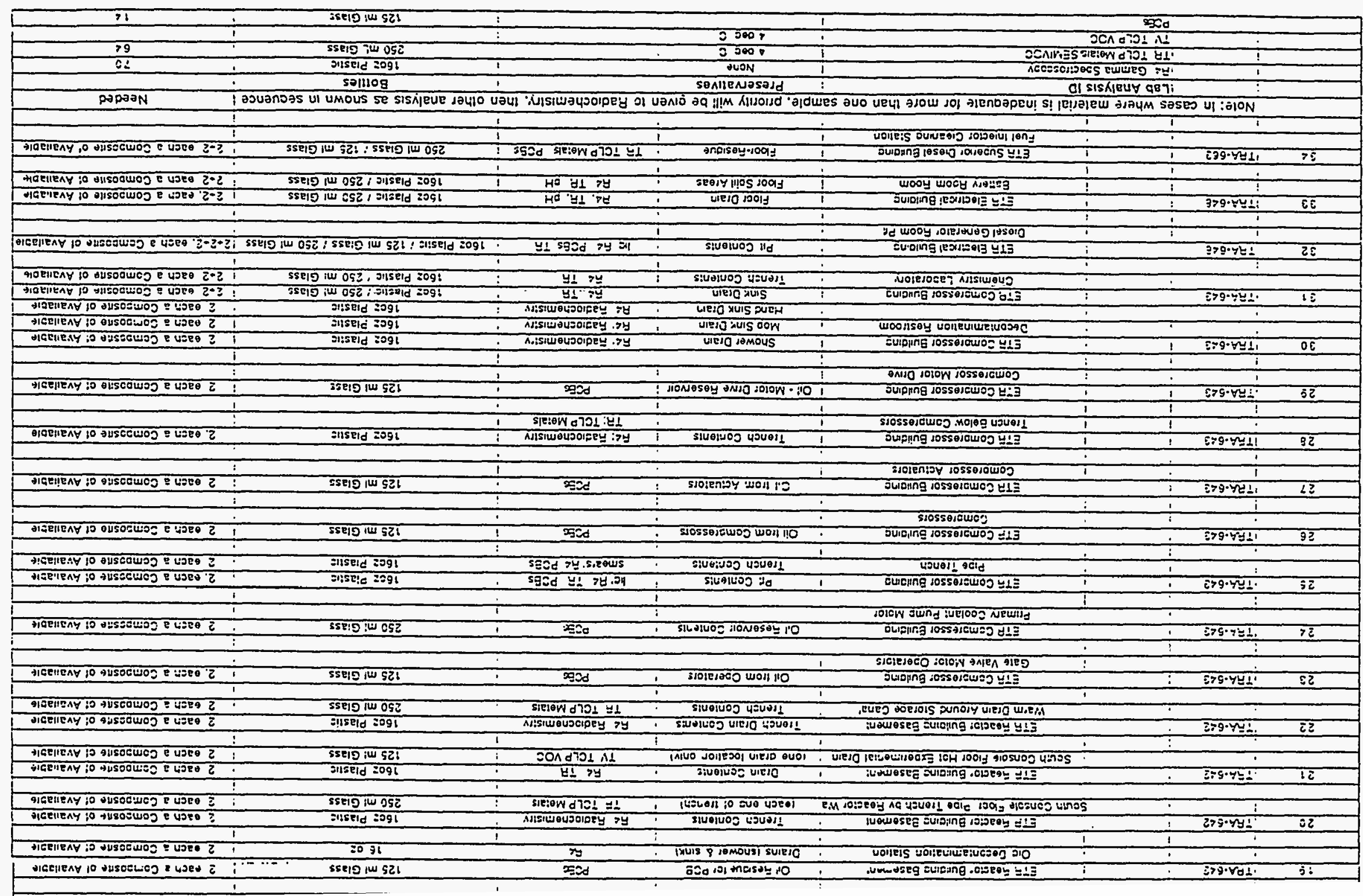


Table 2.9-3. Listing of Sample Numbers Assigned by the INEL SMO.

$P$ lan Table Nunber: TRA-DSD SAP NLniter:

Date: $08 / 30 \overline{\text { Th }}$ Plan Table Revision: 0.0
SAMPLIIIG AII ANALYSIS PLAN TABLE FOR CHEMICAL AMD Project: CHARACTERIZATION OF D\&D AREAS AT TRA

\begin{tabular}{|c|c|c|c|c|c|c|c|c|c|}
\hline \multicolumn{5}{|c|}{ SAMPLE DESCRIPIIOK } & \multirow[b]{2}{*}{$\begin{array}{c}\text { PLAKHED } \\
\text { DATE }\end{array}$} & \multicolumn{4}{|c|}{ SAMPLE LOCATION } \\
\hline $\begin{array}{l}\text { SAMPLING } \\
\text { ACTIVITY }\end{array}$ & $\underset{\text { TYPE }}{\text { SAMPLE }}$ & MEDIA & COLL & $\begin{array}{c}\text { SAMPLIHG } \\
\text { HETHCD }\end{array}$ & & AREA & LOCATIOH & $\begin{array}{l}\text { TYPE OF } \\
\text { LOCATIONI }\end{array}$ & $\begin{array}{r}\text { DEPrH } \\
(f t)\end{array}$ \\
\hline TRS001 & REG & SOIL & CCHP & & $09 / 15 / 94$ & $T R A-611$ & PLUG STORAGE & SOIL COVERIHG & $H / A$ \\
\hline TRSO02 & REG & LIOUID & $\operatorname{cosp}$ & & $09 / 15 / 94$ & TRA-612 & PUHPKQUSE SUMP & RETENTIOH BASIN & $H / A$ \\
\hline TRSO03 & REG & CONCRETE & cokp & & $09 / 15 / 94$ & TRA-644 & OUTSIDE BLOG & HEAT EXC·BLDG & $H / A$ \\
\hline TRS004 & REG & WASTE & СОMP & & $09 / 15 / 94$ & TRA-C:i is & DEGASSER TAMK & HEAT EXC BLDG & $\mathrm{H} / \mathrm{A}$ \\
\hline TRSOOS & REG & LIQUIO & caip & & $09 / 15 / 94$ & TRA-645 & COOLANT PIT & SEC COOL PUMPHS & $H / A$ \\
\hline TRSO06 & KEE & LIOUIO & CCAP & & $09 / 15 / 94$ & TRA-645 & H COOLAHT PIT & SEC COOL PUMPHS & $\mathrm{H} / \mathrm{A}$ \\
\hline TRS007 & REG & LIOUIO & COAP & & $09 / 15 / 94$ & TRA-645 & ACID PIT-DRAIH & SEC COOL PUHPHS & $H / A$ \\
\hline TRSOOB & REG & GRICK & $\cos P$ & & $09 / 15 / 94$ & TRA- 645 & ACID PIT-BRICK & SEC COOL PUHPHS & H/A \\
\hline TRSO09 & REG & SURFACE SOIL & CCMP & & $09 / 15 / 94$ & TRA-645 & S OF BUILDIHG & SEC COOL PUMPHS & $0-0.33$ \\
\hline TRS010 & KEG & HASTE & ССMP & & $09 / 15 / 94$ & TRA-647 & SIHK DRAIH & HP OFFICE -104 & $H / A$ \\
\hline TRSO11 & REG & HASTE & СOMP & & $08 / 15 / 94$ & TRA- 647 & SINK DRAIK & SHOP & $H / A$ \\
\hline TRSO12 & REG & LIOUID & ССMP & & $09 / 15 / 94$ & TRA-647 & PIT CONTENTS & H\&V RM SUMP PIT) & K/A \\
\hline TRS013 & REG & CONCRETE & сомр & & $09 / 15 / 94$ & TRA-647 & PIT HALLS & H\&V RM SUMP PIT & $K / A$ \\
\hline TRS014 & REG & WASTE & CCMP & & $09 / 15 / 94$ & TRA-647 & TAKK CONTEHTS & H\&V RH SUMP PIT & $M / A$ \\
\hline TRS015 & REG & OIL & CCAP & . & $09 / 15 / 94$ & TRA-647 & DASH POTS & HSV RH SUHP PIT & H/A \\
\hline
\end{tabular}

Enter the appropriate analys is type code in the boxes between the double lines under "EHTER AMALYSIS TYPES". Refer to Enter the number of bottles in the single line boxes below the analysis type for each sanpling activity.

Any descriptions for non-standard analysis t;pes (not given in Säp Table 2) should be entered under "commekts" on the

Ar1: Asbestos

AT2: PCOS (8080)

Ai3: Hydrogen Ion ( $\mathrm{pH})$

ATh: Gamma Spectroscopy

AT5: ICLP Metals

AT6: TCLP Volatiles

AT7:

AT8:

AT9:

AT10:
AT11:

AT12:

AT13:

AT14:

AT15:

AT16:

AT17:

AT18:

AT19:

AT20: 
Project Manager: D. E. BAXTER

Form Ho: SAPIIB

ENTER AKALYSIS TYPES (AT) AHO QUANTITY REQUESTED

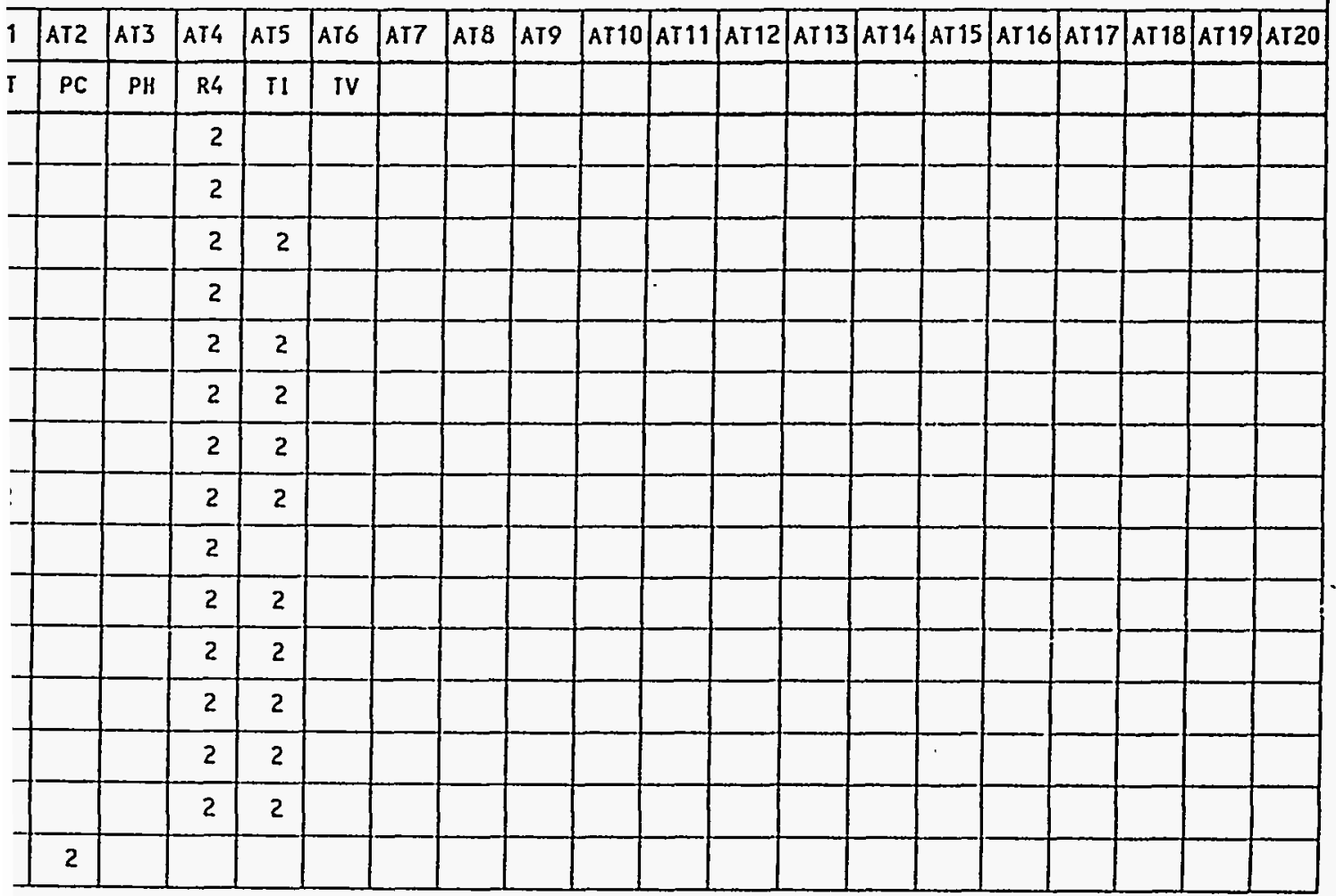

IP Table 2, Sanpling And Analysis Plan Table - Codes \& Descriptions.

jes belor.

COMHENTS

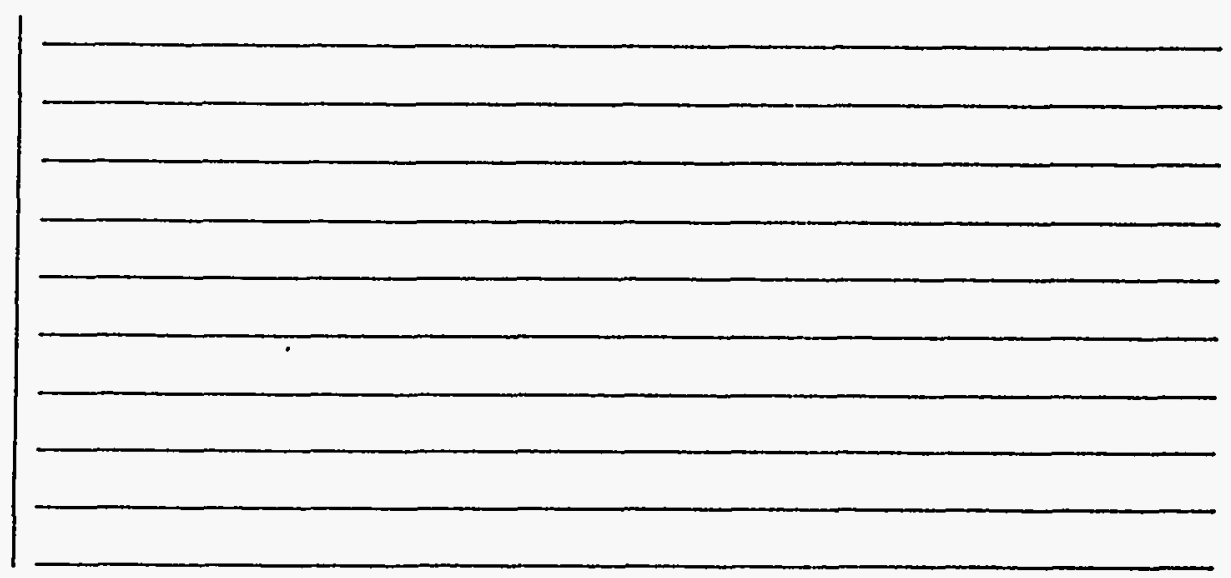

Page 34 of 108 
Table 2.9-3. Listing of Sample Numbers Assigned by the INEL SMO. (Cont.)

Plan Table Numer: TRA-DSD

SAP lluiber:

Date: 08/30794 Plan Table Revision: 0.0
SAMPLING AHD ANALYSIS PLAN TABLE FOR CHEMICAL

Project: CIIARACTERIZATIOH OF D\&D AREAS AT IR SAMPLE DESCRIPTIOII

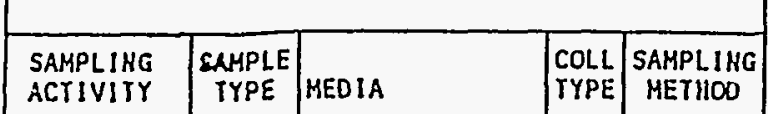

\begin{tabular}{l|l|l|l|l|}
\hline TRS016 & REG & FILTER & COHP & \\
\hline TRS017 & REG & LIOUID & COMP & \\
\hline TRS018 & REG & PAINT & COMP & \\
\hline
\end{tabular}

\begin{tabular}{l|l|l|} 
TRSO18 & REG & PAINT \\
\hline
\end{tabular}

\begin{tabular}{l|l|l|}
\hline TRSO19 & REG & PAIHT \\
\hline TRSO20 & REG & RESIK \\
\hline
\end{tabular}

\begin{tabular}{|l|l|l|}
\hline TRSO21 & REG & HASTE \\
\hline TRS022 & REG & HASTE \\
\hline TRS023 & REG & OIL \\
\hline
\end{tabular}

\begin{tabular}{|l|l|l|l}
\hline TRS024 & REG & SHIPE & COHP \\
\hline TRS025 & REG & HASTE & CO \\
\hline TRSU26 & REG & HASTE & CO \\
\hline TRSU27 & REG & HASTE & CO \\
\hline TRS028 & REG & OIL & COUP \\
\hline TRS029 & REG & OIL & COMP \\
\hline TRS030 & REG & LIOUID & COHP \\
\hline
\end{tabular}

Encer the appropriate analysis type code in the boxes between the double lines under "ENTER ANALYSIS TYPES". Encer the nunber of bottles in the single line boxes below the analys is type for each sanpling activity.

Any descriptions for non-standard analysis typas (not given in SAP Table 2) should be entered under "comments" on

AT1: Asbestos

AT2: PCBS (8080)

AT3: Hydrogin lon (pli)

AT4: Galma Spectroscopy

ATS: TCLP Metals

AT6: TCLP Volatiles

AT7:

$\therefore$ T:

ATS:

AT10:
AT11:

AT12:

AI13:

AT14:

AT15:

AT16:

AT17:

AT18:

AT19:

AT20:
SAMPLE LOCATION

\begin{tabular}{|c|c|c|}
\hline LOCATION & $\begin{array}{l}\text { TYPE OF } \\
\text { LOCATION }\end{array}$ & $\begin{array}{l}\text { DEPT } \\
\text { (ft }\end{array}$ \\
\hline FILTER HEDIA & HI\& RH SUMP PIT & $H / A$ \\
\hline SUMP & RCIR BLDG BSMHT & $M / A$ \\
\hline IN SUB PILE RM & RCTR BLDG BSMNT & $H / A$ \\
\hline OUT SUB PILE RH & RCTR BLDG BSMLIT & $H / A$ \\
\hline $4-3$ CUBICLE & RCTR BLDG BSHHT & $H / A$ \\
\hline TANKS HEAR $\mathrm{H}-3$ & RCTR BLDG BSMHT & $M / A$ \\
\hline COLD NASTE PIT & RCTR BLDG BSMNT & N/A \\
\hline DECON STATION & RCIR BLDG BSMNT & $H / A$ \\
\hline IECON STATIOH & RCTR BLDG BSMNT & $H / A$ \\
\hline CONSOLE TRNCH & RCTR BLDG BSHNT & N/A \\
\hline CONSOLE DRAIH & RCTR BLDG BSMHT & $N / A$ \\
\hline MI DRN-ST CAHAL & RCTR BLDG BSMHT & H/A \\
\hline IOTOR OPERATORS & COMPRESSOR BLDG & W/A \\
\hline$R$ COOLANT PUMP & COMPRESSOR BLDG & $N / A$ \\
\hline IPE TREHCH-PIT & COHPRESSOR BLDG & $H / A$ \\
\hline
\end{tabular}


Project Manager: D. E. BAXTER

Form Ho: SAP118

\begin{tabular}{|c|c|c|c|c|c|c|c|c|c|c|c|c|c|c|c|c|c|c|c|}
\hline \multicolumn{20}{|c|}{ ENTER AHALYSIS TYPES (AT) AND QUAHTITY REQUESTED } \\
\hline AT1 & AT2 & AT3 & AT4 & AT5 & AT6 & AT7 & AT8 & AT9 & AT 10 & AT 11 & AT12 & AT13 & AT14 & AT 15 & AT16 & AT17 & AT 18 & AT19 & AT20 \\
\hline JT & PC & PH & R4 & II & TV & & & & & & & & & & & & & & \\
\hline & & & 2 & 2 & & & & & & & & & & & & & & & \\
\hline & & & 2 & 2 & & & & & & & & & & & & & & & \\
\hline & & & 2 & & & & & & & & & & & & & & & & \\
\hline & & & 2 & & & & & & & & & & & & & & & & \\
\hline & & & 2 & 2 & & & & & & . & & & & & & & & & \\
\hline & & & 2 & 2 & 2 & & & & & & & & & & & & & & \\
\hline & & & 2 & 2 & & & & & & & & & & & & & & & \\
\hline & 2 & & & & & & & & & & & & & & & & & & \\
\hline & & & 2 & & & & & & & & & & & & & & & & \\
\hline & & & 2 & 2 & & & & & & & & & & & & & & & \\
\hline & & & 2 & 2 & 2 & & & & & & & & & & & & & & \\
\hline & & & 2 & 2 & & & & & & & & & & & & & & & \\
\hline & 2 & & & & & & & & & & & & & & & & & & \\
\hline & 2 & & & & & & & & & & & & & & & & & & \\
\hline & 2 & & 2 & 2 & & & & & & & & & & & & & & & \\
\hline
\end{tabular}

- SAP Table 2, Sampling And Analysis Plan Table - Codes \& Descriptions.

lines belor. COHAENTS

Page 35 of 108 
Table 2.9-3. Listing of Sample Numbers Assigned by the INEL SMO. (Cont.)

Plan Table Number: TRA-D\&D

SAP Humber:

Date: $08 / 30 / 94 \quad$ Ptan Table Revision: 0.0

\begin{tabular}{|c|c|c|c|c|c|c|c|c|c|}
\hline \multicolumn{5}{|c|}{ SAMPLE DESCRIPTIOH } & \multirow[b]{2}{*}{$\begin{array}{c}\text { PLAHHED } \\
\text { DATE }\end{array}$} & \multicolumn{4}{|c|}{ SAMPLE LOCATIOH } \\
\hline $\begin{array}{l}\text { SAHPLIHG : } \\
\text { ACTIVITY }\end{array}$ & $\begin{array}{c}\text { SAMPLE } \\
\text { TYPE }\end{array}$ & HEOIA & $\begin{array}{l}\text { COLL } \\
\text { TYPE }\end{array}$ & $\begin{array}{c}\text { SAMPLIHG } \\
\text { KETHOO }\end{array}$ & & AREA & LOCATION & $\begin{array}{l}\text { TYPE OF } \\
\text { LOCATION }\end{array}$ & $\begin{array}{r}\text { DEPTH } \\
(\mathrm{ft})\end{array}$ \\
\hline TRS031 & REG & SHEAR & COMP & & $09 / 15 / 94$ & $T R A-643$ & PIPE TRENCH & COHPRESSOR BLDG & $H / A$ \\
\hline TRS032 & REG & OIL & сCна & & $09 / 15 / 94$ & TRA- 643 & COAPRESSORS & CONPRESSOR BLDG & H/A \\
\hline TRSO33 & REG & OIL & COMP & & $09 / 15 / 94$ & TRA- 643 & COAP ACTUATORS & CQMPRESSOR BLDG) & $\mathrm{H} / \mathrm{A}$ \\
\hline TRS034 & REG & WASTE & $\cos p$ & & $09 / 15 / 94$ & TRA-643 & TRHCH BELOH CMP & COMPRESSOR BLDG & $N / A$ \\
\hline TRSO35 & REG & OIL & СОसP & & $09 / 15 / 94$ & TRA-643 & COMP MTR DRIVE & CCHPRESSOR BLOG & $H / A$ \\
\hline TRSO36 & REG & HASTE & $\operatorname{cosp}$ & & $09 / 15 / 94$ & TRA- 643 & SHOWER ORAIN & COMPRESSOR BLDG| & $H / A$ \\
\hline TRS037 & REG & HASTE & COMP & & $09 / 15 / 94$ & TRA -643 & MOP SINK DRAIH & COHPRESSOR BLDG & $H / A$ \\
\hline TRS038 & REG & HASTE & COMP & & $09 / 15 / 94$ & TRA -643 & HAHD SIHK DRAIH & COMPRESSOR BLDG & $H / A$ \\
\hline TRS039 & REG & HASTE & COMP & & $09 / 15 / 94$ & TRA-643 & CHH LAB SHK DRH & COHPRESSOR BLDG & $H / A$ \\
\hline IRS040 & REG & HASTE & COAP & . & $09 / 15 / 94$ & TRA- 643 & CHM LAB TREHCH & COHPRESSOR BLDG & $H / A$ \\
\hline TRSO41 & REG & LIOUID & COMP & & $09 / 15 / 94$ & TRA- 643 & GEH ROOY PIT & ELECTRICAL BLOG & N/A \\
\hline YRSO42 & REG & HASTE & CONP & 1 & $09 / 15 / 94$ & TRA- 648 & BATTRY RH DRAIH & ELECTRICAL BLDG & $H / A$ \\
\hline TRSO43 & REG & WASTE & COMP & & $09 / 15 / 94$ & TRA -648 & BATTRY RH SPILL & ELECTRICAL BLDG & H/A \\
\hline TRSO44 & REG & KESIDUE & COMP & & $09 / 15 / 94$ & TRA -663 & FUEL IHS-FLOOR & SUP.DIESEL BLDG & H/A \\
\hline
\end{tabular}

SAMPLING AND ANALYSIS PLAM TABLE FOR CHEMICAL AH Project: CHARACTERIZATION OF D\&D AREAS AT TRA. SAMPLE LOCATION

Enter the appropriate analysis type code in the boxes between the double lines under "ENTER AHALYSIS TYPES". Refer Enter the number of botrles in the single line boxes below the analysis type for each sampling activity.

Any descriptions for non-standard analys is types (not given in SAP Table 2) should be entered under "Catments" on the

AT1: Asbestos

AT2: PCBS (8080)

AT3: Hydrogen Ion (pH)

AT4: Ganma Spectroscopy

AT5: ICLP Metals

AT6: ICLP Volatiles

AT7:

AT8:

AT9:

AT10: 
Project Hanager: D. E. BAXTEK

Form Ho: SAP11B

ENTER AHALYSIS TYPES (AT) AHO QUAHTITY REQUESTED

\begin{tabular}{|c|c|c|c|c|c|c|c|c|c|c|c|c|c|c|c|c|c|c|c|}
\hline I 1 & AT2 & AT3 & AT4 & ATS & AT6 & Ar7 & AT8 & ATS & AT10 & АT11 & AT12 & AT13 & AT14 & AT15 & AT16 & AT17 & AT18 & AT19 & AT20 \\
\hline JT & $P C$ & PH & R4 & II & TV & & & & & & & & & & & & & & \\
\hline & 2 & & 2 & 2 & & & & & & & & & & & & & & & \\
\hline . & 2 & & & & & & & & & & & & & & & & & & \\
\hline & 2 & & & & & & & & & & & & & & & & & & \\
\hline & & & 2 & 2 & & & & & & & & & & & & & & & \\
\hline & 2 & & & & & & & & & & & & & & & & & & \\
\hline & & & 2 & & & & & & & & & & & & & & & & \\
\hline & & & 2 & & & & & & & & & & & & & & & & \\
\hline & & & 2 & & & & & & & & & & & & & & & & \\
\hline & & & 2 & 2 & & & & & & & & & & & & & & & \\
\hline & & & 2 & 2 & & & & & & & & & & & & & & & \\
\hline & 2 & & 2 & 2 & & & & & & & & & & & & & & & \\
\hline & & 2 & 2 & 2 & & & & & & & & & & & & & & & \\
\hline & & 2 & 2 & 2 & & & & & & & & & & & & & & & \\
\hline & 2 & & & 2 & & & & & & & & & & & & & & & \\
\hline & & & & & & & & & & & & & & & & & & & \\
\hline
\end{tabular}

SAP Table 2, Sampling And Analys is Plan Table - Codes \& Descriptions.

ines belor. $\quad$ COHMENTS

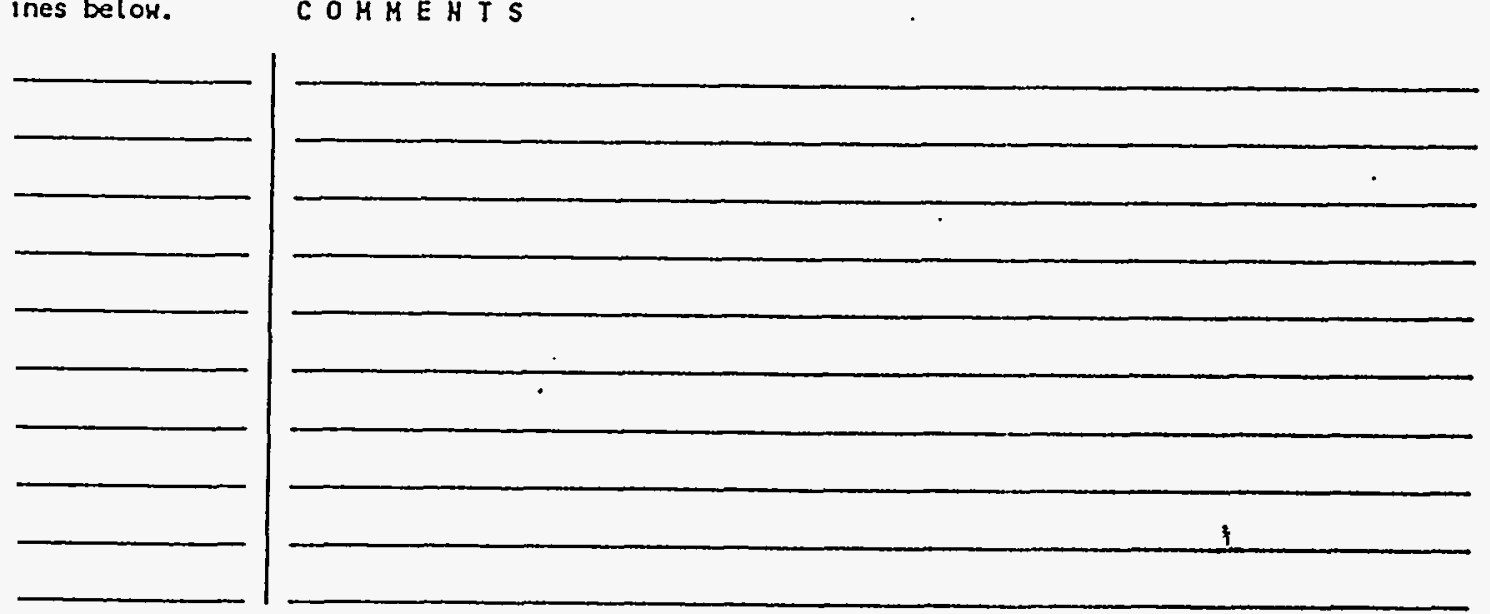

Page 36 of 108 
Table 2.9-4. Environmental Monitoring Target Radionuclide List.

\begin{tabular}{ll}
\multicolumn{1}{c}{ Radionuclide } & Half-life \\
\hline Actinium-228 & \\
Americium-241 & 6.13 hours \\
Antimony-125 & 458 years \\
Bismuth-212 & 2.7 years \\
Bismuth-214 & 60.6 minutes \\
Cerium-144 & 19.8 minutes \\
Cesium-134 & 284 days \\
Cesium-137 & 2.05 years \\
Cobalt-60 & 30.2 years \\
Europium-152 & 5.27 years \\
Europium-154 & 12 years \\
Europium-155 & 16 years \\
Lead-212 & 1.81 years \\
Lead-214a & 10.6 hours \\
Manganese-54 & 26.8 minutes \\
Plutonium-238 & 303 days \\
Plutonium-239b & 87.7 years \\
Plutonium-240 & 24,000 years \\
Protactinium-234 & 6,580 years \\
Radium-226a & 6.7 hours \\
Silver-110 m ${ }^{\mathrm{a}}$ & 1600 years \\
Strontium-90 & 253 days \\
Thallium-208 & 28.8 years \\
Thorium-234 & 3 minutes \\
Uranium-234 & 24.1 days \\
Uranium-238 & $2.5 \times 10^{5}$ years \\
Zinc-65a & $4.5 \times 10^{9}$ years \\
\hline
\end{tabular}

a. Radionuclides with no radiological release criteria guidelines.

b. To be determined by radiochemical techniques and methods. All others listed are determined by gamma spectrometric techniques.

NOTE: Thorium-234, protactinium-234, uranium-234, radium-226, lead-214, and bismuth-214 are decay products (daughters) of the natural uranium series decay chain. Actinium-228, lead-212, bismuth-212, and thallium-208 are decay products (daughters) of the natural thorium series decay chain. 
Table 2.9-5. Typical Requirements - Soils/Sediments/Sludges/Biota (DOE, 1989a).

\begin{tabular}{|c|c|c|c|c|c|}
\hline \multirow{2}{*}{$\begin{array}{l}\text { Analytical } \\
\text { parameter }\end{array}$} & \multicolumn{2}{|c|}{ Container } & \multirow[t]{2}{*}{ Preservative } & \multirow{2}{*}{$\begin{array}{l}\text { Holding } \\
\text { time }\end{array}$} & \multirow{2}{*}{$\begin{array}{l}\text { Sample } \\
\text { volume }\end{array}$} \\
\hline & Size & Type & & & \\
\hline $\begin{array}{l}\text { Volatile organic } \\
\text { Hydrocarbons }\end{array}$ & $125 \mathrm{ml}$ & (WM) glass jar & $4^{\circ} \mathrm{C}$ & $14 \mathrm{~d}$ & $\begin{array}{c}50 \mathrm{~g} \\
\text { (minimum) }\end{array}$ \\
\hline $\begin{array}{l}\text { Semivolatile organic } \\
\text { Anions } \\
\text { TCLP semivols } \\
\text { PCB } \\
\text { Pesticide }\end{array}$ & $250 \mathrm{ml}$ & (WM) glass jar & $4^{\circ} \mathrm{C}$ & $\begin{array}{l}\text { Ext. org. }-14 \mathrm{~d} \\
\text { TCLP }-28 \mathrm{~d} \\
\text { Sulfides }-7 \mathrm{~d} \\
\text { Pest. }-7 \mathrm{~d}\end{array}$ & $150 \mathrm{~g}$ \\
\hline High explosives & & (WM) glass jar & $4^{\circ} \mathrm{C}$ & $N / A$ & $200 \mathrm{~g}$ \\
\hline $\begin{array}{l}\text { CLP metals } \\
\text { ICP metals } \\
\text { Cations } \\
\text { Cyanide } \\
\text { TCLP metals } \\
\mathrm{Pb} \\
\mathrm{Hg} \\
\mathrm{Cr} \\
\mathrm{Cr}^{+6} \\
\mathrm{As} \\
\mathrm{Tl} \\
\mathrm{Sn}\end{array}$ & $250 \mathrm{ml}$ & (WM) glass jar & $4^{\circ} \mathrm{C}$ & $\begin{array}{c}6 \text { mo } \\
\text { Cyanide }-28 d \\
\text { Mercury-28d }\end{array}$ & $75 \mathrm{~g}$ \\
\hline $\begin{array}{l}\text { Gamma analysis } \\
\text { Gross a \& b analysis } \\
\text { Total Pu } \\
\text { H } \\
\text { Total U } \\
\text { Th } \\
\text { Sr-90 } \\
\text { Am } \\
\text { Ra-226 } \\
\text { Cs-137 }\end{array}$ & 1602 & Plastic squat jar & None & $\overline{1 y}$ & Fill to top \\
\hline $\begin{array}{l}\text { Environmental asbestos } \\
\text { Bulk asbestos }\end{array}$ & $500 \mathrm{ml}$ & Plastic squat jar & $4^{\circ} \mathrm{C}$ & None & $400 \mathrm{ml}$ \\
\hline Soil gas & $\overline{-}$ & Canister & $4^{\circ} \mathrm{C}$ & $6 w k$ & Variable \\
\hline
\end{tabular}

a. Holding times are from the date of collection as referred to in Federal Register, Vol. 49, No. 209, October 26, 1984. 


\subsection{Radiolngical Considerations}

Based on the nature of the work to be performed at TRA and the results of previous RADCON surveys, radiological contamination will be encountered during sampling. A certified Radiological Control Technician (RCT) will support sampling activities at all times. RCT general surveys will be conducted in all roons, Contamination areas, and High Contamination areas. PPE will be evaluated on a case-by-case basis and any additions to minimal clothing requirements stated will be identified on the radiological work permit. Detailed work control documentation will be prepared in accordance with the DOE Radiological Control Manual.

\subsection{Decontamination Procedures}

Establishing decontamination procedures for personnel and equipment is necessary to control both chemical and radiological contamination and to protect field personnel. If equipment or personnel are radiologically contaminated, decontamination will be supervised by the RCT.

To prevent cross-contamination of samples, all onsite sampling equipment will be decontaminated. Decontamination will be performed througinout the workday as equipment is used and clean equipment supplies are depleted. Sampling equipment decontamination will follow the Environmental Monitoring Decontamination Standard Operating Procedure (SOP-EM-SR-1.12).

\subsubsection{Disposal of Contaminated Materials}

Materials and equipment known or suspected to be contaminated and for which decontamination or treatment is not feasible shall be properly disposed. D\&D Programs will provide the necessary containers for disposal of contaminated materials. These materials may include disposable clothing, tools, or other equipment resulting from sampling activities. All project personnel will be responsible for using the appropriate waste container for the type of contamination encountered (radiological, hazardous, and/or mixed waste). D\&D Programs will be responsible for final disposition of all wastes. It is the responsibility of all site personnel to minimize waste generation where possible. 


\subsection{DATA QUALITY OBJECTIVES AND REQUIREMENTS}

The overall objective of the project is to produce data of known quality that can be used to characterize wastes and assist in planning future D\&D actions at the site.

Sampled materials will be analyzed to determine the presence of gamma-emitting isotopes and/or TCLP metals, volatiles and semi-volatiles. Validation of laboratory data will be performed by the INEL SMO according to SMO SOPs 12.1.2-12.1.15. Data reporting, tracking, sample handling, etc. shall be according to ER PDs cited elsewhere in this document.

\subsection{Completeness and Critical Samples}

Many of the planned sample locations are in areas that have been unused for years. If no material is present, it will not be possible to obtain samples. If material is present, composites will be taken where possible. As a minimum, radiological smears should be obtainable from $90 \%$ of the planned locations. Soils to be sampled are known to be present and it is expected that $90 \%$ of these critical samples will be obtainable. 


\subsection{DOCUMENTATION}

Environmental Monitoring (EM) will send a closure package containing copies of the following items listed below to the project manager:

- Chain-of-Custody. Samples must be labeled and handled according to standard custody procedures as necessary to ensure the project objectives are fulfilled. These procedures will be in accordance with ER PD 5.7, Chain of Custody, "Sample Handling and Packaging."

- Field Logbooks. Field activities must be recorded with waterproof ink in the appropriate field logbook. The use of logbooks will be in accordance with ER PD 4.2, "Logbooks."

- Laboratory Data. Analytical results must be reported within 30 working days after sample receipt by the laboratory. Analytical data produced for the requested analyses will be reported to Donna Kirchner of EG\&G Idaho, Environmental Restoration Program, Sample Management Office, P.O. Box 1625, Idaho Falls, ID 83415-1403, telephone (208) 526-9873.

Data must be reported for all samples submitted for analysis and shall include all QA/QC data (except for RML data).

\section{Waste Disposal}

Samples submitted to the laboratories must be disposed after the data results have been interpreted. Samples will be disposed of by the laboratories.

A report will be issued upon completion of the data evaluation by the Environmental Monitoring Unit to the requester, Don Baxter. The report will evaluate the results of the sampling (e.g., maximums and standard deviations) with respect to regulatory standards. 


\subsection{DATA VALIDATION AND REPORTING}

The EG\&G Sample Management Office (SMO) will validate the data according to (a) requirements associated with the MTR-ETR D\&D project, (b) analytical methods selected by the laboratory, and (c) SMO validation procedures.

When appropriate as determined by the analytical level, data will be reported with statistically supported limits of uncertainty to indicate limitations on the use of the data. All data, when reported, will be rounded to the number of significant figures consistent with the confidence limits. ER PD 3.7, "Characterization Process in Environmental Restoration," details the flow of characterization data collected in the field. 


\subsection{CORRECTIVE ACTION}

Corrective action will be initiated when the project objectives are not met, or when assessment of the data reveals questionable or unknown data quality. Corrective action may be initiated by any individual on the project subject to approval by the project manager. These corrective actions will include, but are not limited to, modifications of the sampling procedure, sampling design, analytical techniques within EPA-approved guidelines, and data reporting procedures.

\subsection{Field Corrective Action}

The initial responsibility for monitoring the quality of field measurements lies with the field personnel. The project manager is responsible that all quality assurance (QA) procedures are followed. This requires that the D\&D Project Manager assess the field methods and their ability to meet the QA objectives, and to make a subjective assessment of the impact a procedure has on field objectives and subsequent data quality. If a problem occurs that might jeopardize the integrity of the project, cause failure to meet QA objectives, or impact data quality, the EM Project Manager will immediately contact the project requester.

The EM Project Manager will document the situation, the field objectives affected, the corrective actions taken, and the results of that action. Copies of documentation will be provided to the project requester.

Corrective action will be implemented when the project objectives are not met or when conditions adverse to quality standards have been identified. Conditions adverse to quality shall be promptly identified and corrected as soon as possible. The identification, cause, and corrective action to prevent reoccurrence shall be determined and documented for significant conditions adverse to quality.

\subsection{Laboratory Corrective Action}

The laboratory corrective action plan will be detailed in the laboratory quality program plan. The need for corrective action may come from several sources: equipment malfunctions, failure of internal QC checks, blank contamination, failure of performance or system assessments, and noncompliance with QA requirements.

Laboratory measurement equipment or analytical methods that fail to meet project $\mathrm{QC}$ requirements will be immediately brought to the attention of the laboratory $\mathrm{QC}$ manager. If failure is due to the equipment malfunctioning, the equipment will be repaired, re-calibrated and the analysis repeated. All attempts will be made to repeat all affected parts of the analysis so that the end product will not be affected by failure to meet $\mathrm{QC}$ requirements. Nonconforming data will be qualified with a note specifying any reasons for the qualification. All incidents of failure to meet $\mathrm{QC}$ requirements and all corrective actions will be documented. Corrective action 
reports will be immediately implemented for deficiencies noted during checks of raw data. This action will vary depending upon problems noted, and can range from correcting miscalculated data to requiring reanalysis of samples. As soon as sufficient time has elapsed for corrective action to be implemented, evidence of corrective action will be presented. Documentation of corrective action measures will be forwarded to the EM Project Manager. Corrective action documentation will include the following: a discussion of the nature of the problem; date and time of discovery; parameters affected; sample lot affected; date, time, and description of the resulting corrective action; and signature of the complying manager.

The laboratory QA officer will prepare a written report on corrective action for the EM Project Manager. The report will review the validity, quality, and completeness of the data in question and, if necessary, make recommendations for corrective action. 


\subsection{REFERENCES}

1. Data Quality Objectives for Remedial Response Activities: Developmental Process U.S. Environmental Protection Agency (USEPA), 1987

2. DOE, 1986 Environmental Monitoring Program Report for the Idaho National Engineering laboratory (DOE/ID-12082), 1986.

3. DOE, Environmental Survey Manual, DOE/EH-0053, Second Edition., January 1989.

4. EG\&G Idaho, Inc., Buried Waste Program Data Qualification Manual, EGGWM-8488, 1989.

5. EG\&G Idaho, Inc., Data Collection Quality Assurance Plan for the Buried Waste Program, EGG-WM-8220, Revision 1, December 1988.

6. EG\&G Idaho, Inc., Quality Program Plan for D\&D, QPP-149.

7. EG\&G Idaho, Inc., Levels of Method Validation. Environmental Restoration Program, Sampling Management Office, SMO-SOP-12.1.1, July 12, 1991.

8. Environmental Restoration Program Directives Manual, EG\&G Idaho, Inc.

ER PD 3.7, Characterization Process in Environmental Restoration.

ER PD 4.1, Document Control, Handling, Storing, and Shipping Samples. ER PD 4.2, Logbooks.

ER PD 5.7, Chain of Custody, Sample Handling and Packaging.

9. EPA, Test Methods for Evaluating Solid Waste, SW-846, Third Edition, 1986.

10. Hazardous Materials Transportation Manual, EG\&G Idaho, Inc.

11. NIOSH (National Institute of Occupational Safety and Health), Occupational Safety and Health Guidance Manual for Hazardous Waste Site Activities, October 1985.

12. OSHA, 29 CFR 1910.120. 


\section{Exhibit 1.1: Location Drawing for Sample Group 1}

TRA -611 Plug Storage Facility: Soil Sampling Required Below Plug Storage Channels (\#1) 


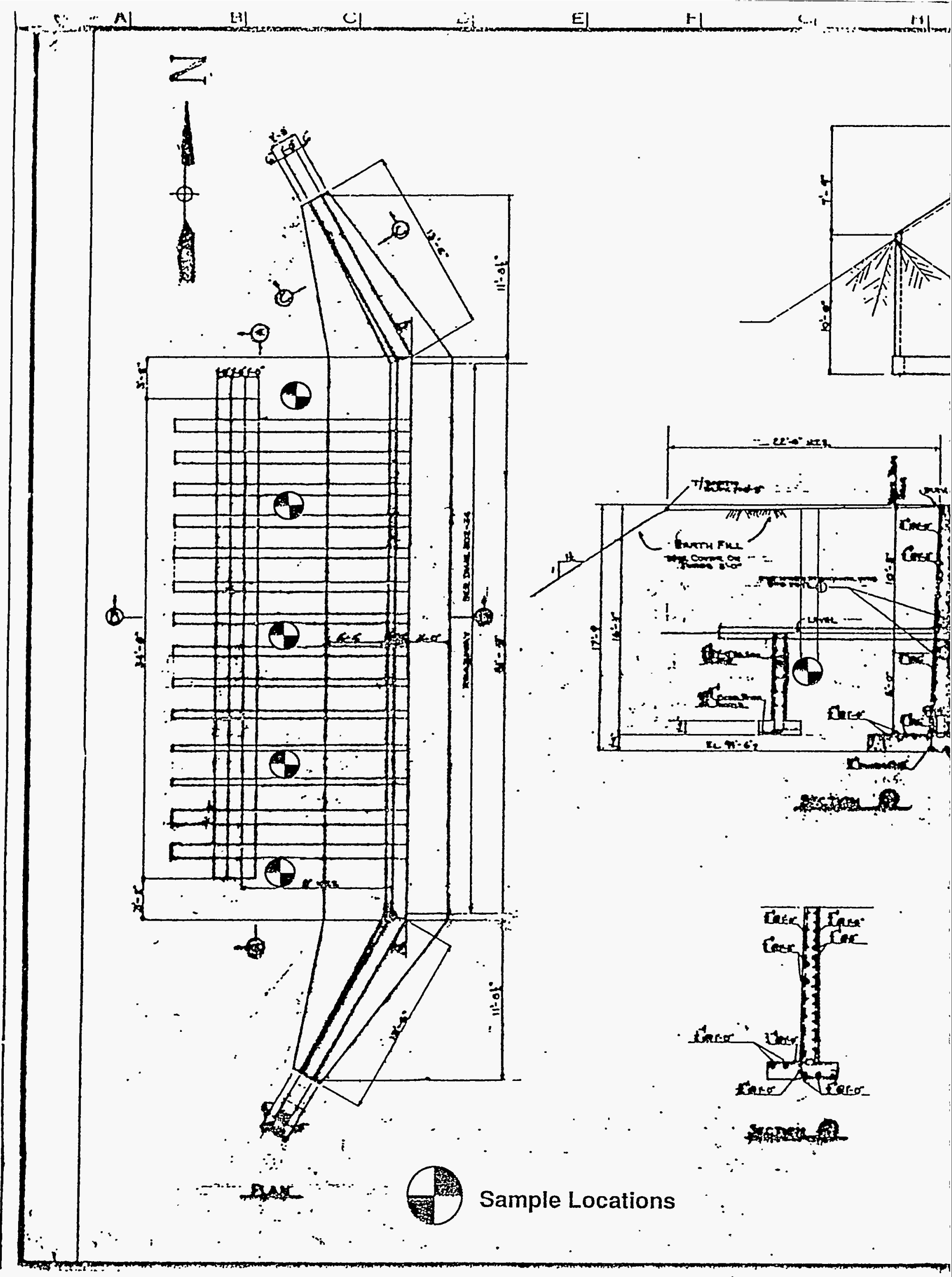




\section{Exhibit 1.2: Location Drawing for Sample Group 2}

TRA -612 MTR Retention Basin Sump Pumphouse: Liquid and Sludge Sampling Required in Sump (\#2) 


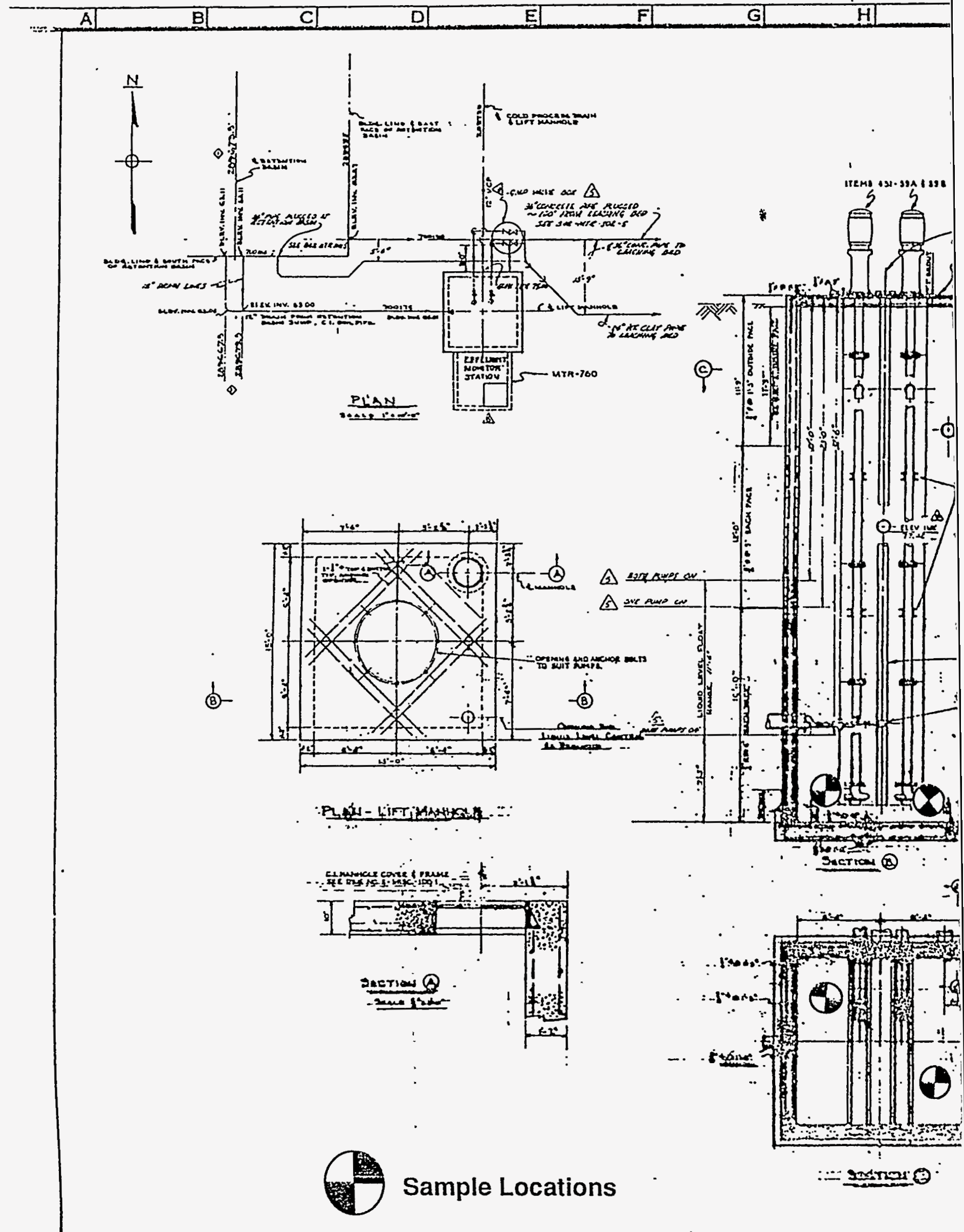




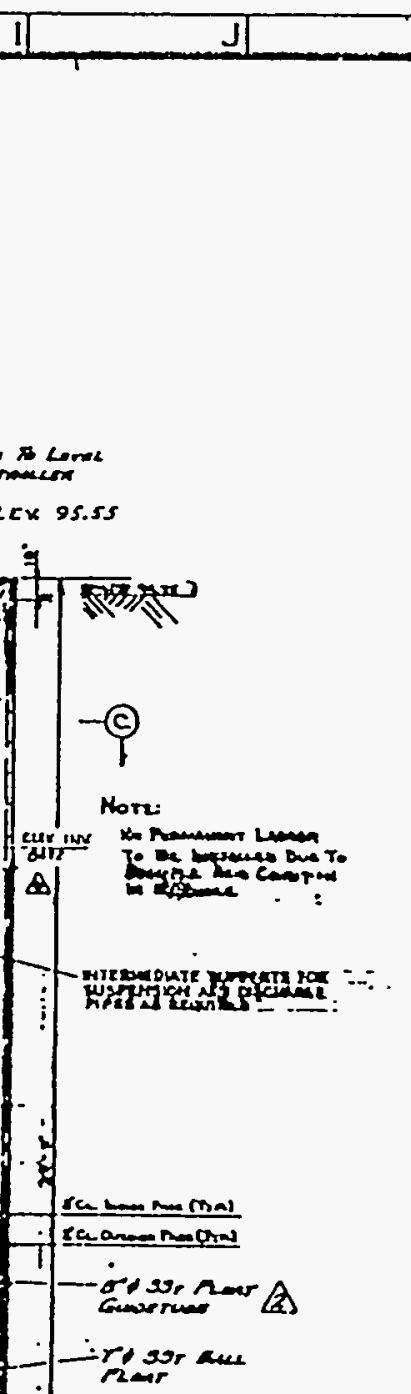

$K$

$L$

MI

이

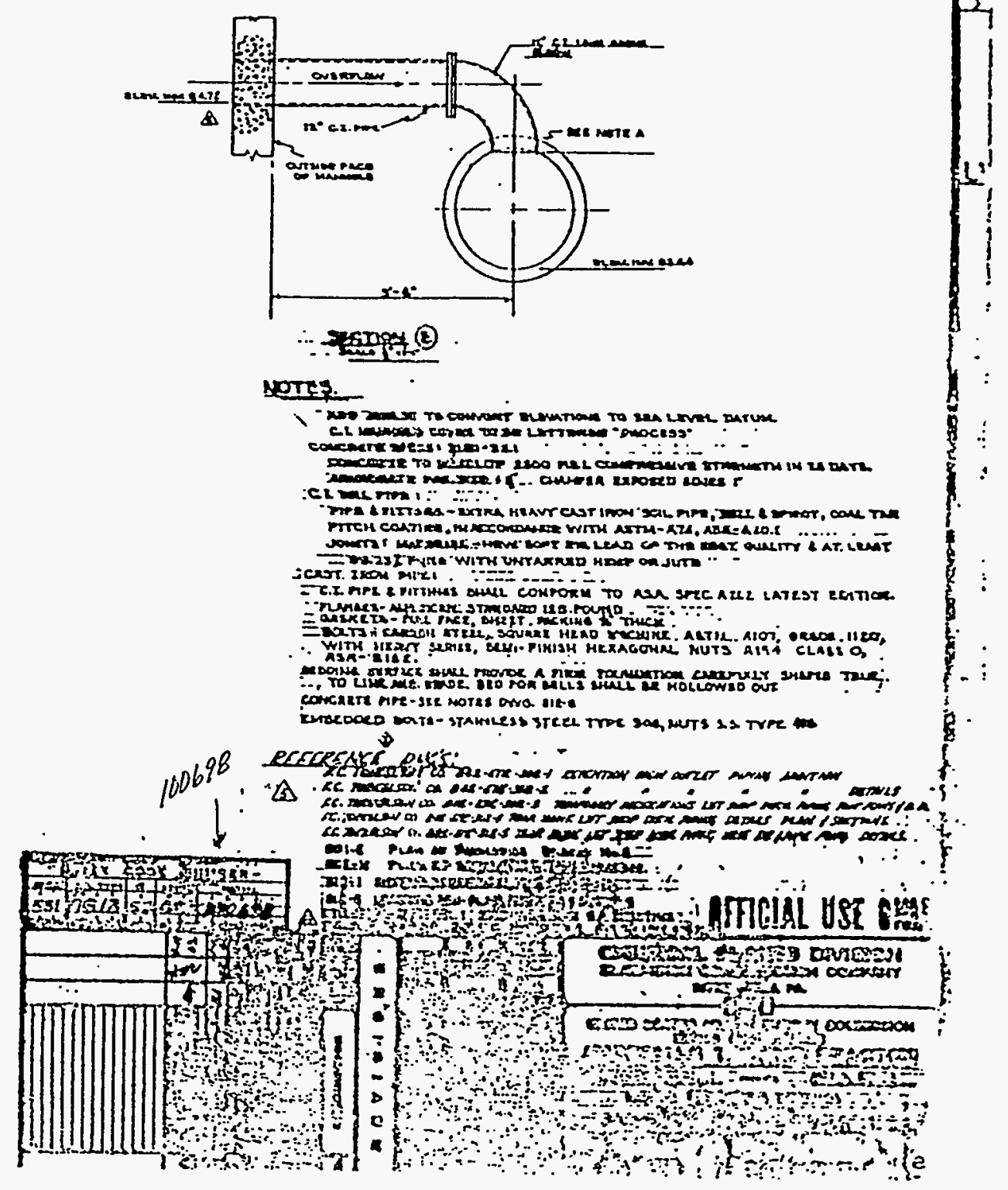


Exhibit 1.3: Location Drawing for Sample Groups 3 and 4 ( 1 of 2)

TRA -644 ETR Heat Exchanger Building: Concrete Sampling Required in Resin Transfer Area (\#3) and in Degasifier Tank Room, Roof of Building (\#4) 


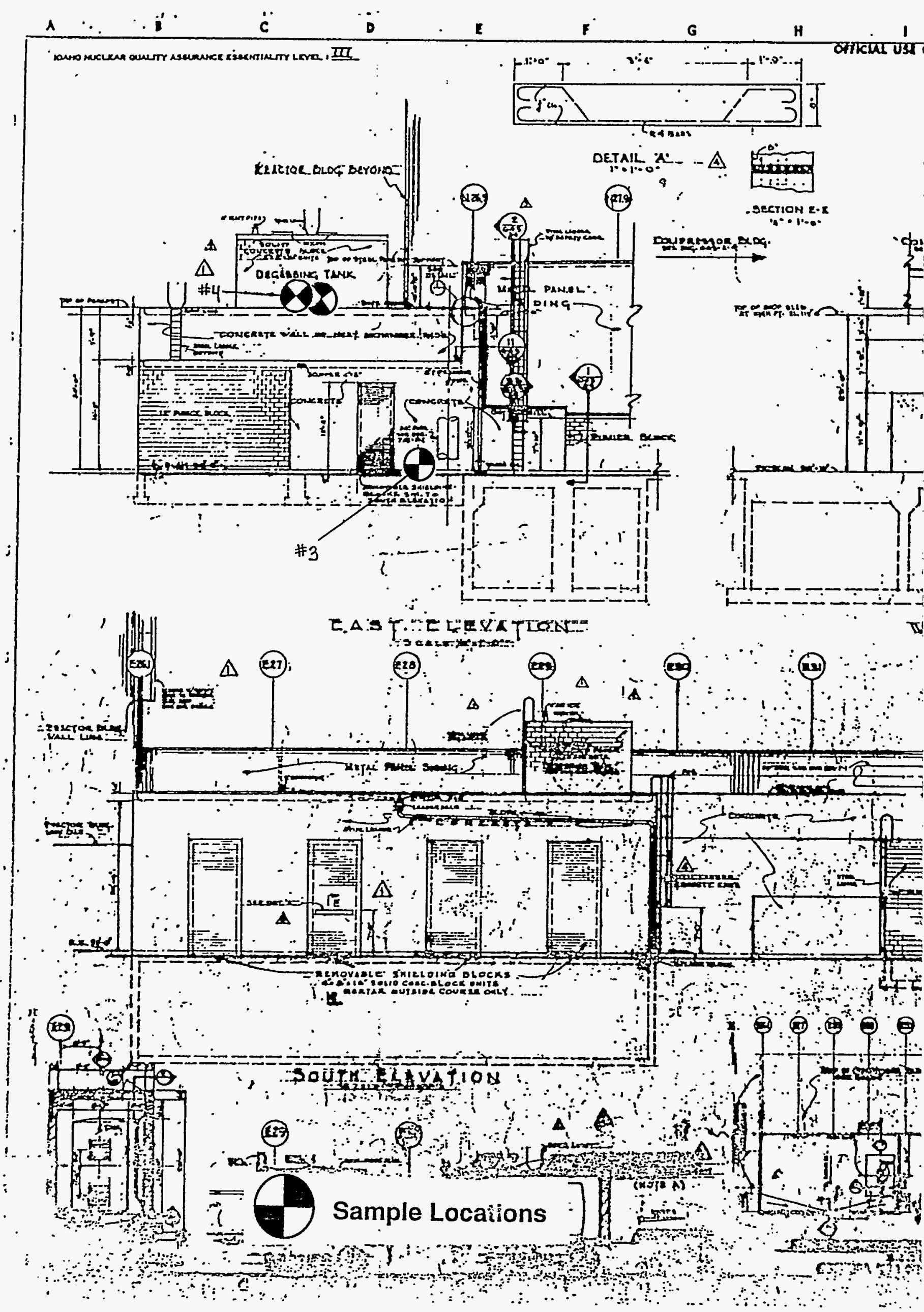




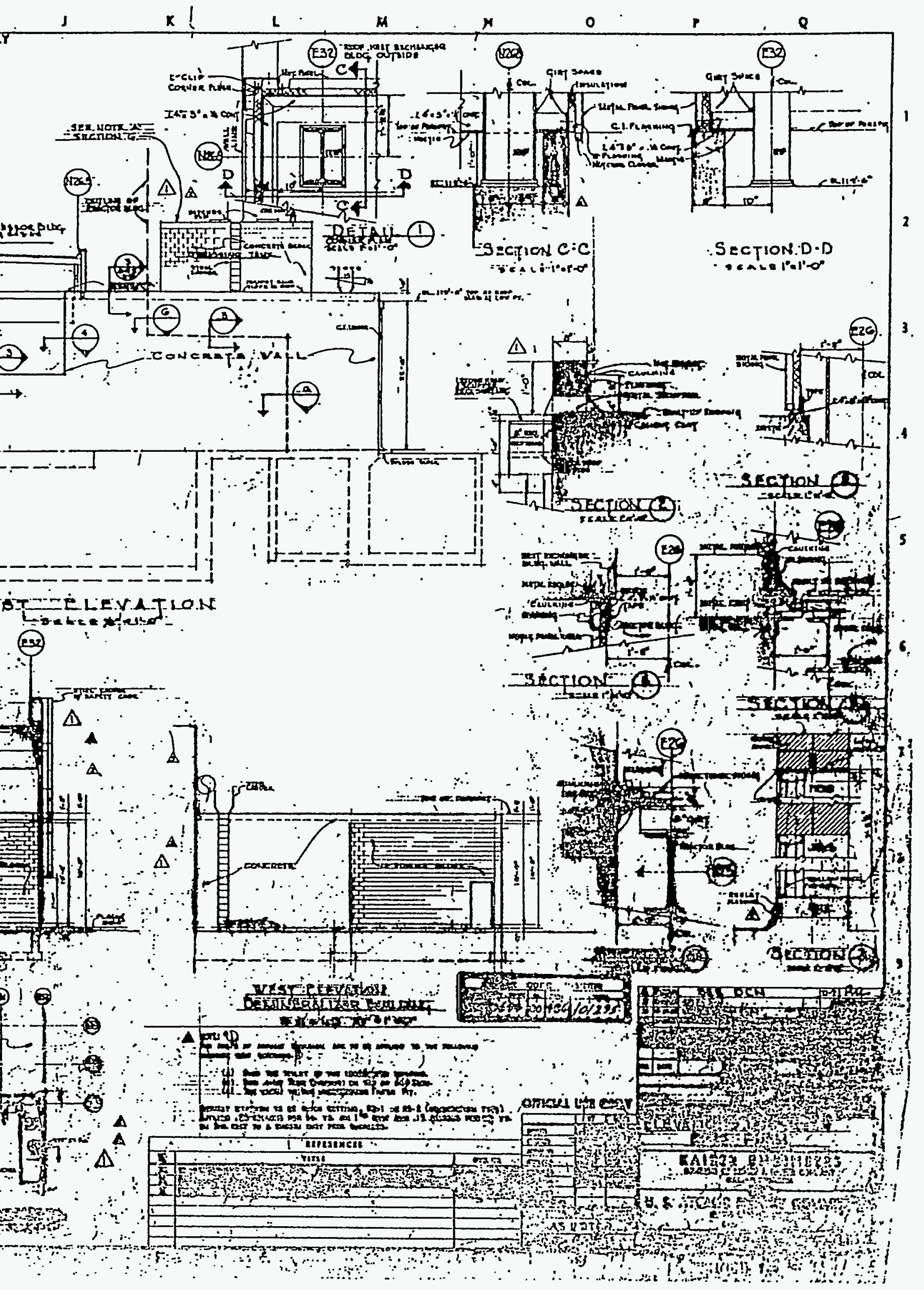


Exhibit 1.4.: Location Drawing for Sample Groups 3 and 4

TRA -644 ETR Heat Exchanger Building: Concrete Sampling Required in Resin Transfer Area (\#3), and in Degasifier Tank Room, Roof of Building (\#4) 


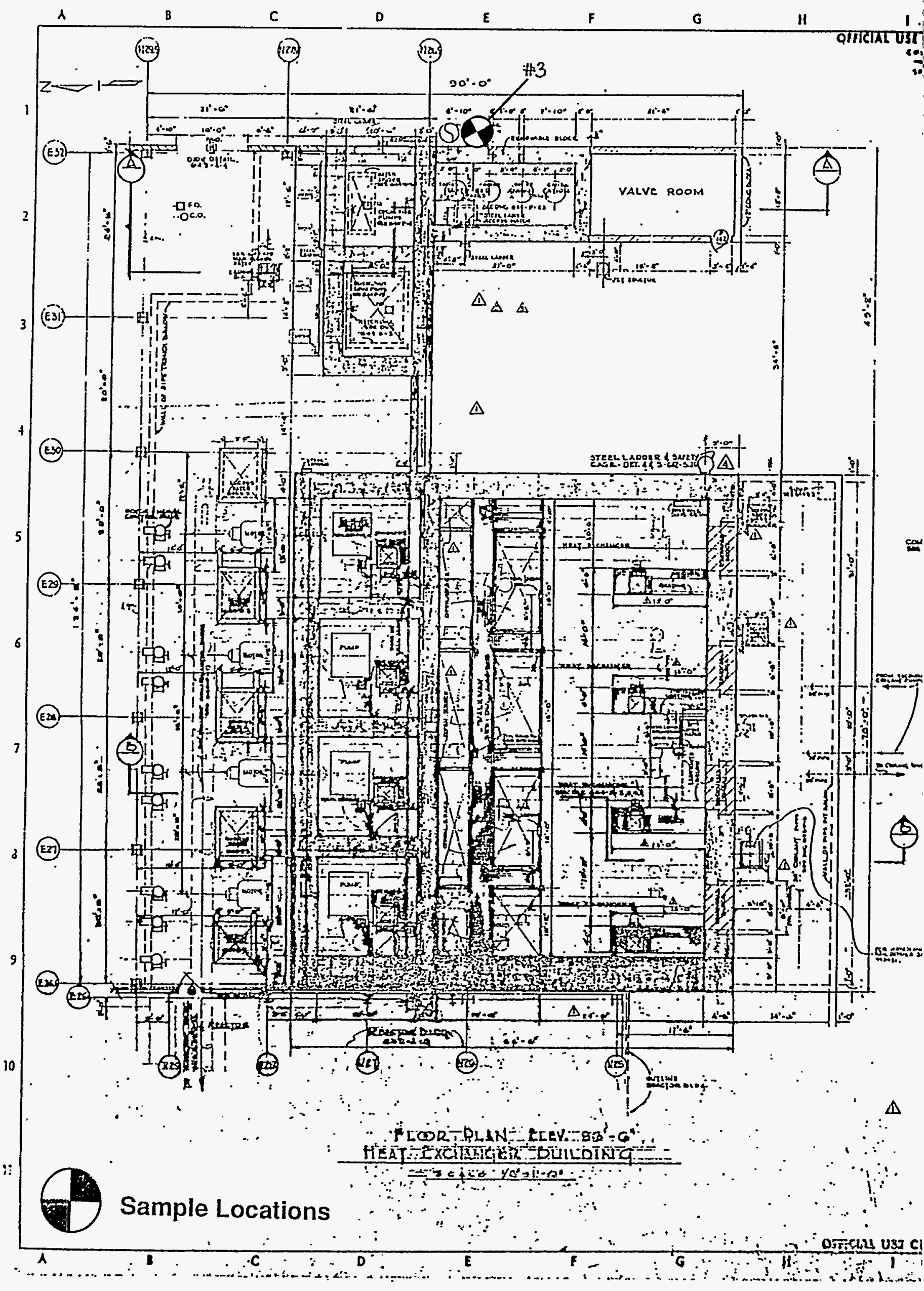



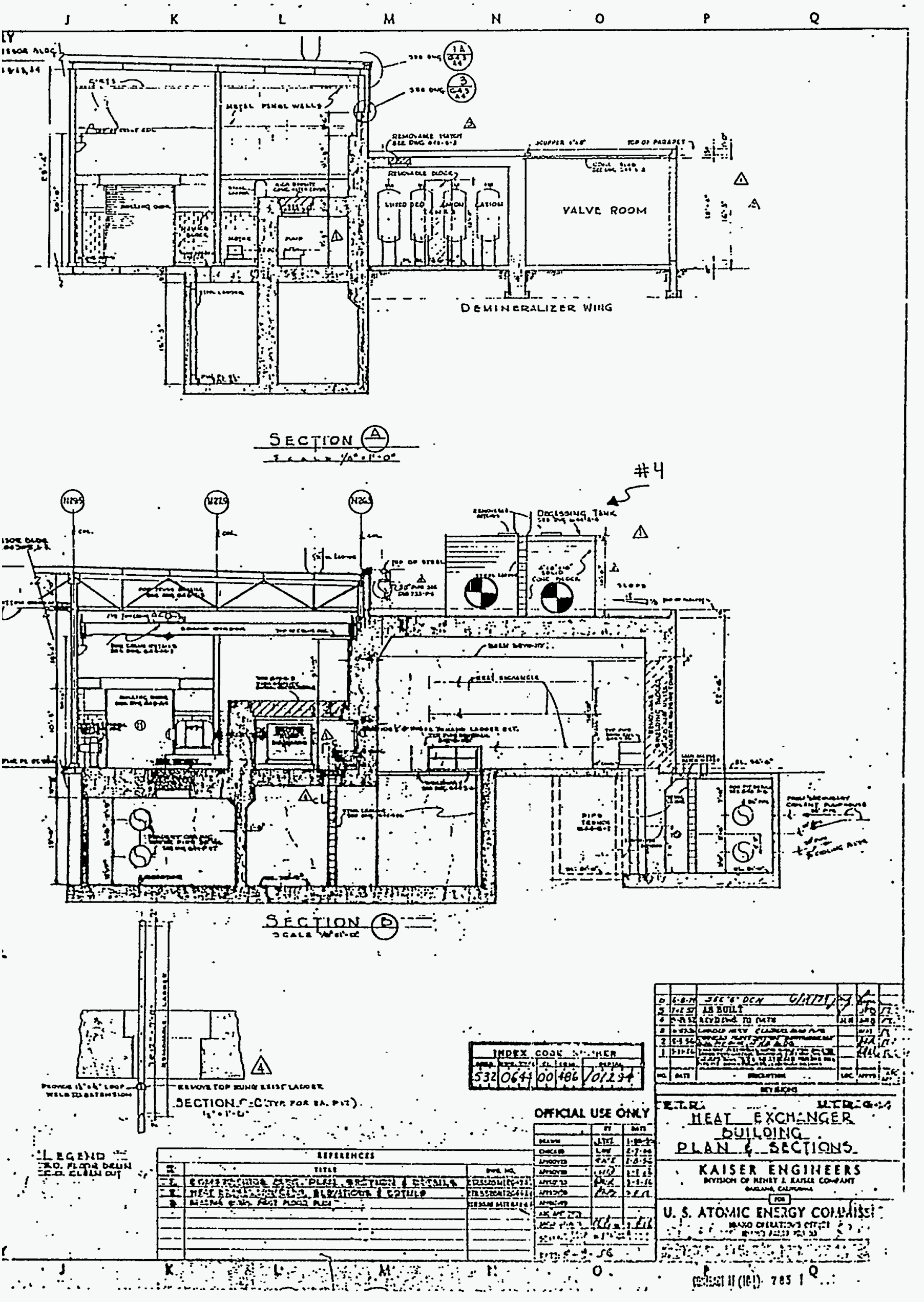
Exhibit 1.5: Location Drawing for Sample Groups 5 through 8

TRA -645 ETR Secondary Coolant Pump House:

Samples Required in Pit Area (\#5 and \#6)

Samples of Drain and Brick Required (\#7)

Three Soil Samples Required (\#8) 


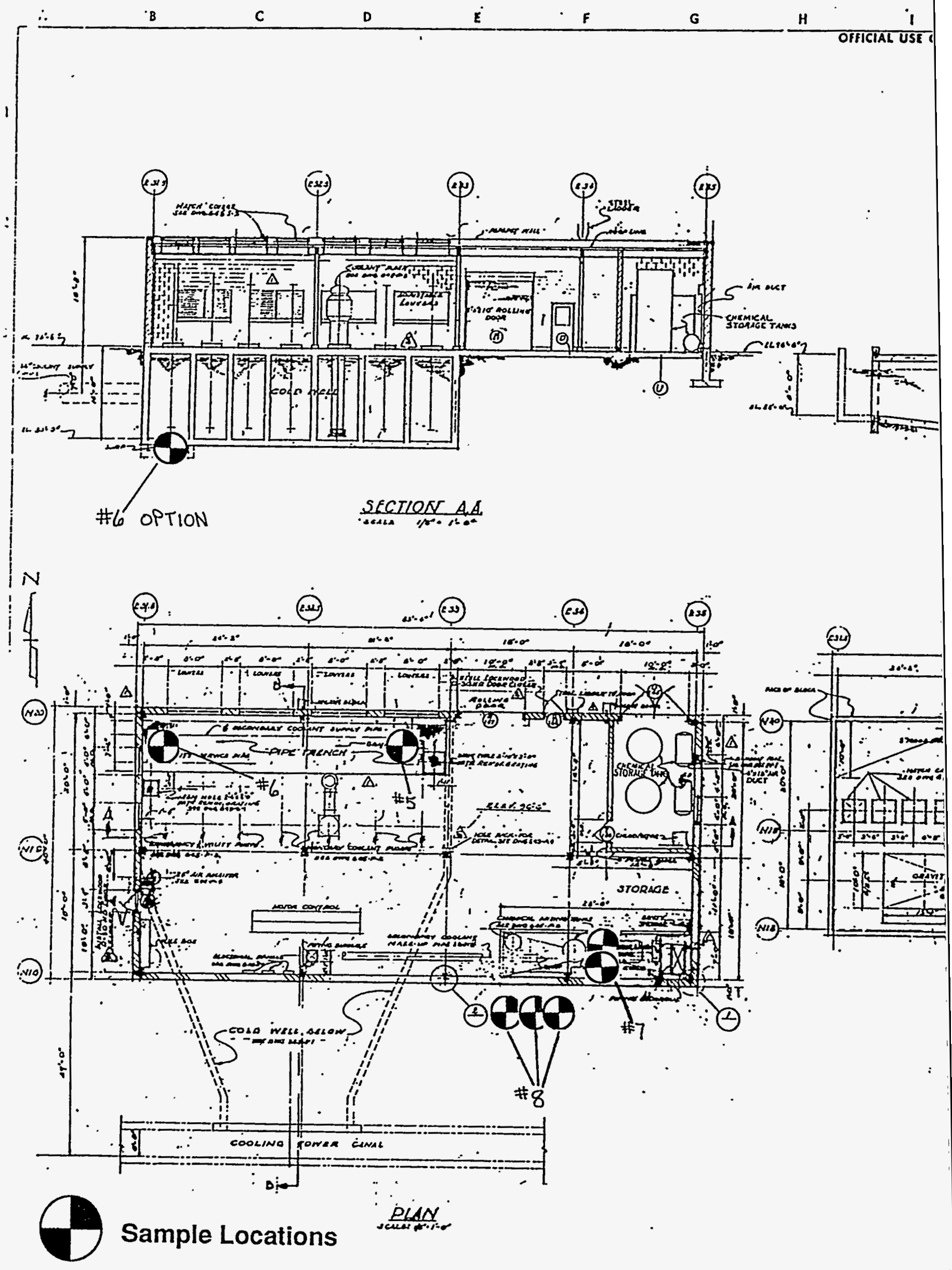

OABCLAS UST OMLY 


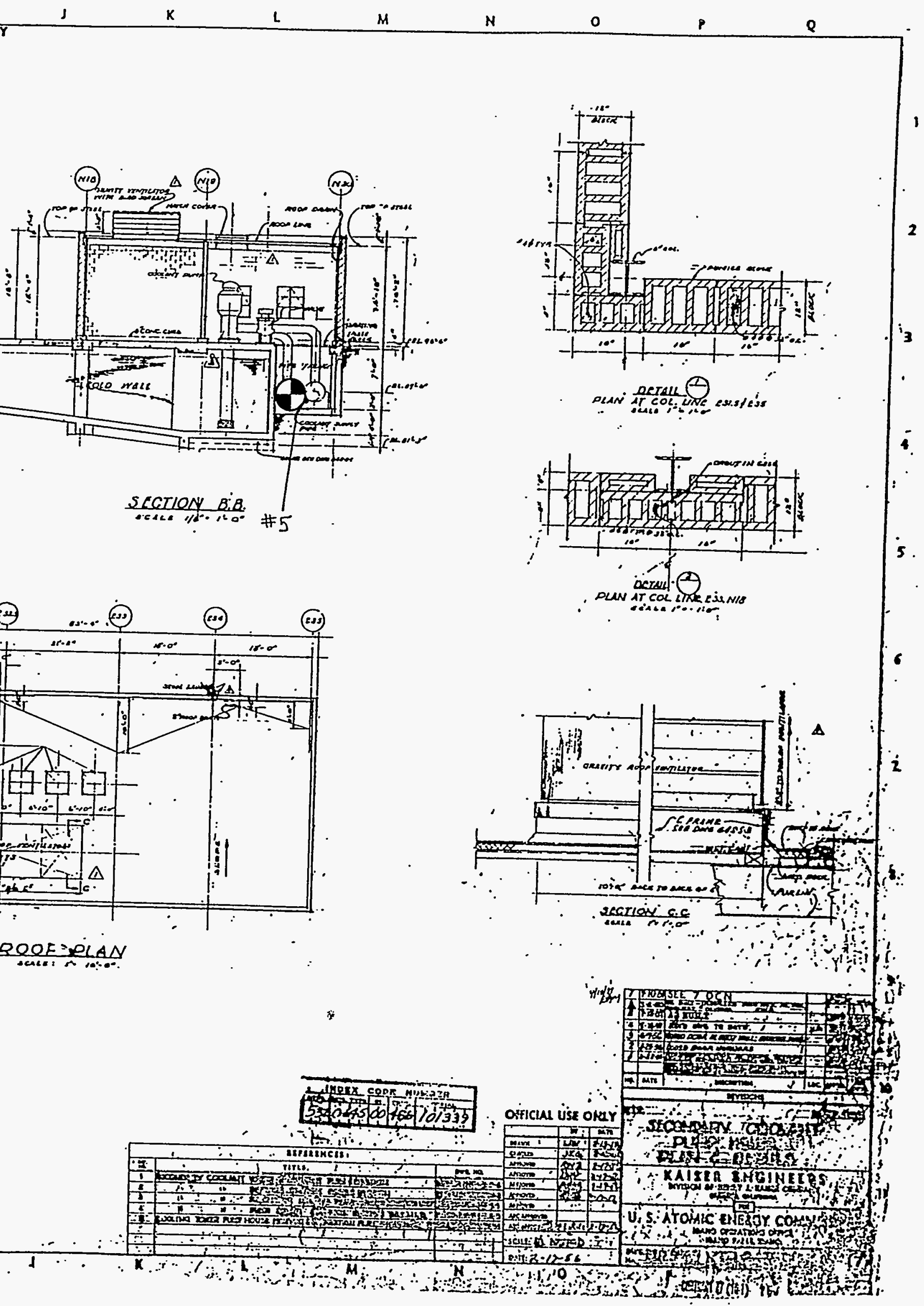


Exhibit 1.6: Location Drawing for Sample Groups 9 through 13

TRA -647 ETR Office Building

Room 104, Sink Drain Samples Required (\#9)

Shop, Sink Drain Sarrîples Required (\#10)

Basement HVAC Room

Sump Pit with Tank in Pit, Samples Required for Tank and Pit (\#11)

Samples Required of Hydraulic Oil in Dash Pots (\#12)

Air Intake Filters, Filter Media Samples Required for Lead (\#13) 


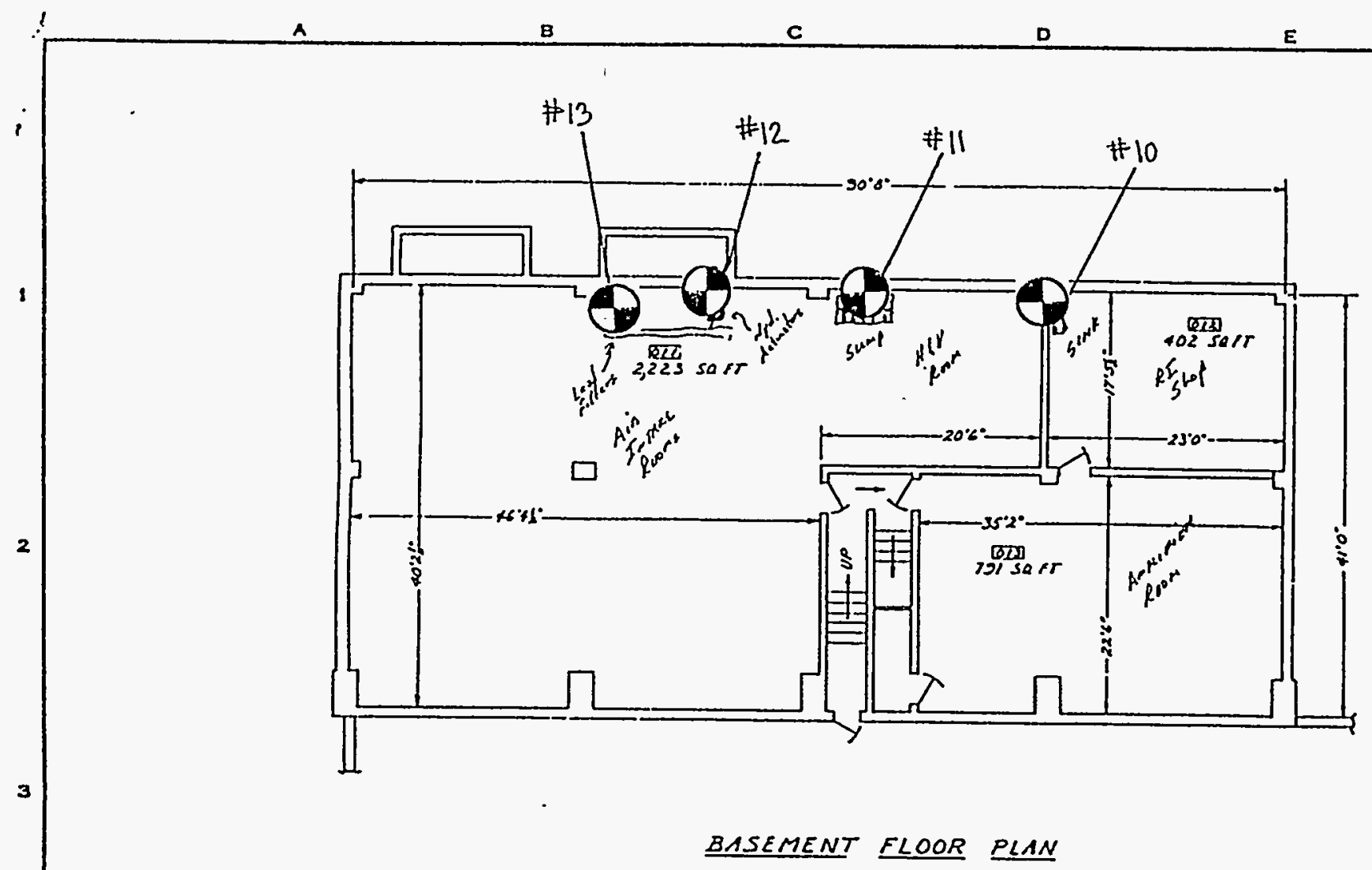

$\boldsymbol{b}$

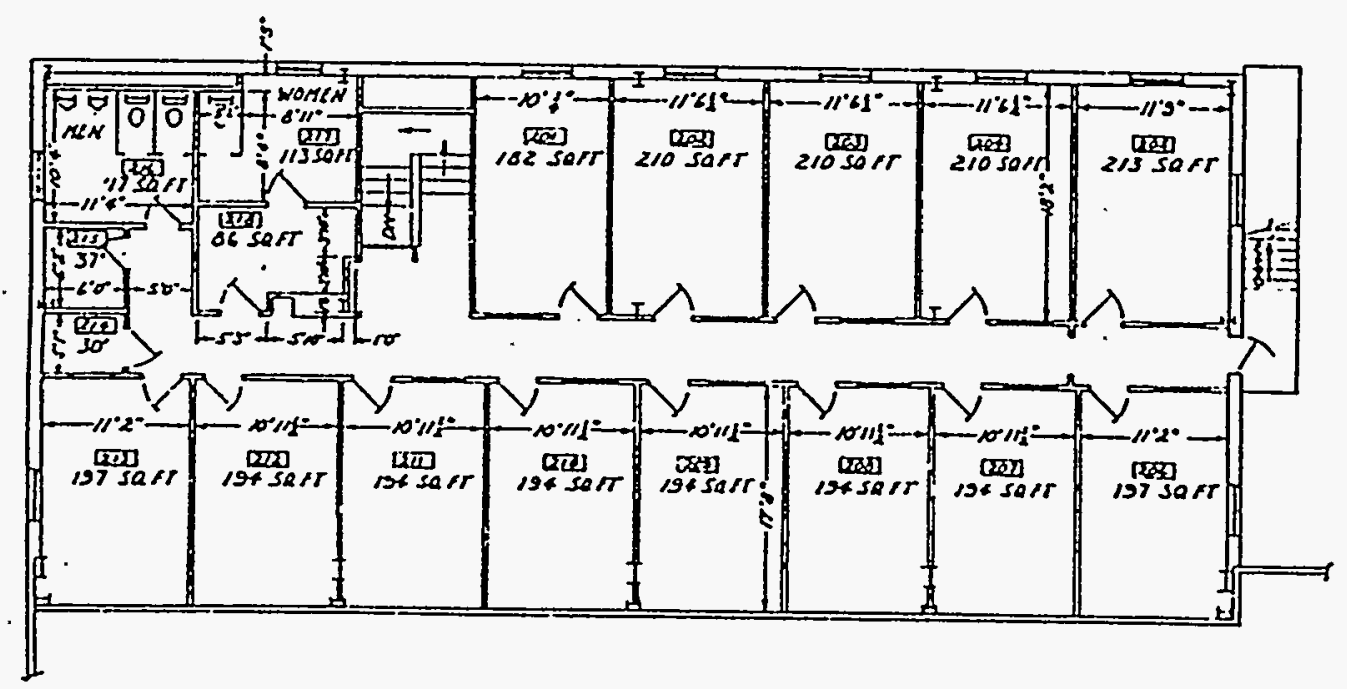

7 $\underbrace{\text { SECOND }}_{\Delta}$ SLOQR PLAN

Sample Locations 
Exhibit 1.7: Location Drawing for Sample Groups 14 through 18

TRA -642 ETR Reactor Building Basement,

Basement Sump Samples Required (\#14)

Sub Pile Room, Paint Samples Required Inside and Outside of Room (\#15)

Cubicle No. M-3,

Resin Samples Required from Inside M-3 (\#16)

Warm Waste Tanks Below Floor, Tank Samples Required (\#17)

Cold Waste Pit Below Floor, Pit Interior Samples Required

to Verify Cleanliness (\#18) 


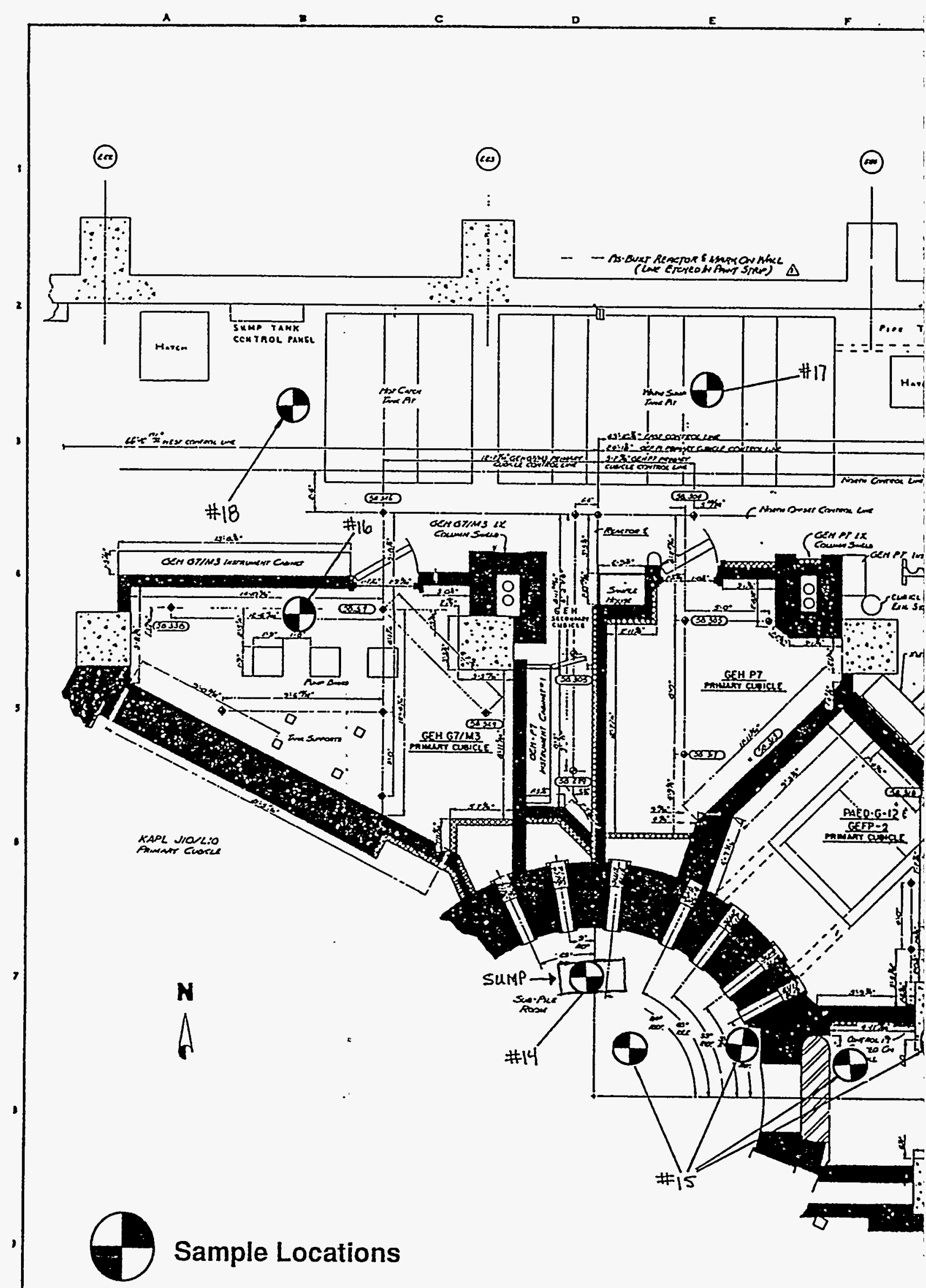




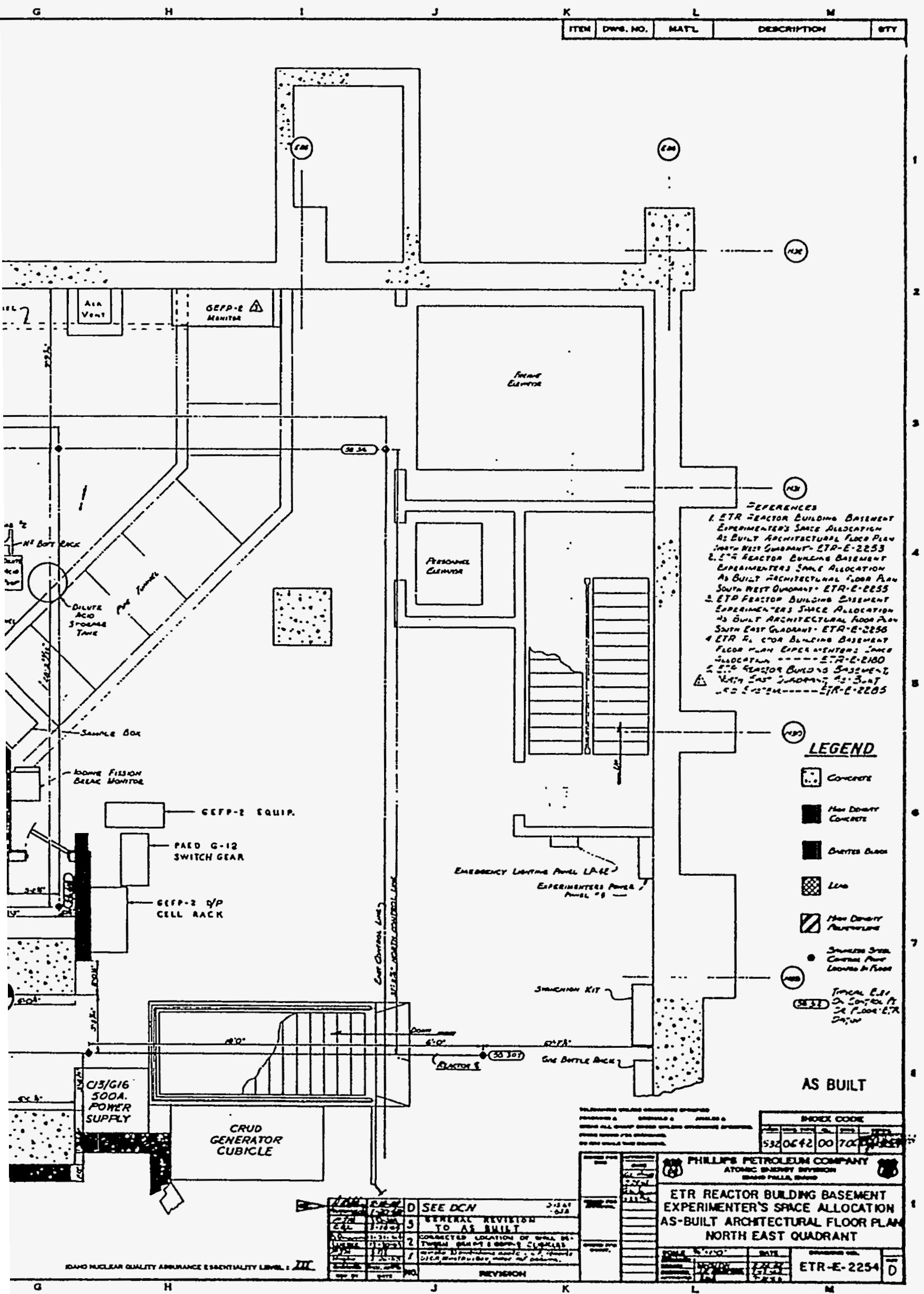


Exhibit 1.8: Location Drawing for Sample Group 19

TRA -642 ETR Reactor Building Basement Decontamination Station, Oil Residue Samples Required for PCB Analysis (\#19) 


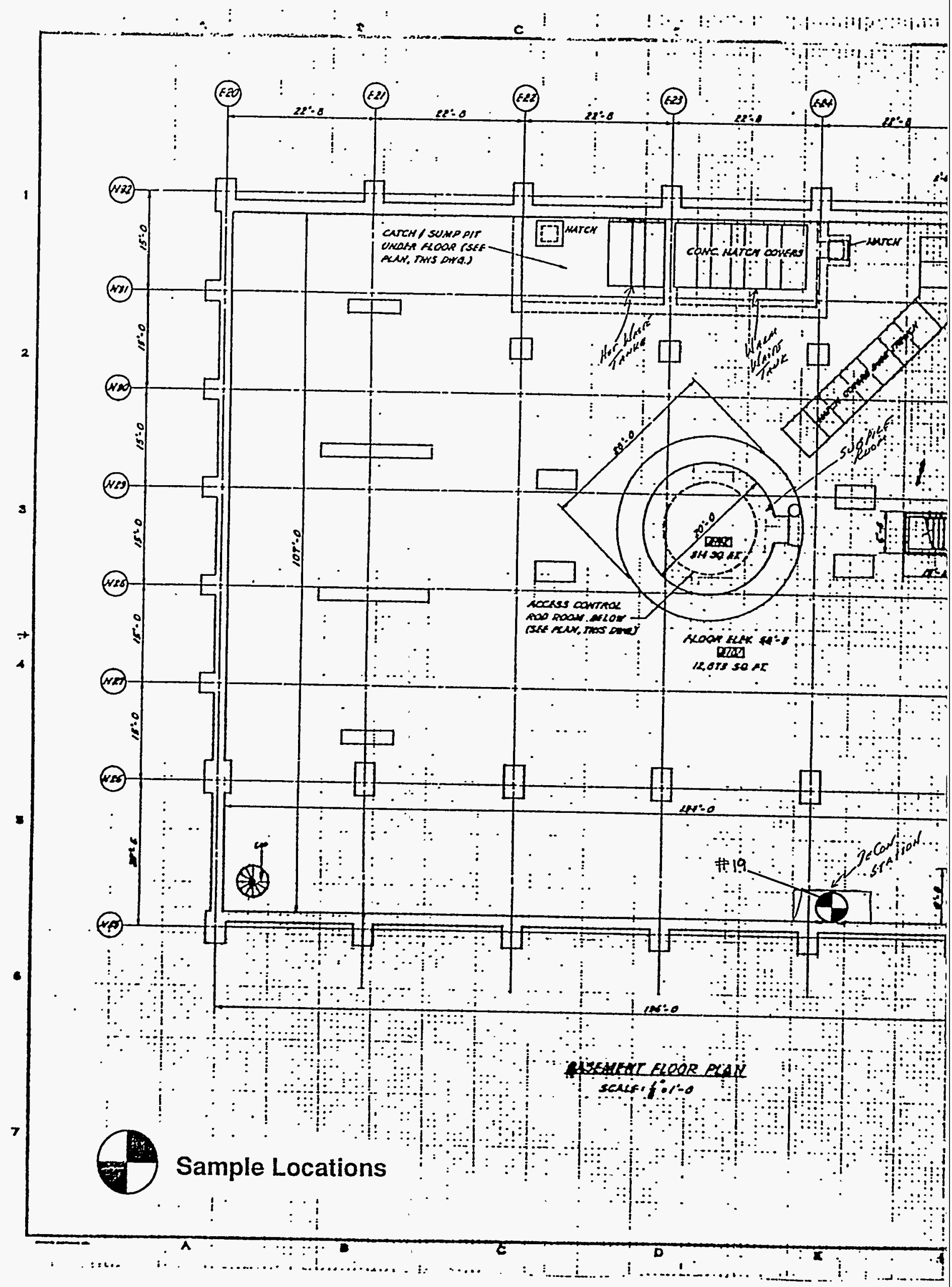


Exhibit 1.9: Location Drawing for Sample Groups 20 through 23

TRA -642 ETR Reactor Building Basement, South Console Floor Pipe Trench Adjacent to Reactor Containment, Samples Required from Trench (\#20, \#21)

Hot Experiment Drain, Representative Drain Sample Required from One Drain (\#22)

Warm Drain Around Storage Canal, Sample Required from Drain and Trench Drain (\#23) 


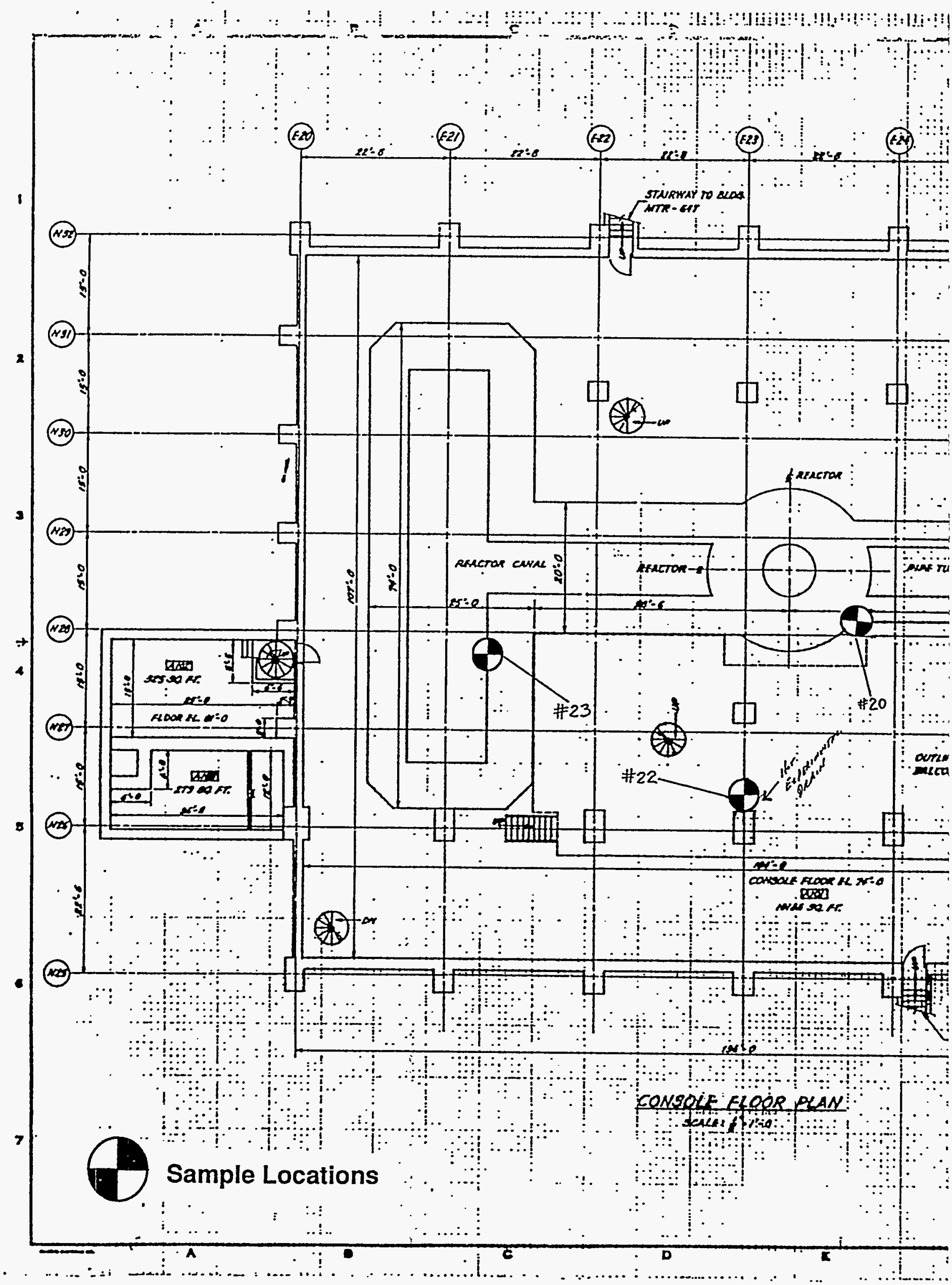




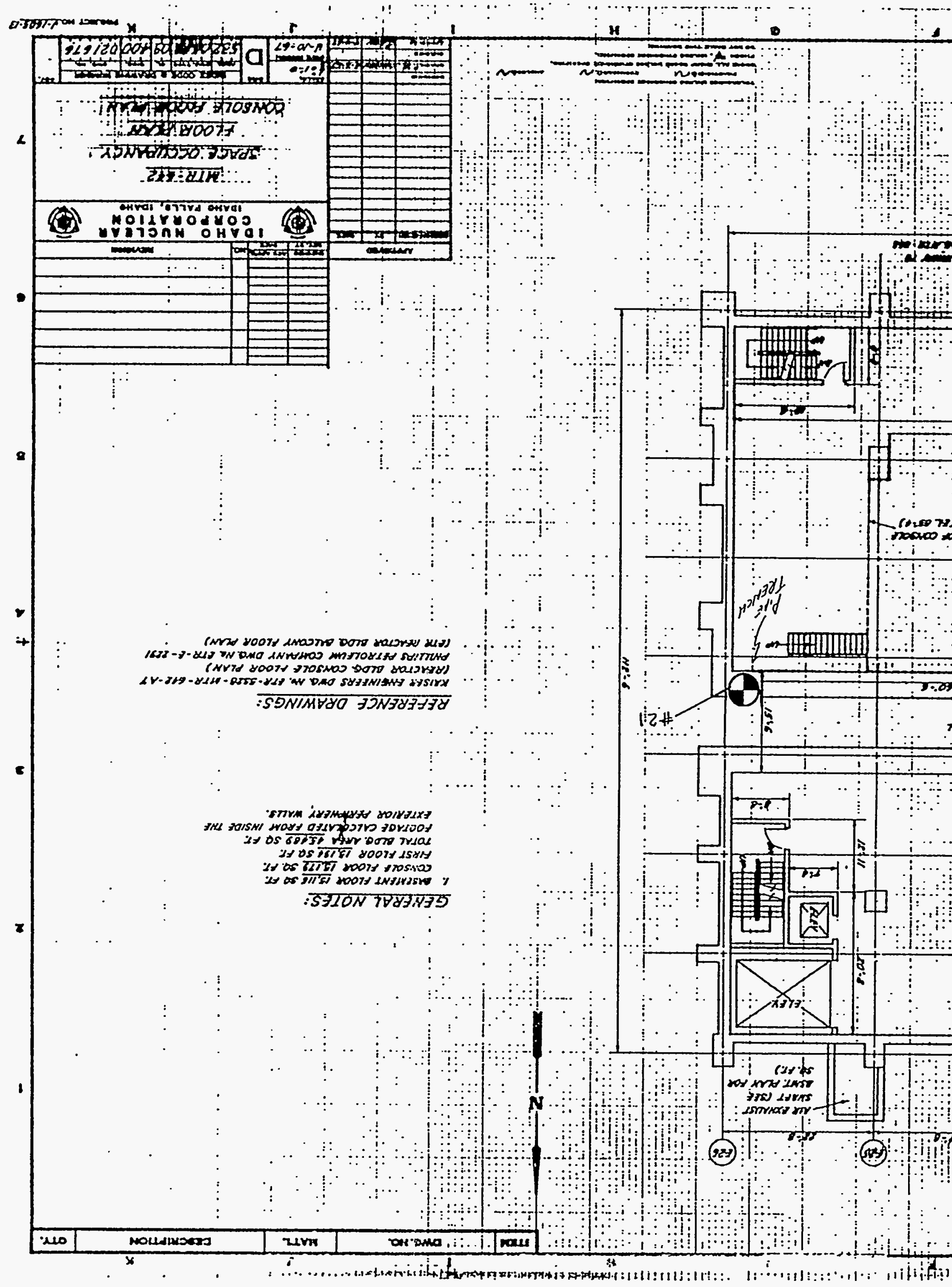


Exhibit 1.10: Location Drawing for Sample Groups 24 through 32

TRA -643 ETR Compressor Building

Gate Valve Motor Operators, Representative Oil Sample Required (\#24)

Primary Coolant Pump Motor, 460V, Representative Oil

Reservoir Sample Required (\#25)

Pipe Trench, Pit and Trench Samples Required (\#26)

Compressors, Representative Oil Sample Required (\#27)

Compressor Actuators, Representative Oil Sample Required (\#28)

Trench Below Compressors, Trench Sample Required (\#29)

Compressor Motor Drive, Oil Reservoir Sample Required (\#30)

Decon Restroom, Samples from Shower Drain and Sinks Required (\#31)

Chemistry Laboratory, Samples from Sink and Trench Required (\#32) 


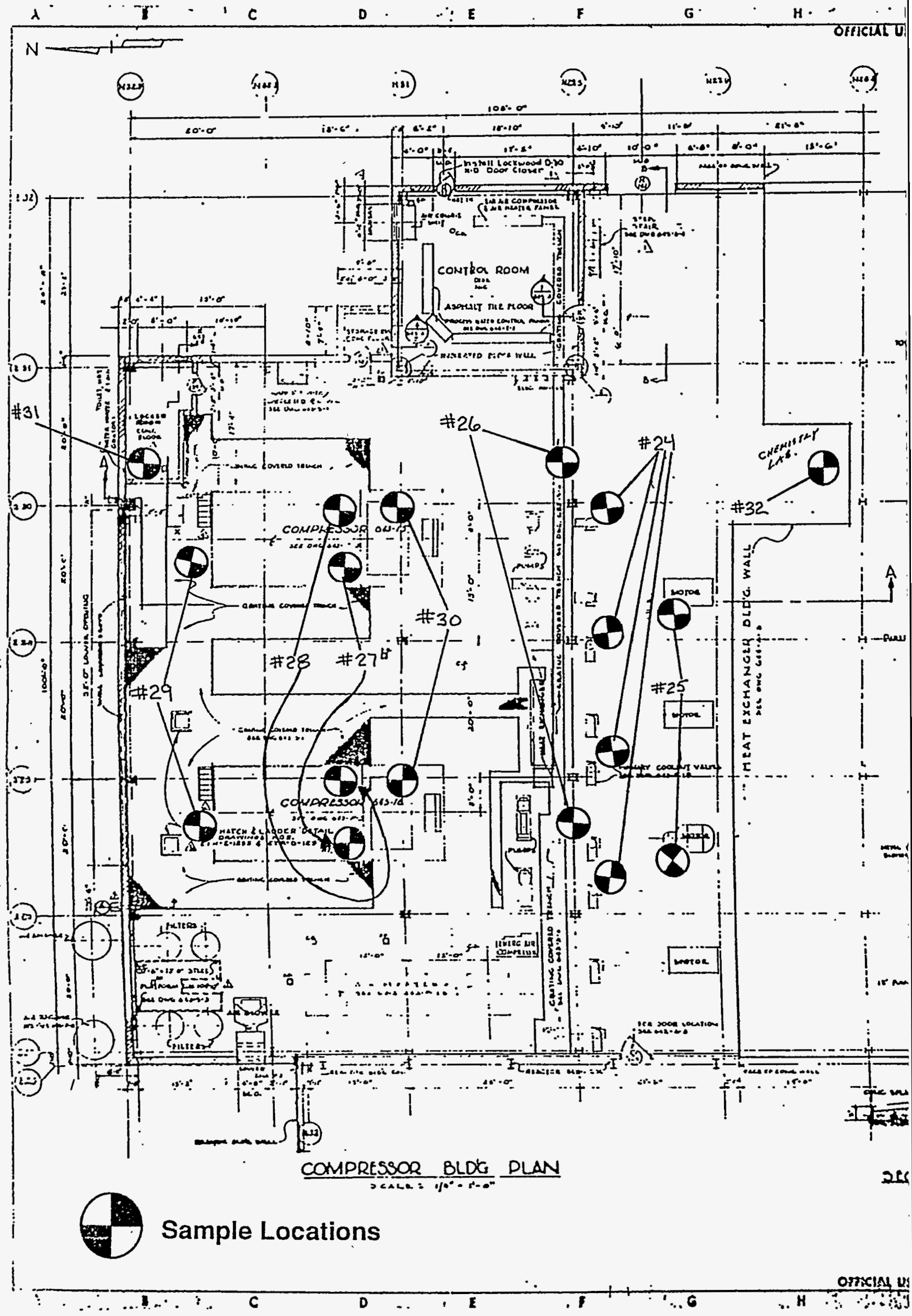




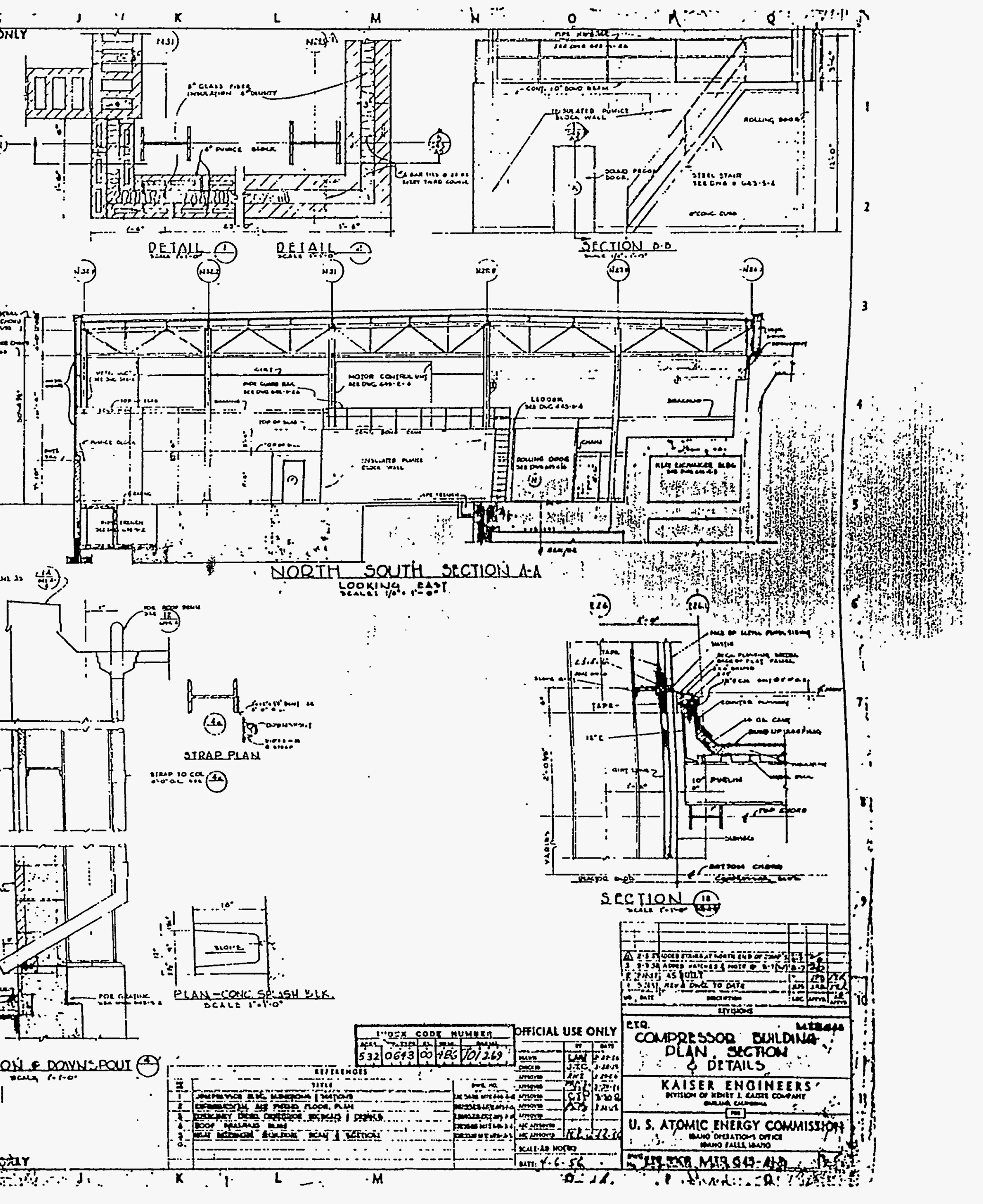


Exhibit 1.11: Location Drawing for Sample Groups 33 through 35

TRA -648 ETR Electrical Building ,

Diesel Generator Room: Pit, Pit Samples Required (\#33)

Battery Room, Samples of Drain and Floor Spill Areas Required (\#34)

TRA -663 ETR Superior Diesel Building (Adjacent to TRA-648, to SW, not shown)

Fuel Injector Cleaning Station, Residue Samples Required (\#35) 


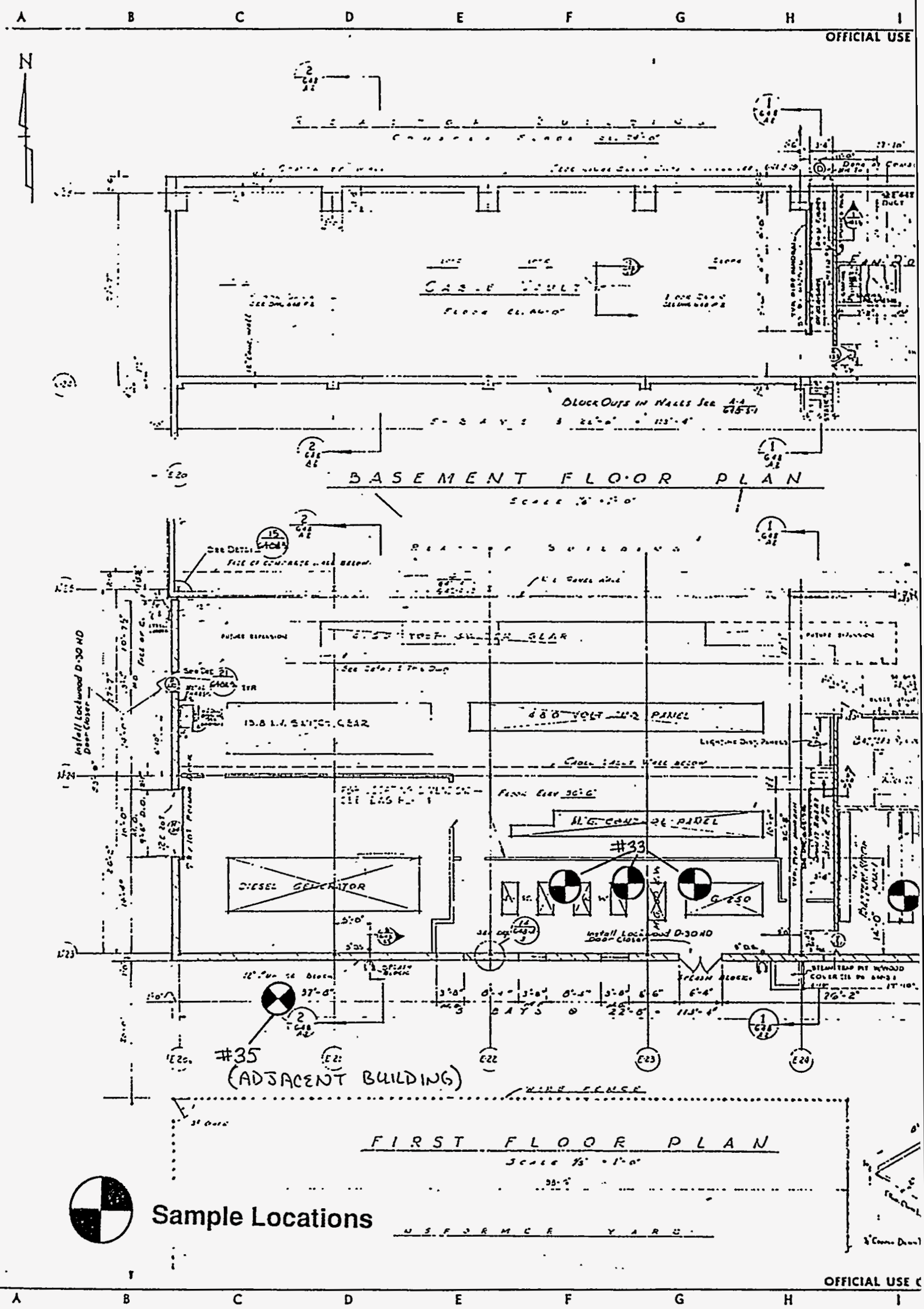




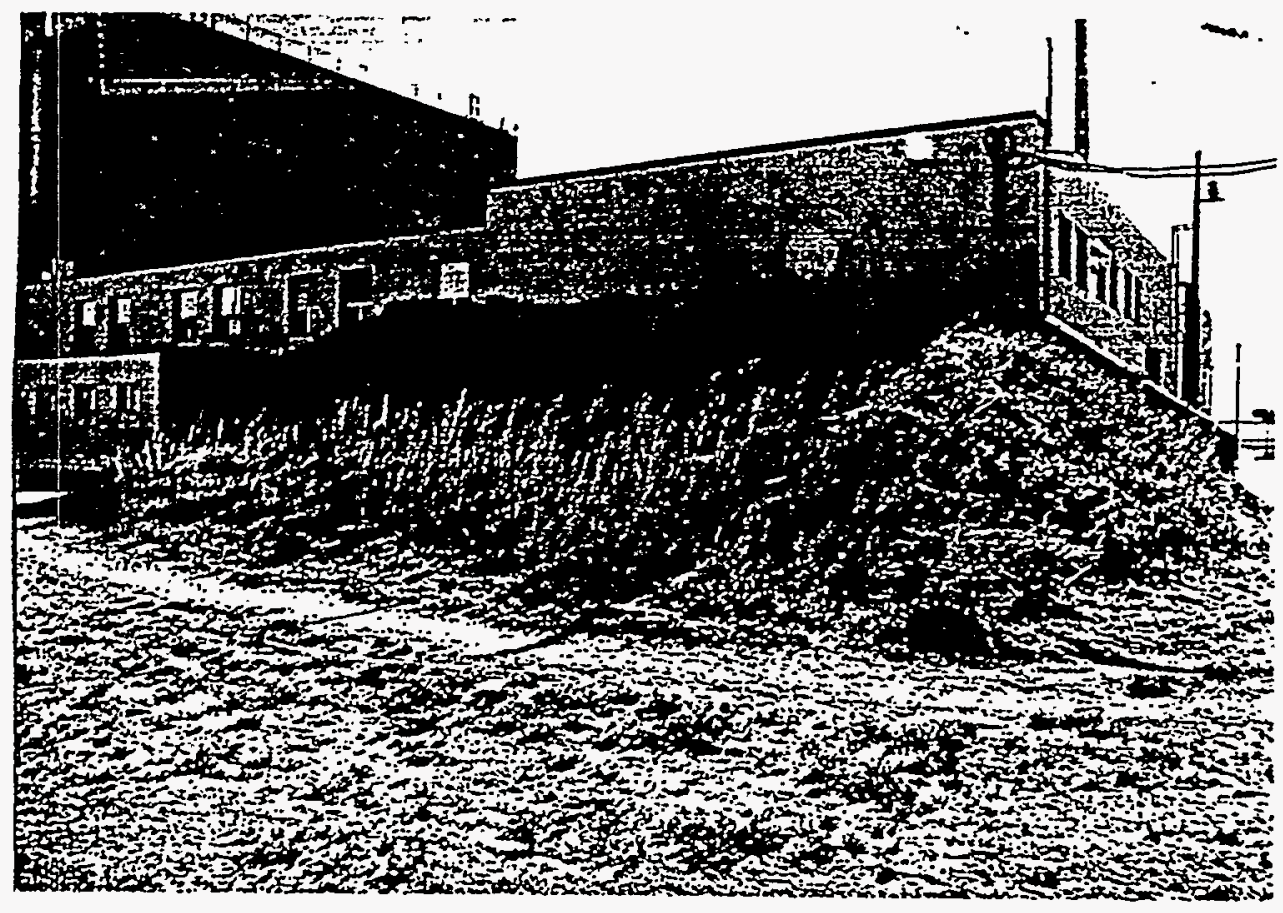

Exhibit 2.1: Photograph of TRA -611 Plug Storage Facility. Soil Covering Potentially Contaminated Soil Sampling Required Below Channels (View to East) 


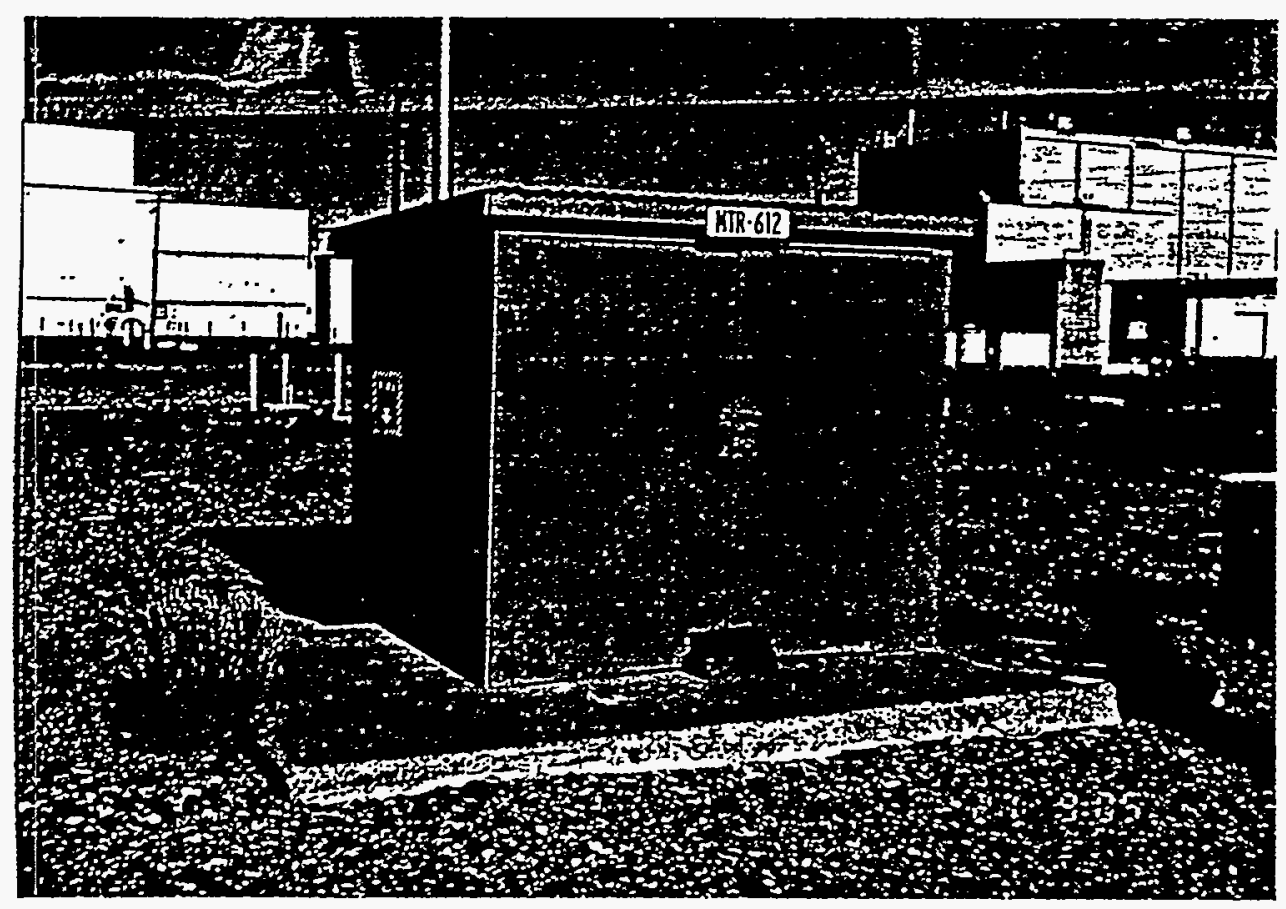

Exhibit 2.2: Photograph of TRA -612 MTR Retention Basin Sump Pumphouse Liquid and Sludge Sampling Required from Floor, 40 feet down (View to Northwest) 


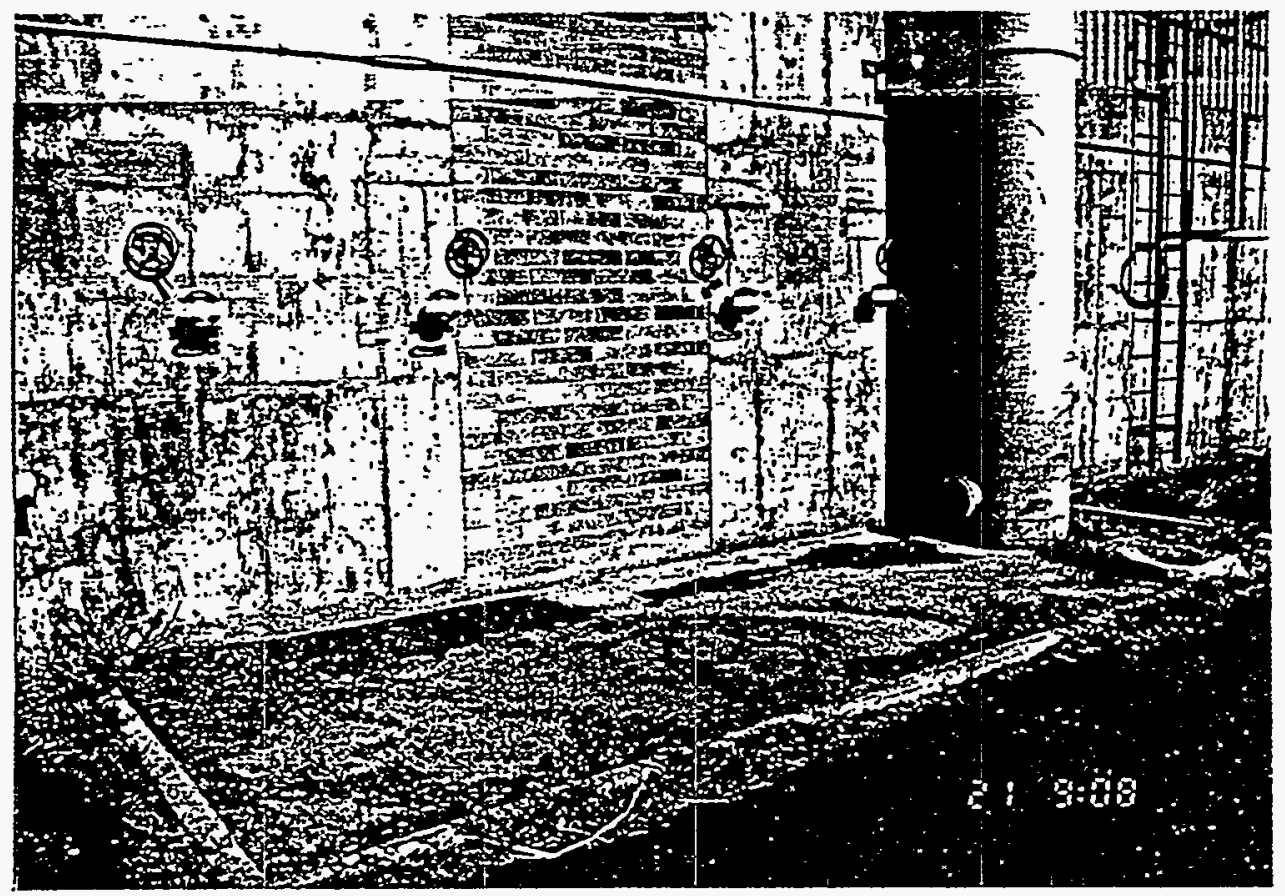

Exhibit 2.3: Photograph of TRA -644 ETR Heat Exchanger Building Concrete Samples Required Outside of Building, in Resin Handling Area (View to Northwest) 


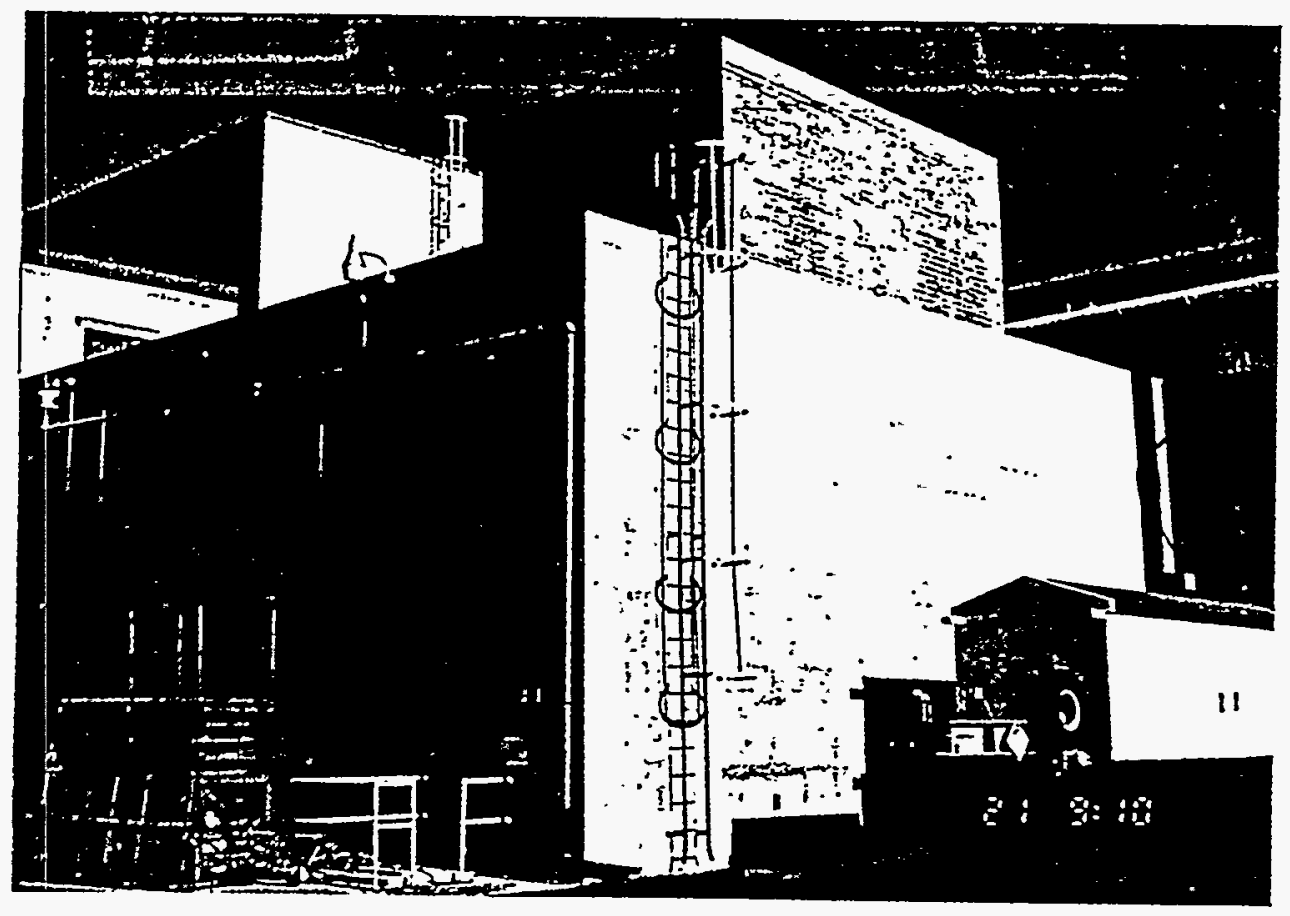

Exhibit 2.4: Photograph of TRA -644 ETR Heat Exchanger Building Sampling Required in Degasifier Tank, Roof of Building (View to Northwest) 
80 เ jo $น 2$ ว8ిed

\section{( ҰSวM 여 Mว! $\Lambda$ )}

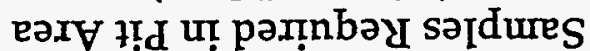

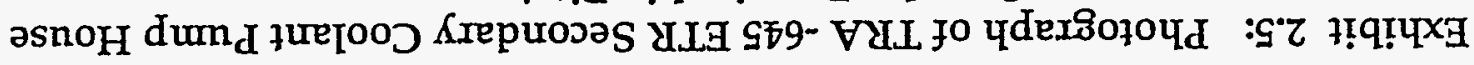





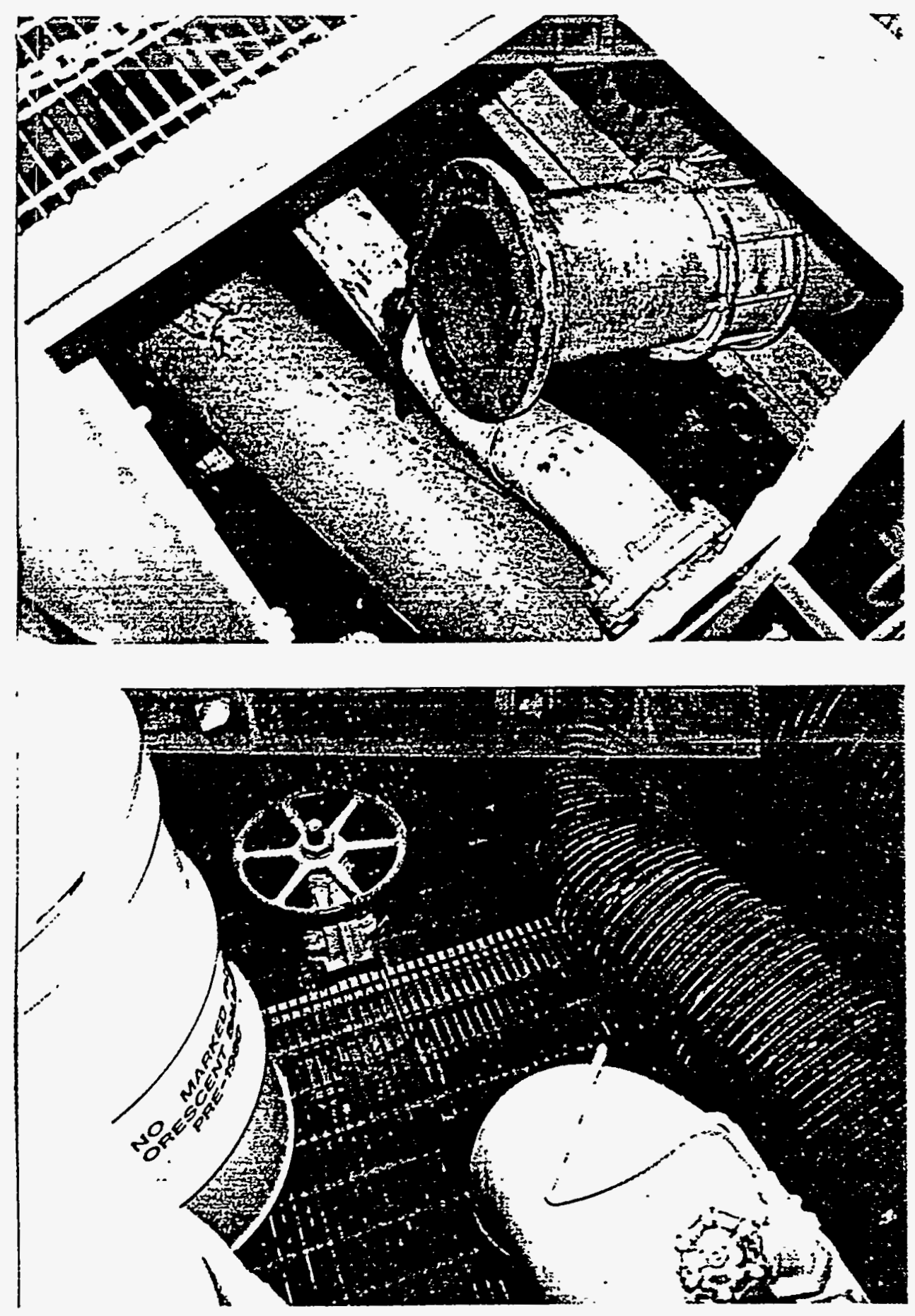

Exhibit 2.6: Photograph of TRA -645 ETR Secondary Coolant Pump House Top-- Closeup of Coolant Pit

Bottom-- West Side of Coolant Pump House

Samples Required in Pit Area 


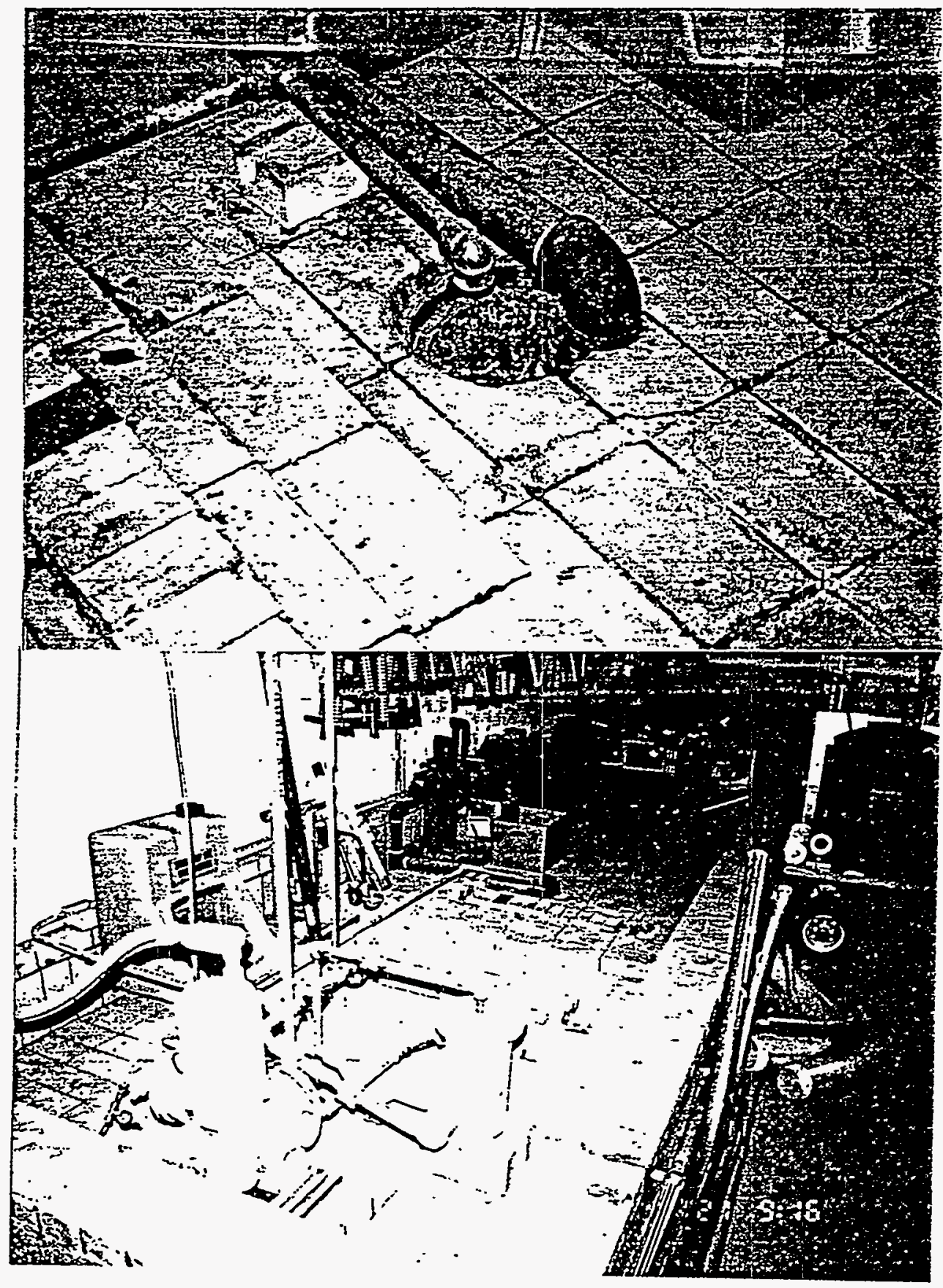

Exhibit 2.7: Photograph of TRA -645 ETR Secondary Coolant Pump House Top -- Acid Pit Area Drain Bottom -- Acid Pit Area

Samples of Drain and Brick Required

(View to South) 


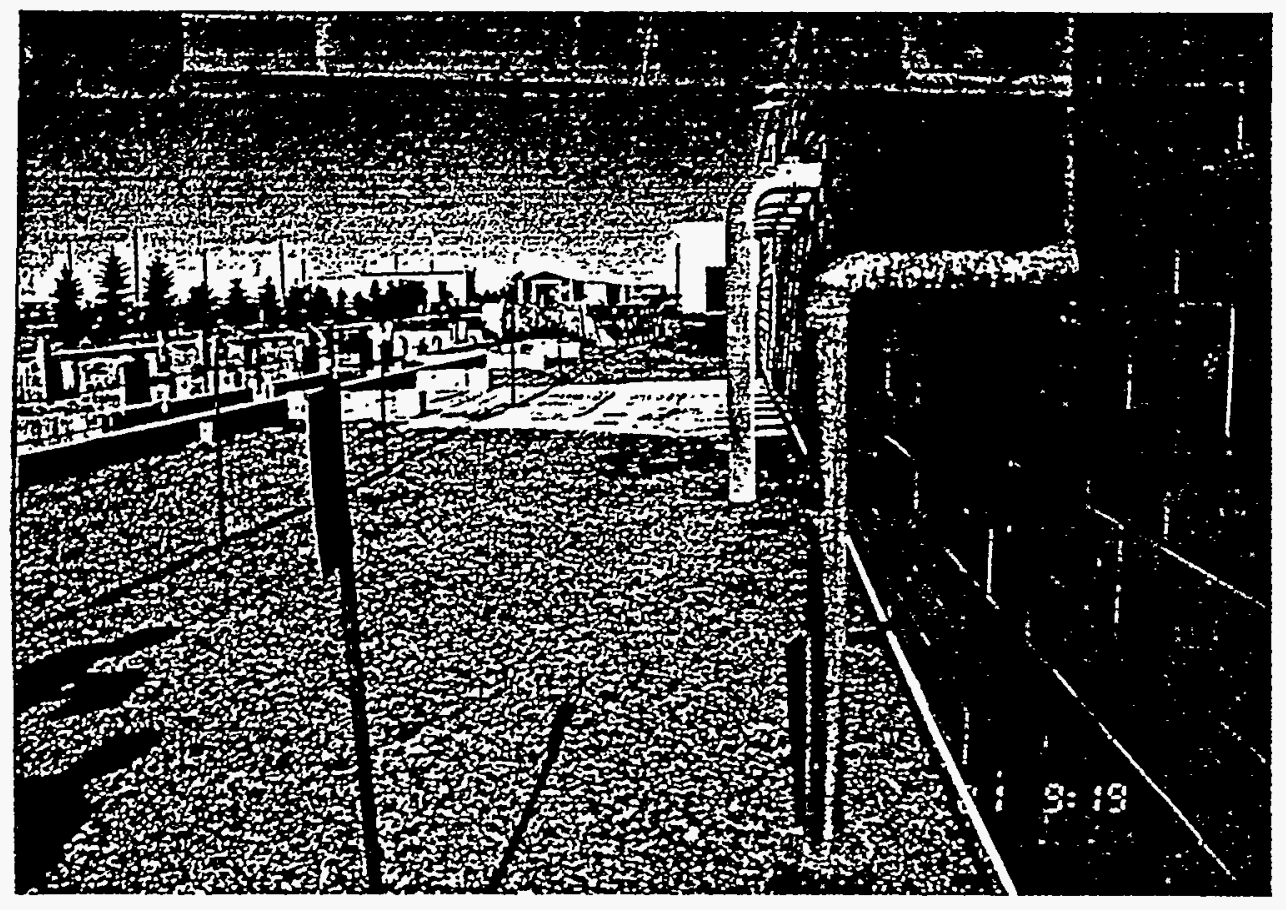

Exhibit 2.8: Photograph of TRA -645 ETR Secondary Coolant Pump House South Side of Building Three Soil Samples Required (View to West) 


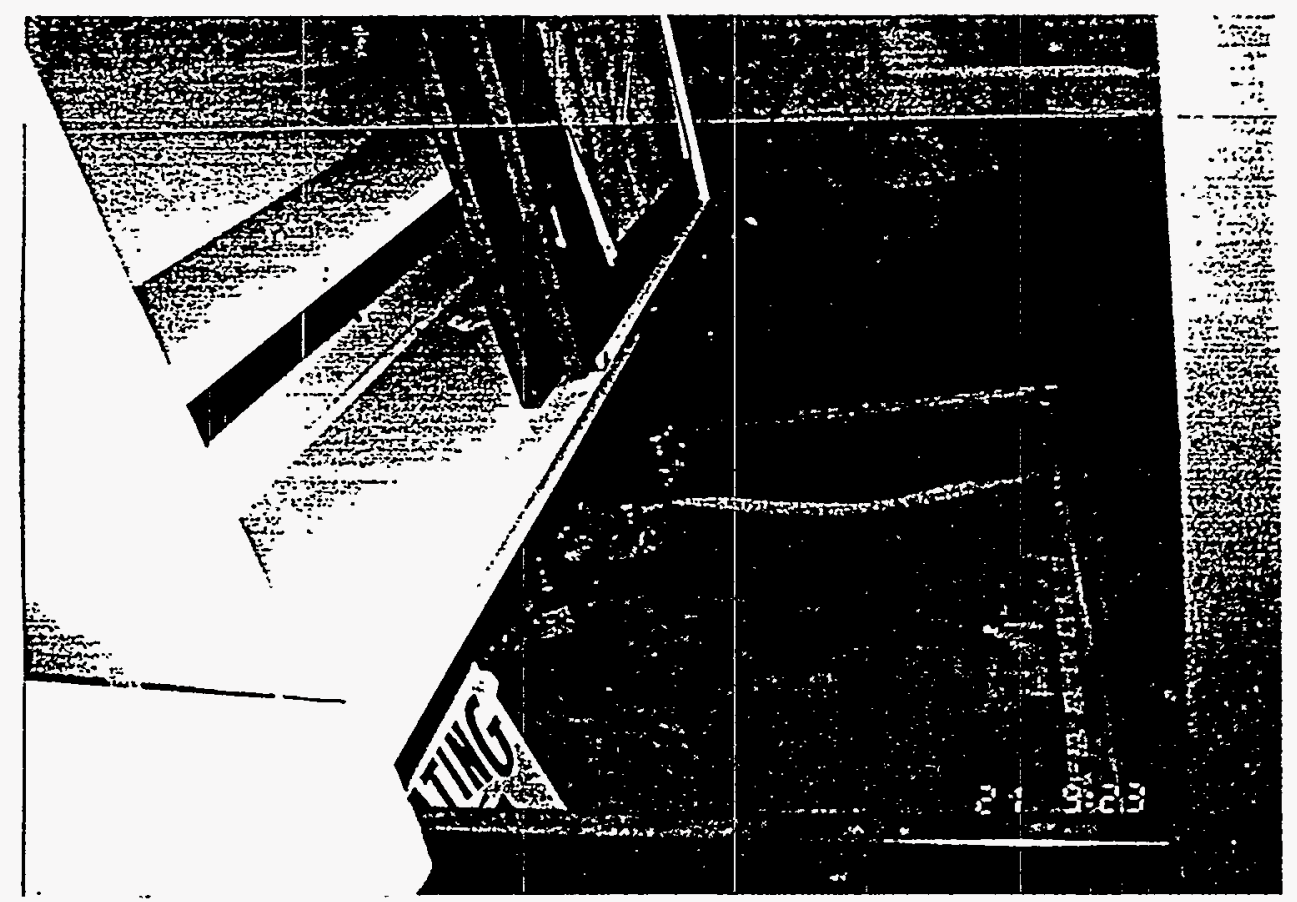

Exhibit 2.9: Photograph of TRA -647 ETR Office Building, Room 104 Sink Drain Samples Required

(View to East) 


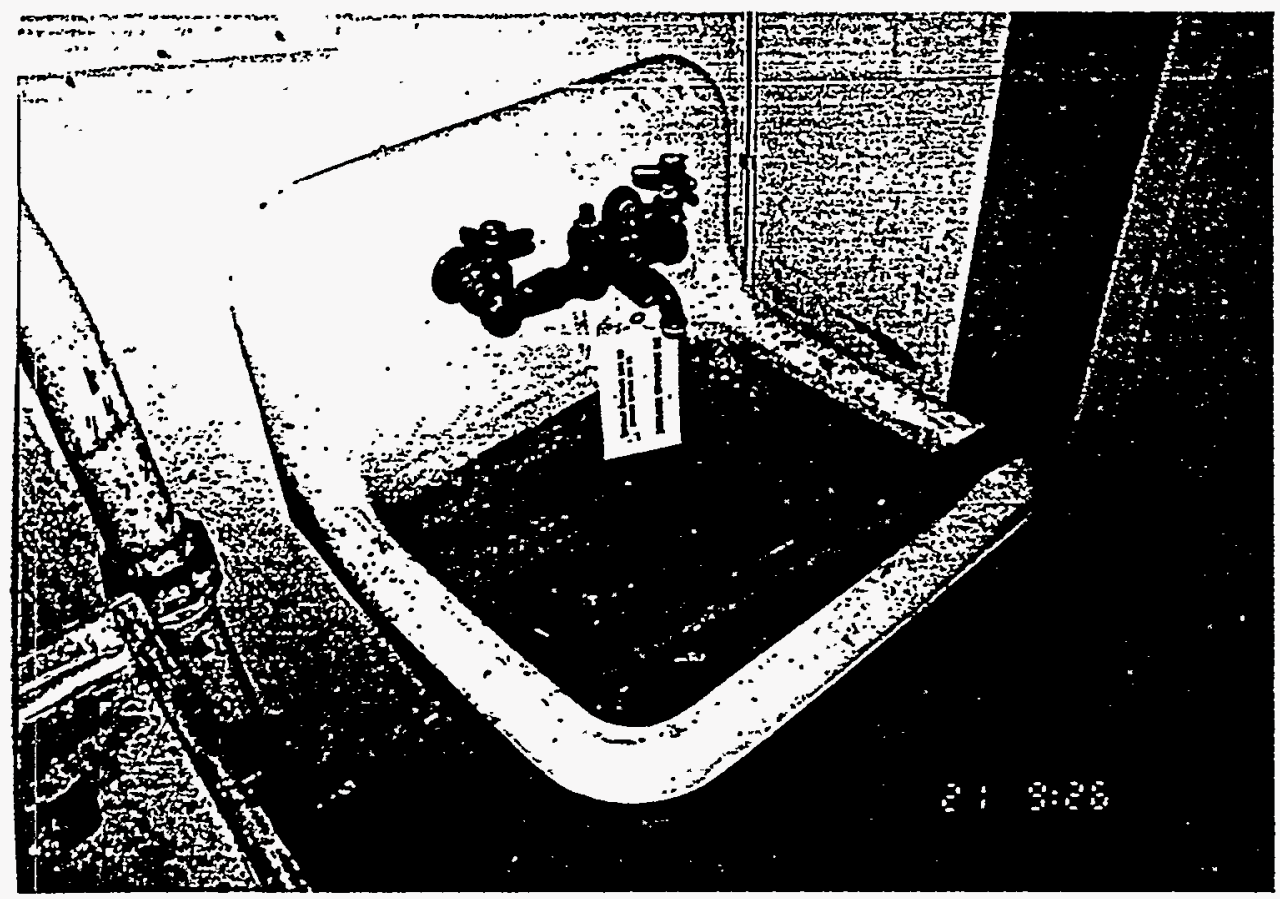

Exhibit 2.10: Photograph of TRA -647 ETR Office Building, Shop Sink Drain Samples Required

(View to North) 


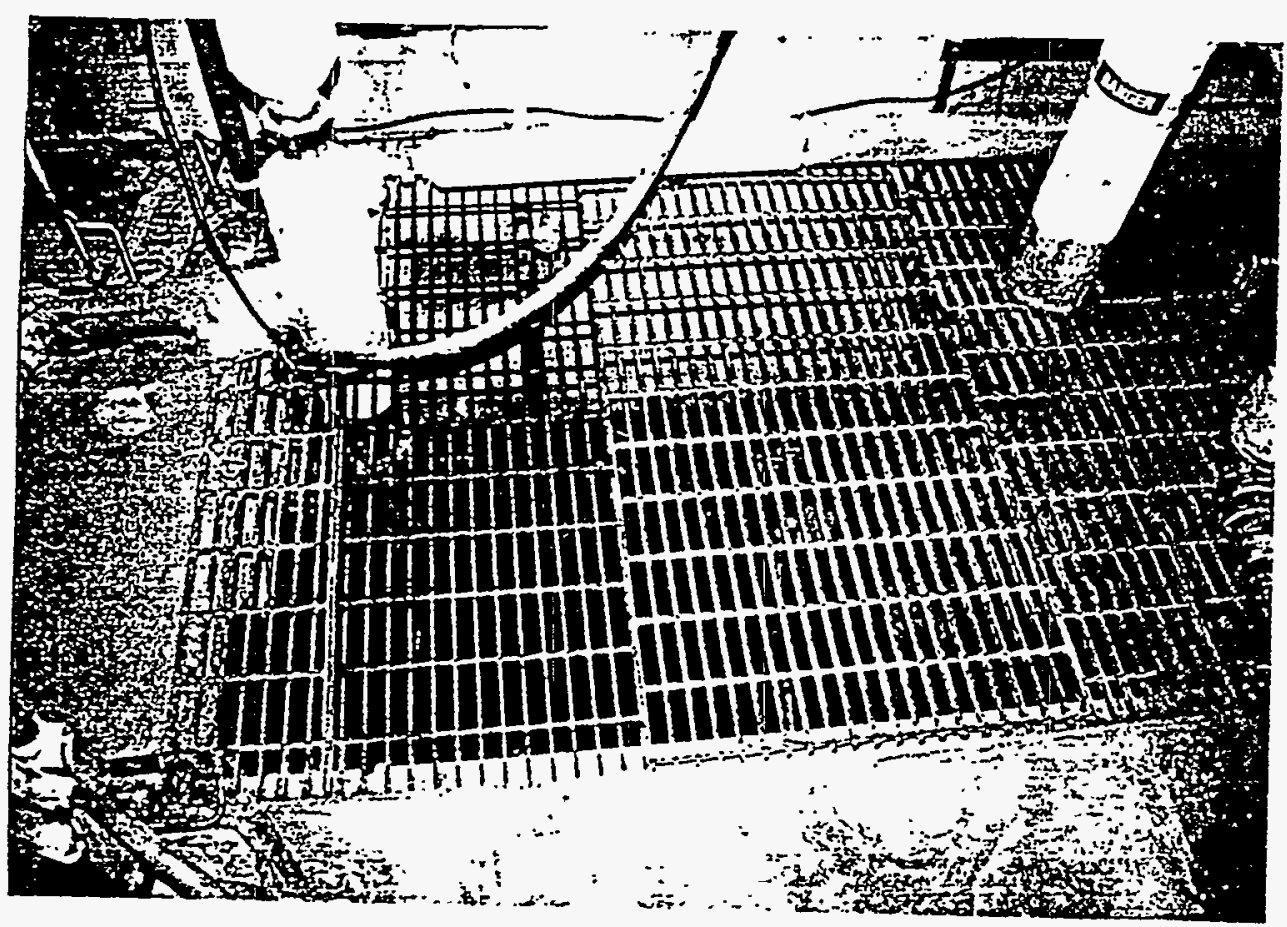

Exhibit 2.11: Photograph of TRA -647 ETR Office Building Basement HVAC Room Sump Pit with Tank in Pit

Samples Required for Tank and Pit

(View to North) 


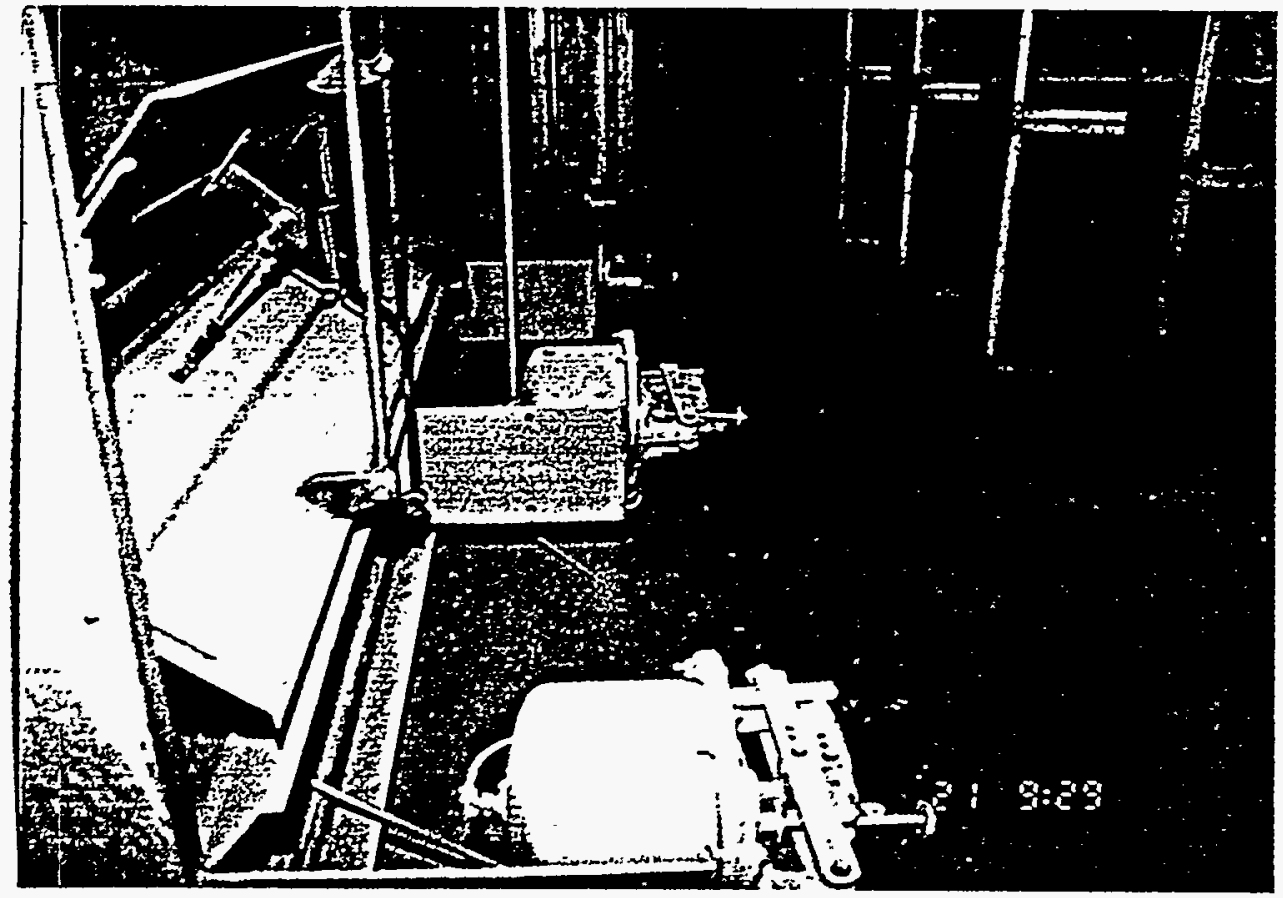

Exhibit 2.12: Photograph of TRA -647 ETR Office Building Basement HVAC Room Closeup of Sump Pit Area

Samples Required of Hydraulic Oil in Dash Pots (View to East) 


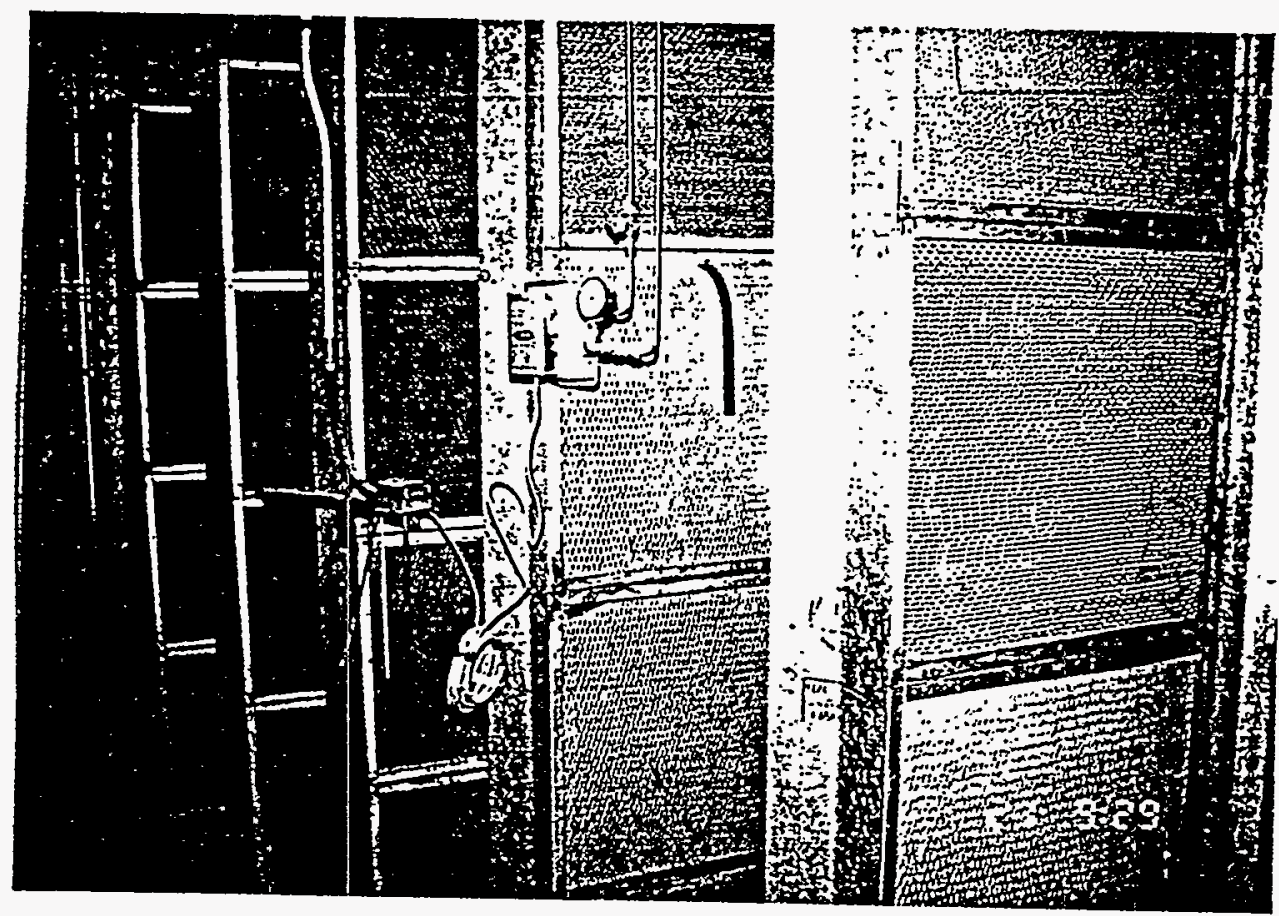

Exhibit 2.13: Photograph of TRA -647 ETR Office Building Basement HVAC Room Air Intake Filters

Filter Media Samples Required for Lead

(View to East) 


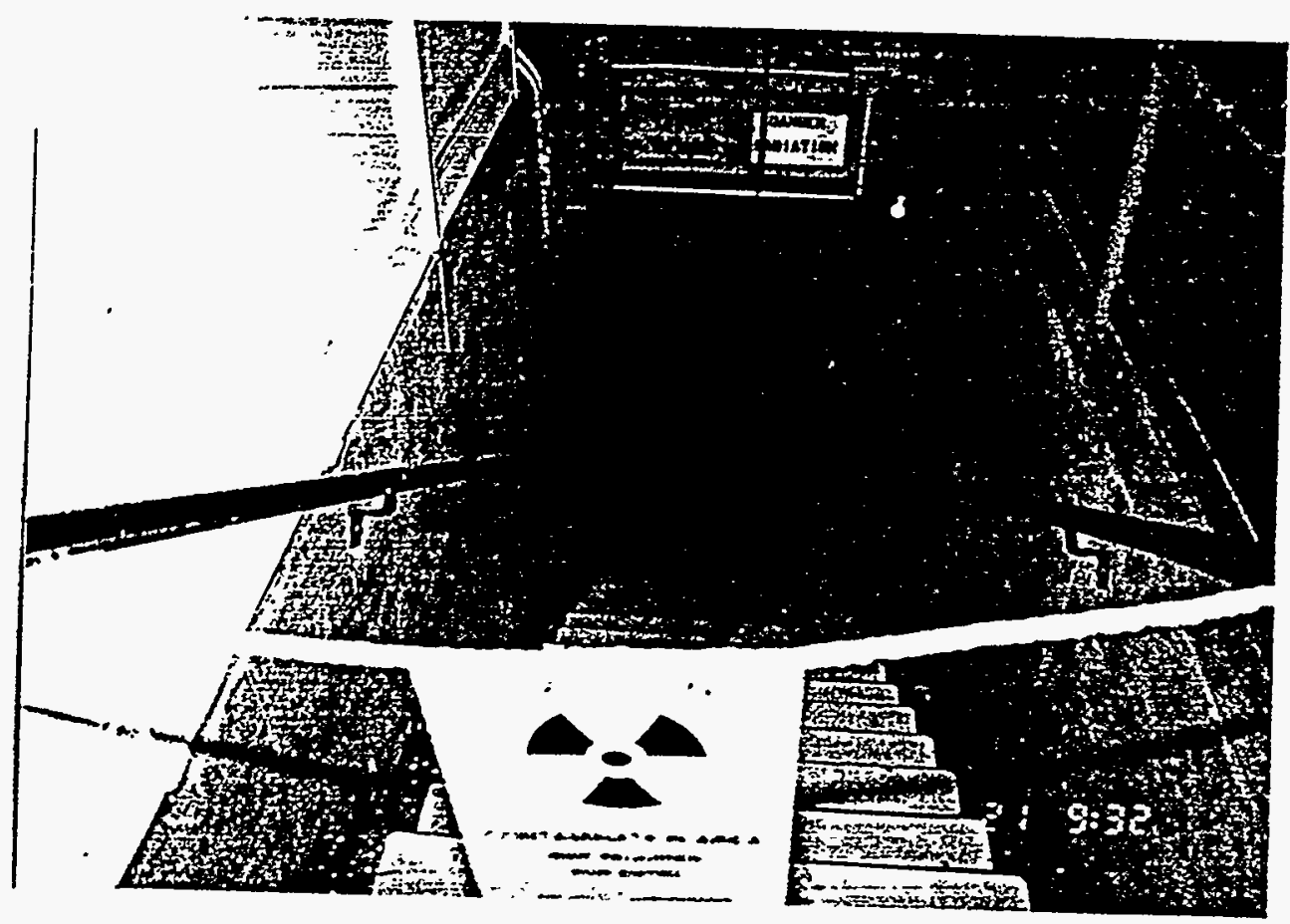

Exhibit 2.14: Photograph of TRA -642 ETR Reactor Building Basement Stairs to Rod Access Room

Sump Samples Required

(View to West) 


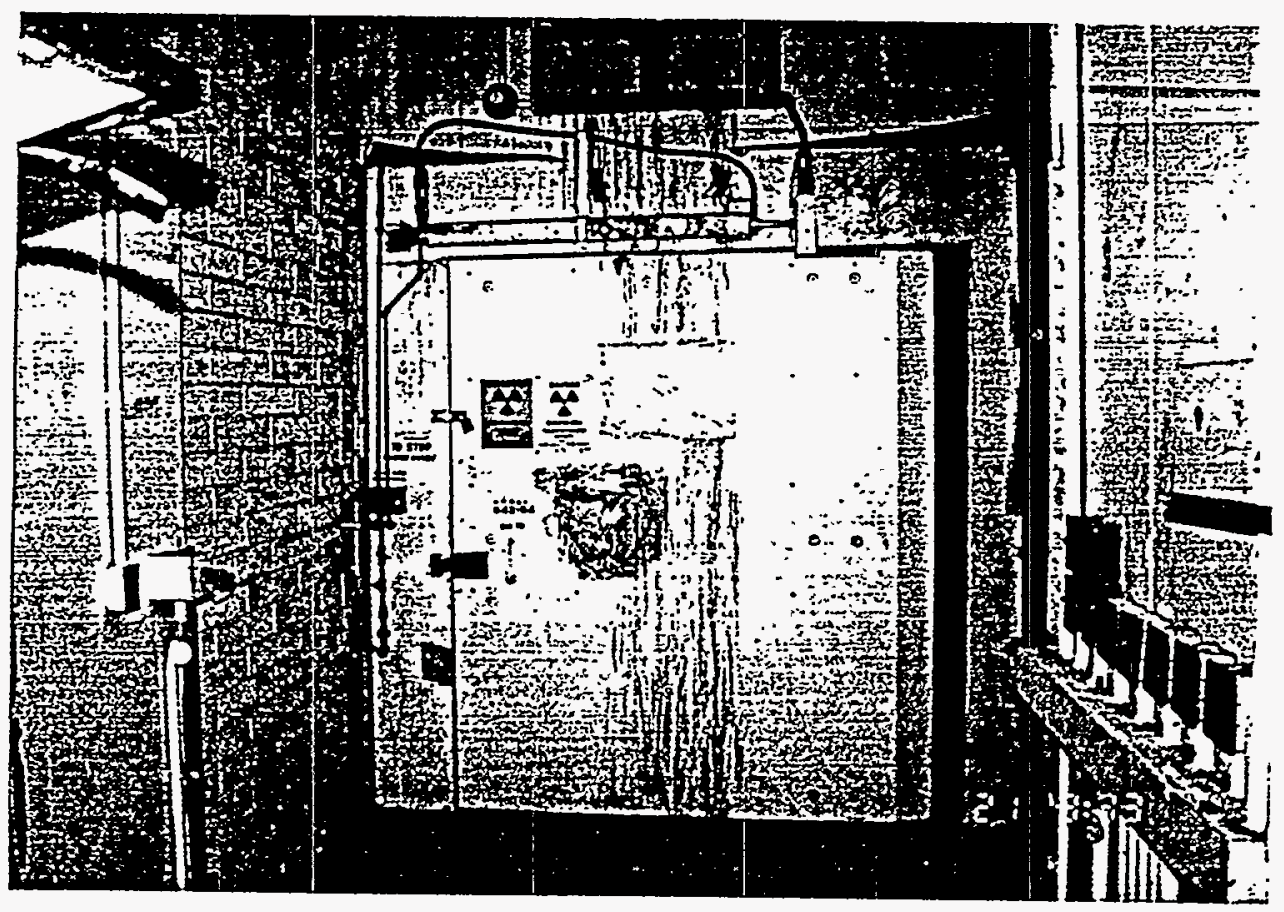

Exhibit 2.15: Photograph of TRA -642 ETR Reactor Building Basement Sub Pile Room

Paint Samples Required Inside and Outside of Room

(View to West) 


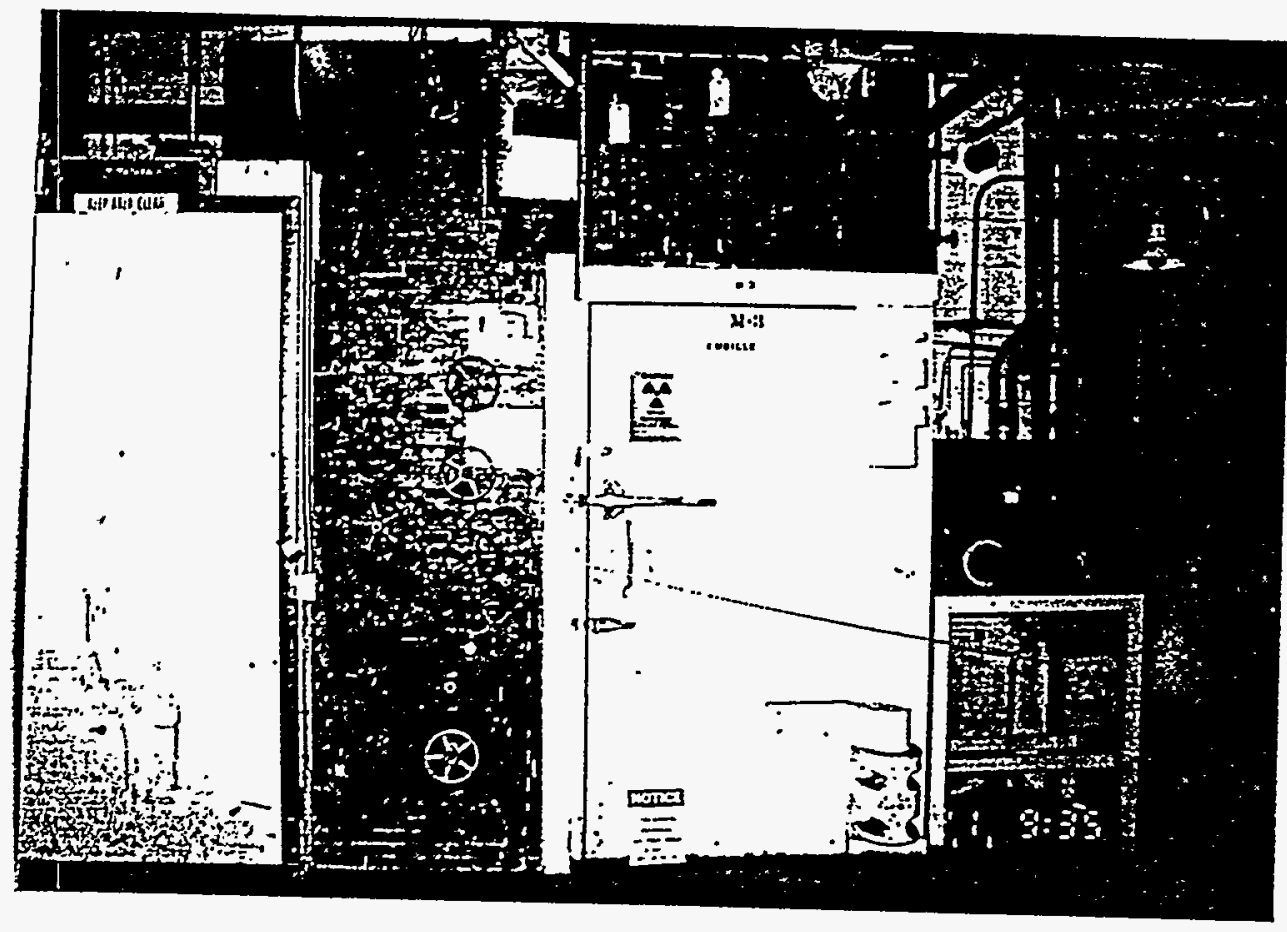

Exhibit 2.16: Photograph of TRA -642 ETR Reactor Building Basement Cubicle No. M-3,

Resin Samples Required from Inside M-3

(View to South ) 


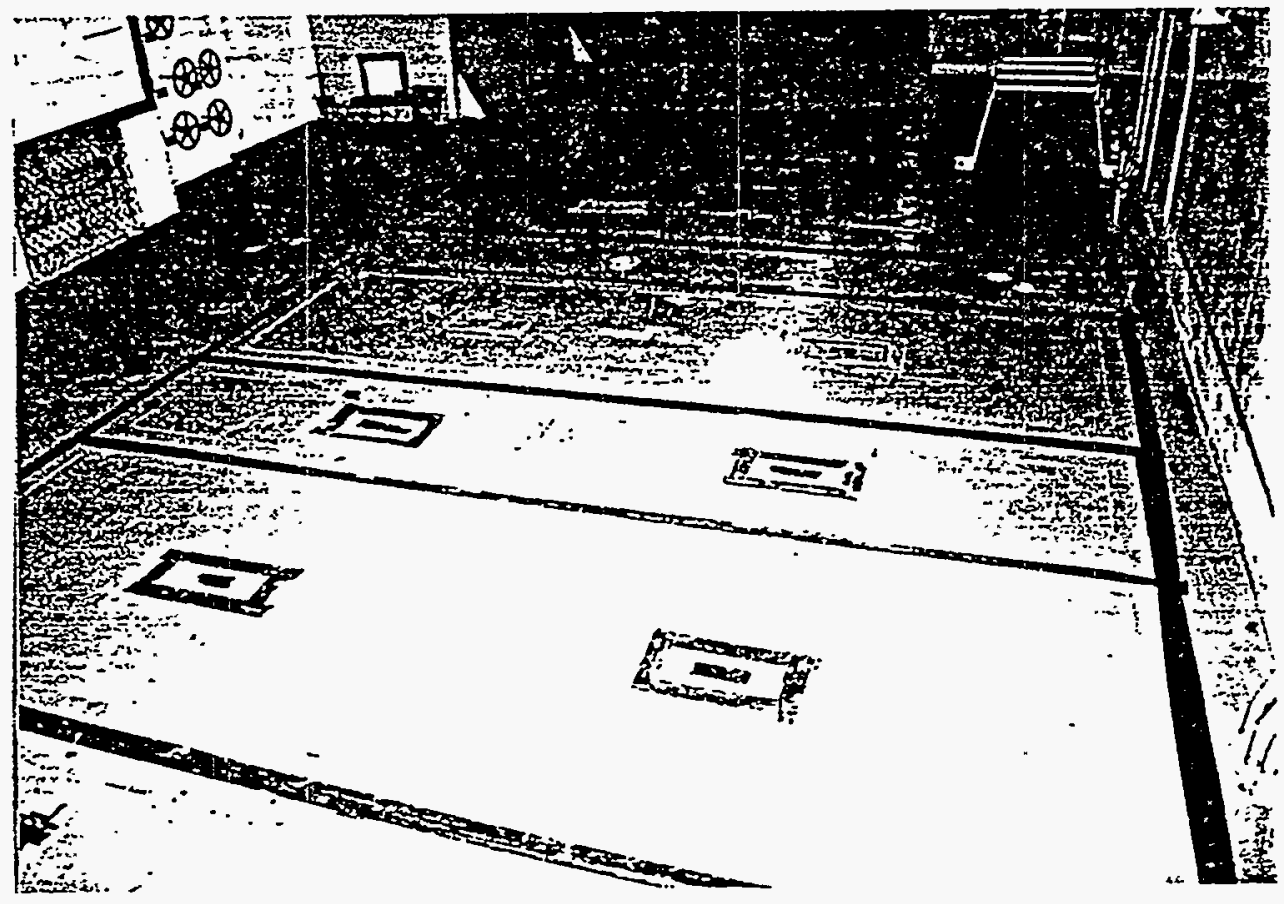

Exhibit 2.17: Photograph of TRA -642 ETR Reactor Building Basement Cubicle No. M-3, Warm Waste Tanks Below Floor

Tank Samples Required (View to West ) 


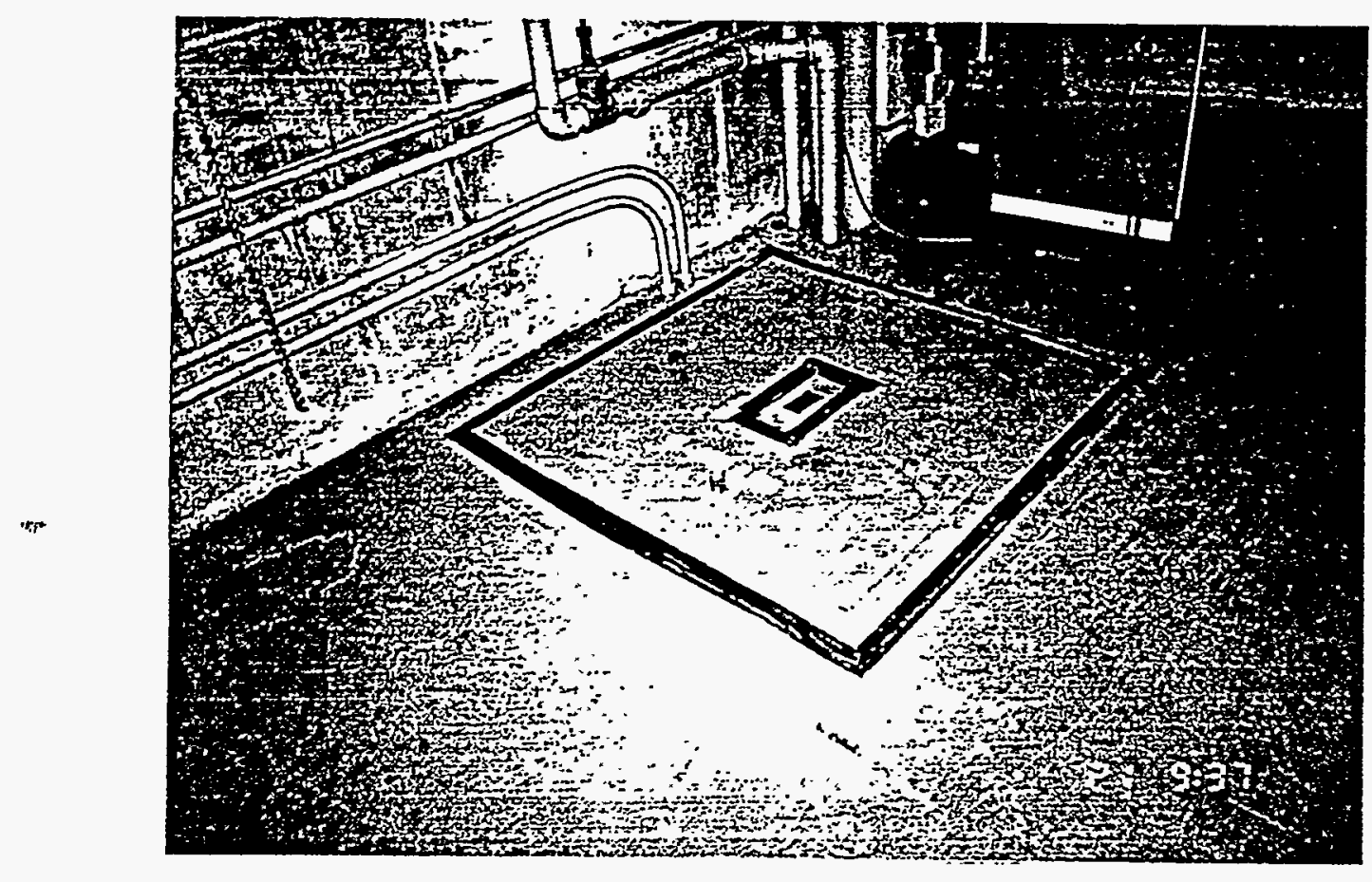

Exhibit 2.18: Photograph of TRA -642 ETR Reactor Building Basement Cubicle No. M-3, Cold Waste Pit Below Floor

Pit Interior Samples Required to Verify Cleanliness

(View to Northeast) 


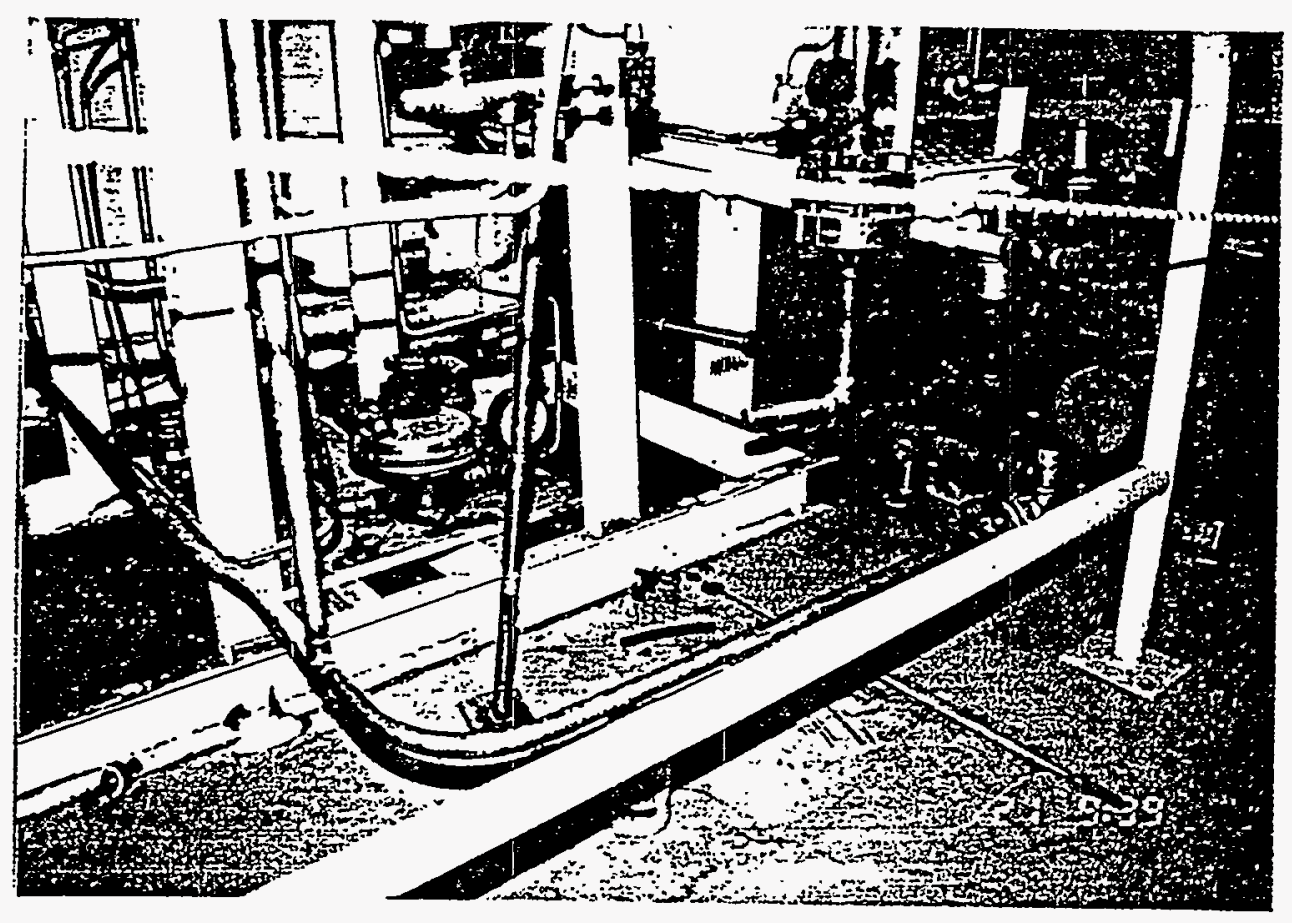

Exhibit 2.19: Photograph of TRA -642 ETR Reactor Building Basement Decontamination Station

Oil Residue Samples Required for PCB Analysis

(View to South) 


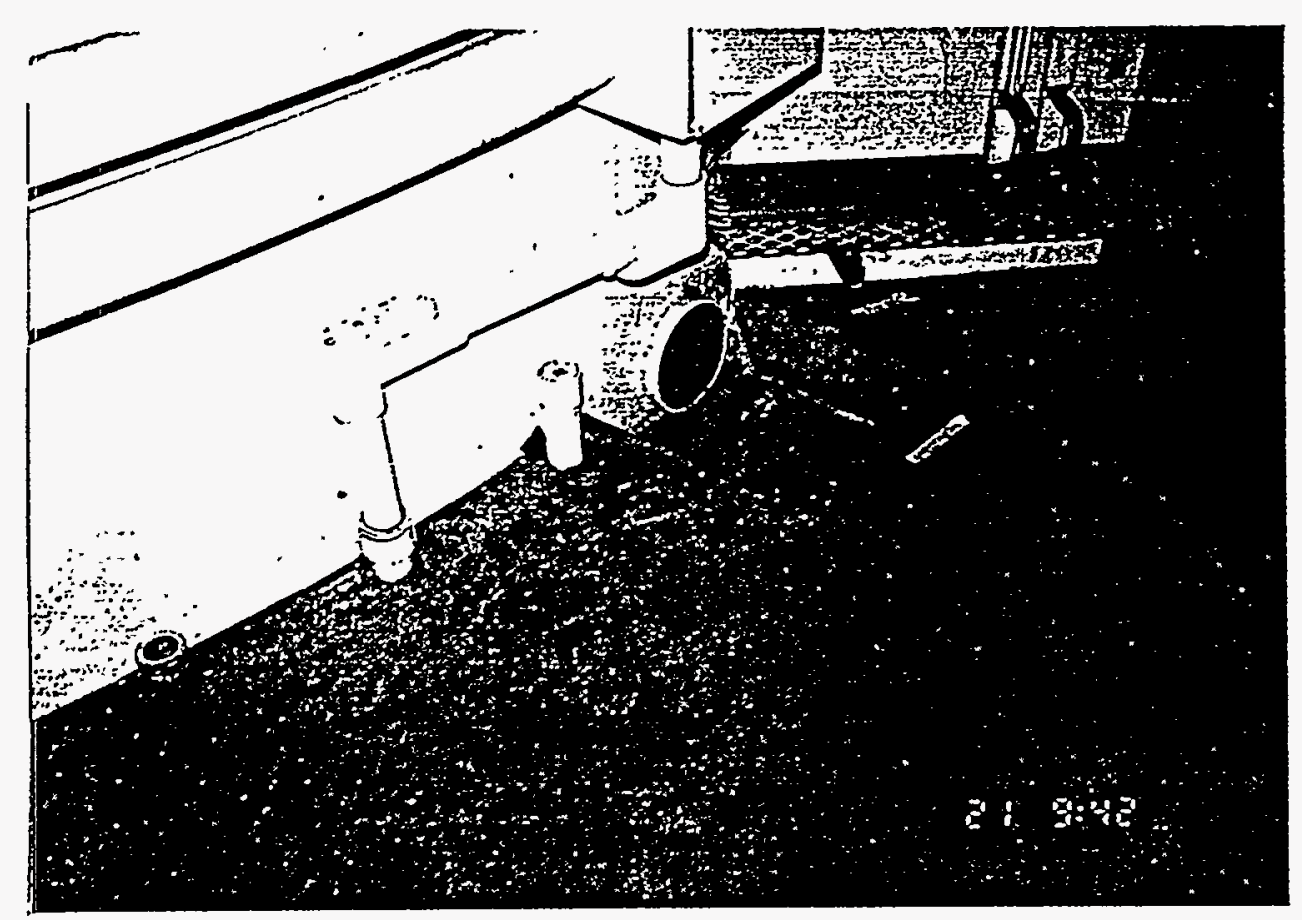

Exhibit 2.20: Photograph of TRA -642 ETR Reactor Building Basement South Console Floor, Pipe Trench Adjacent to Reactor Containment Samples Required from Trench

(View to Northwest ) 


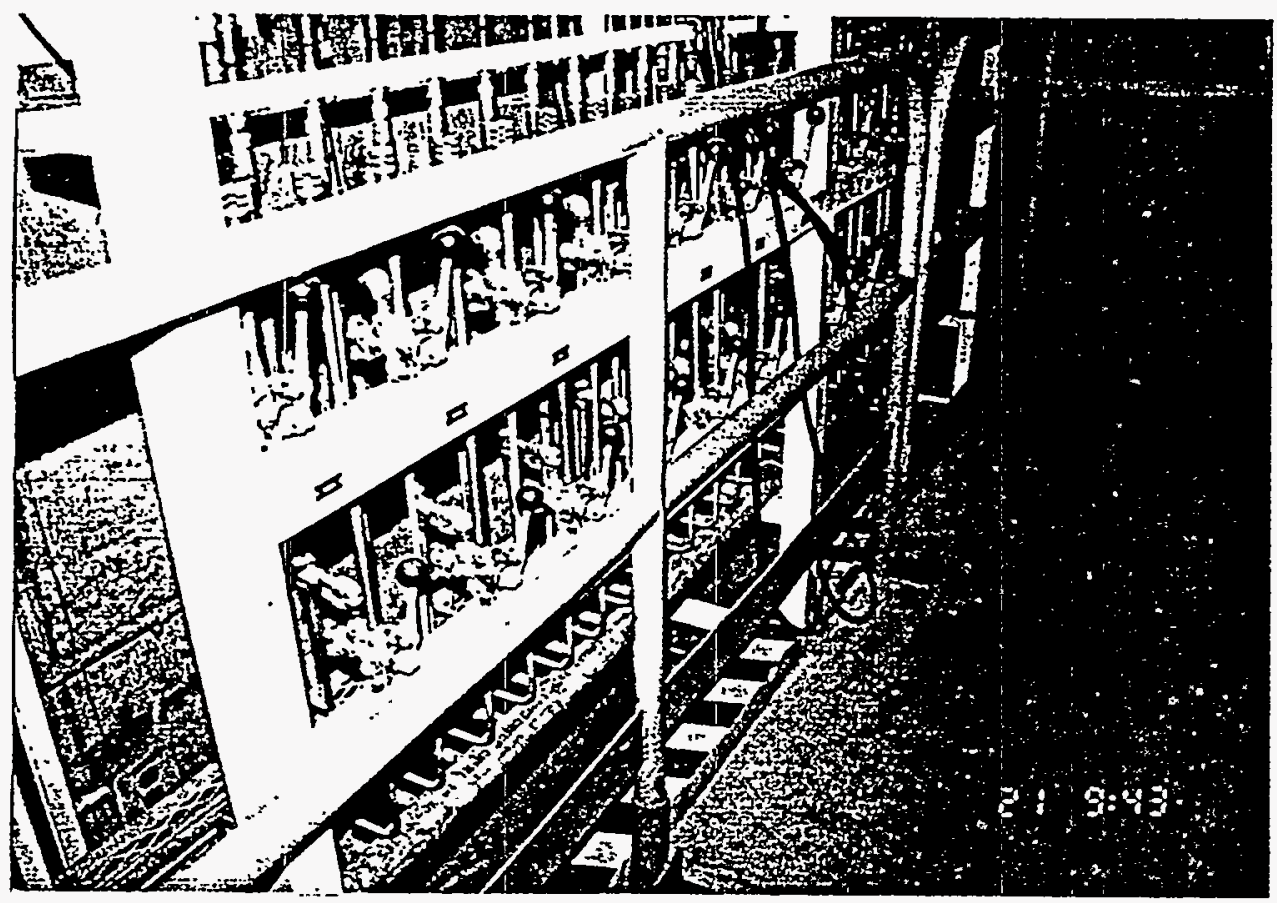

Exhibit 2.21: Photograph of TRA -642 ETR Reactor Building Basement South Console Floor, Pipe Trench Adjacent to Reactor Containment Samples Required from this End of Trench (View to Northeast ) 


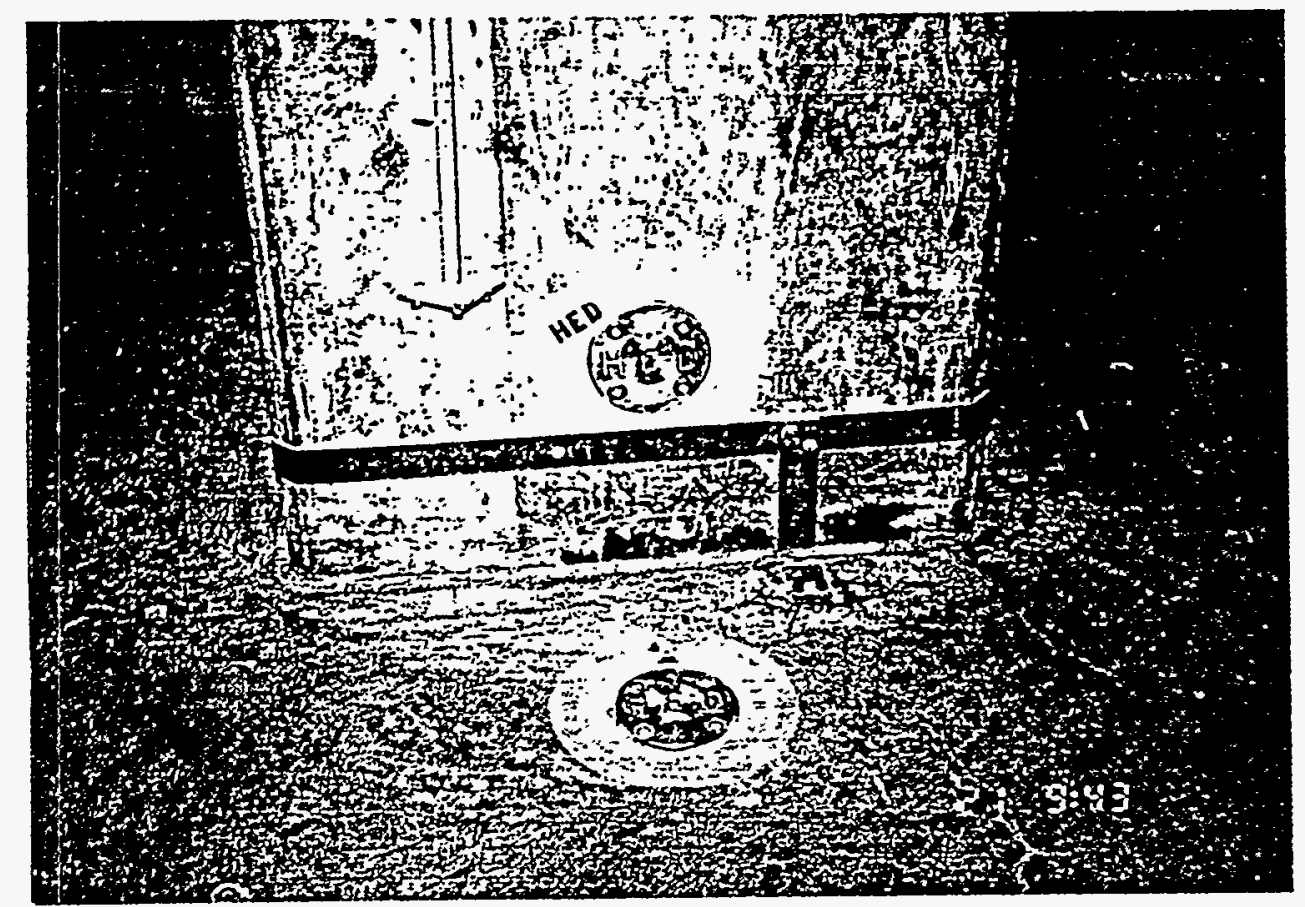

Exhibit 2.22: Photograph of TRA -642 ETR Reactor Building Basement South Console Floor, Hot Experiment Drain Representative Drain Sample Required from One Drain (View to South ) 


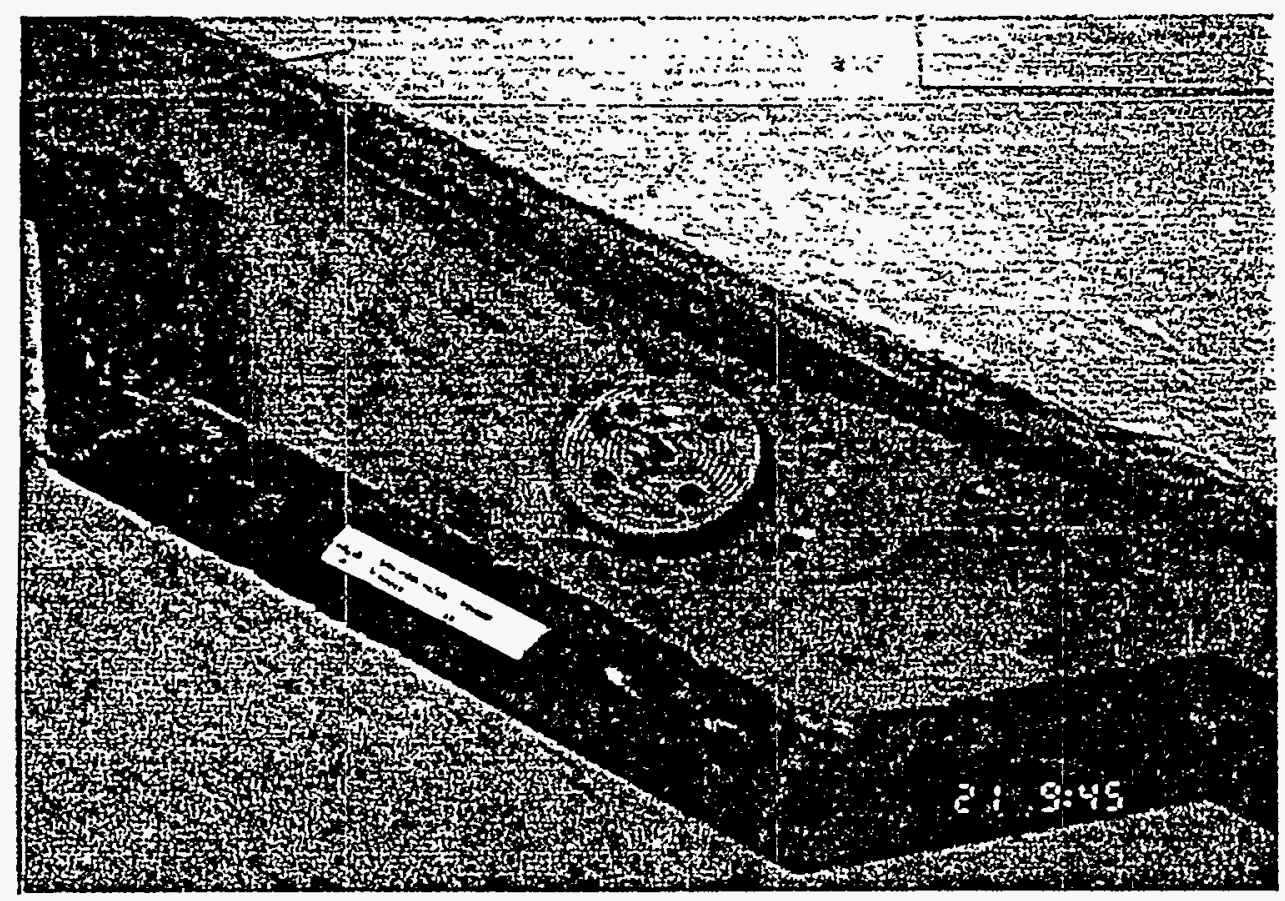

Exhibit 2.23: Photograph of TRA -642 ETR Reactor Building Basement South Console Floor, Warm Drain Around Storage Canal Sample Required from Drain and Trench Drain

(View to West) 


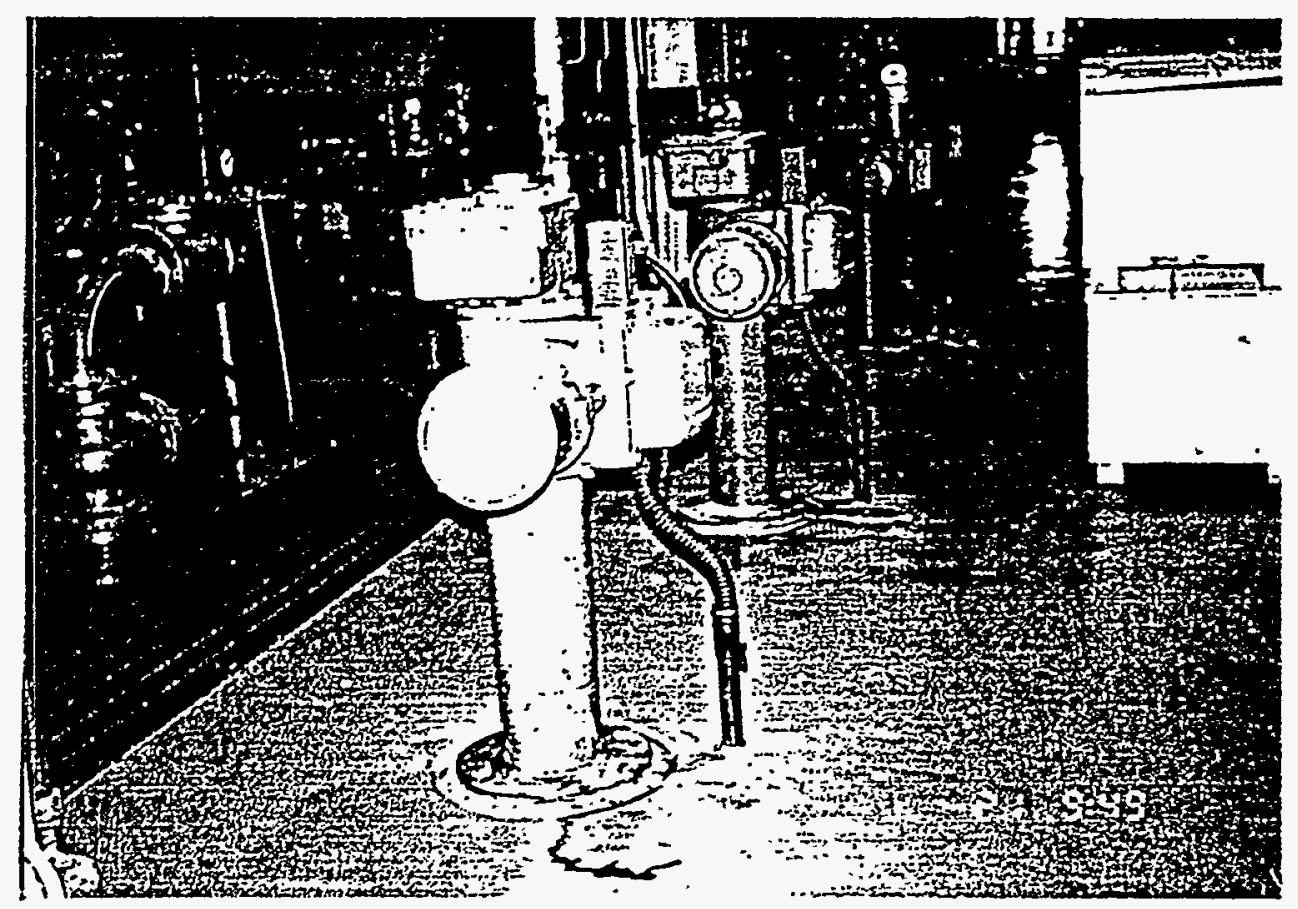

Exhibit 2.24: Photograph of TRA -643 ETR Compressor Building Gate Valve Motor Operators

Representative Oil Sample Required

(View to East) 


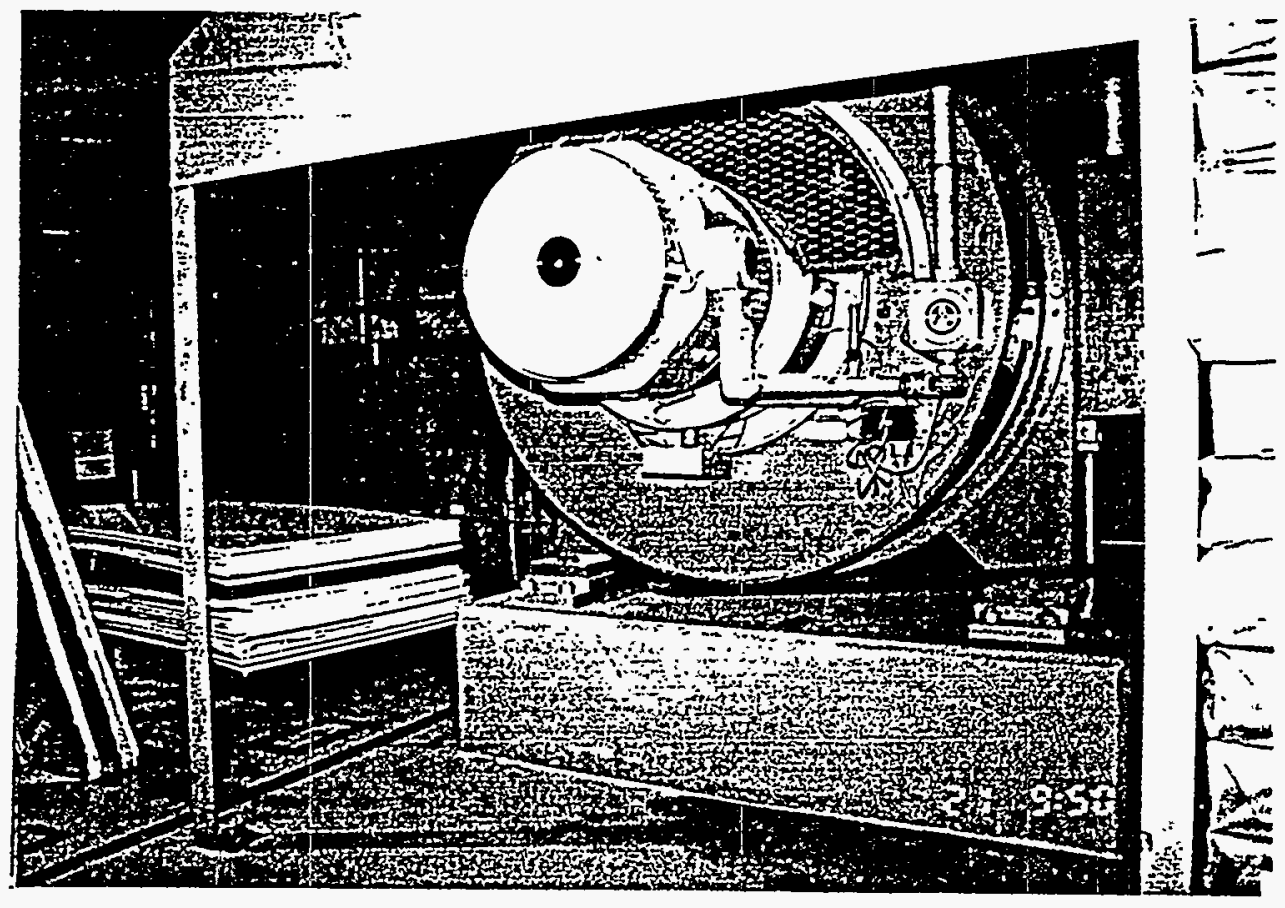

Exhibit 2.25: Photograph of TRA -643 ETR Compressor Building Primary Coolant Pump Motor, $460 \mathrm{~V}$ Representative Oil Reservoir Sample Required (View to North) 


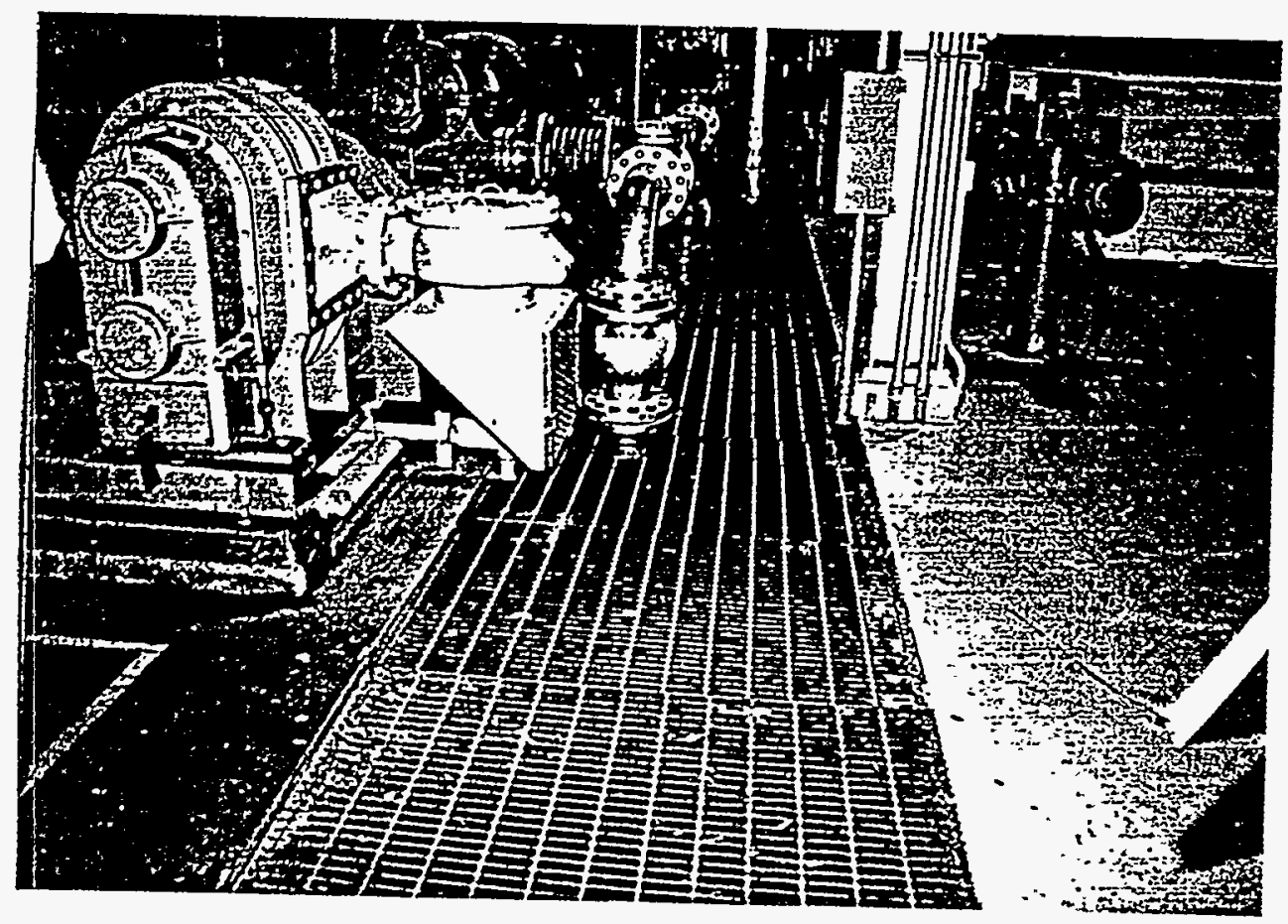

Exhibit 2.26: Photograph of TRA -643 ETR Compressor Building Pipe Trench

Pit and Trench Samples Required

(View to East) 


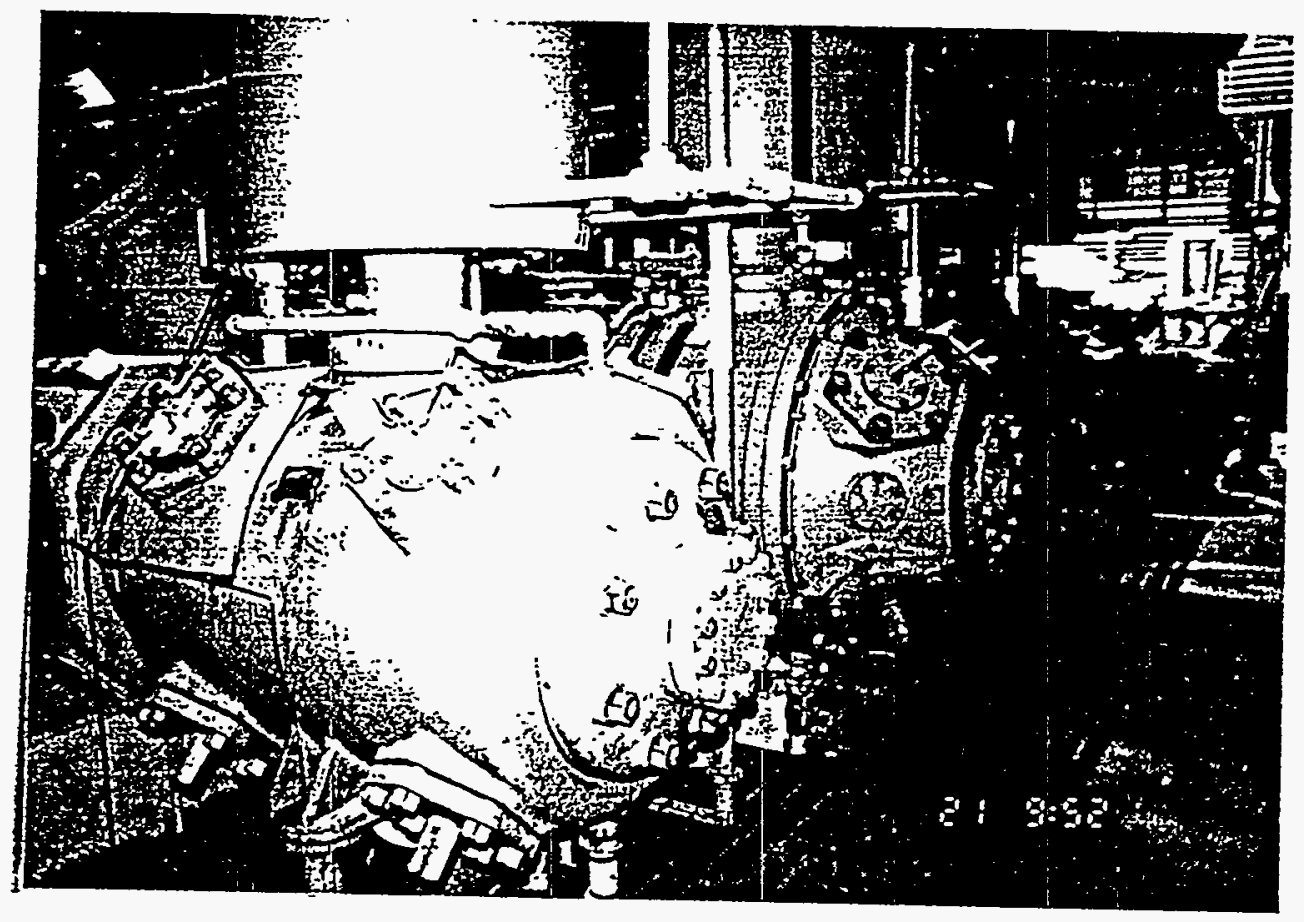

Exhibit 2.27: Photograph of TRA -643 ETR Compressor Building Compressors Representative Oil Sample Required (View to South) 


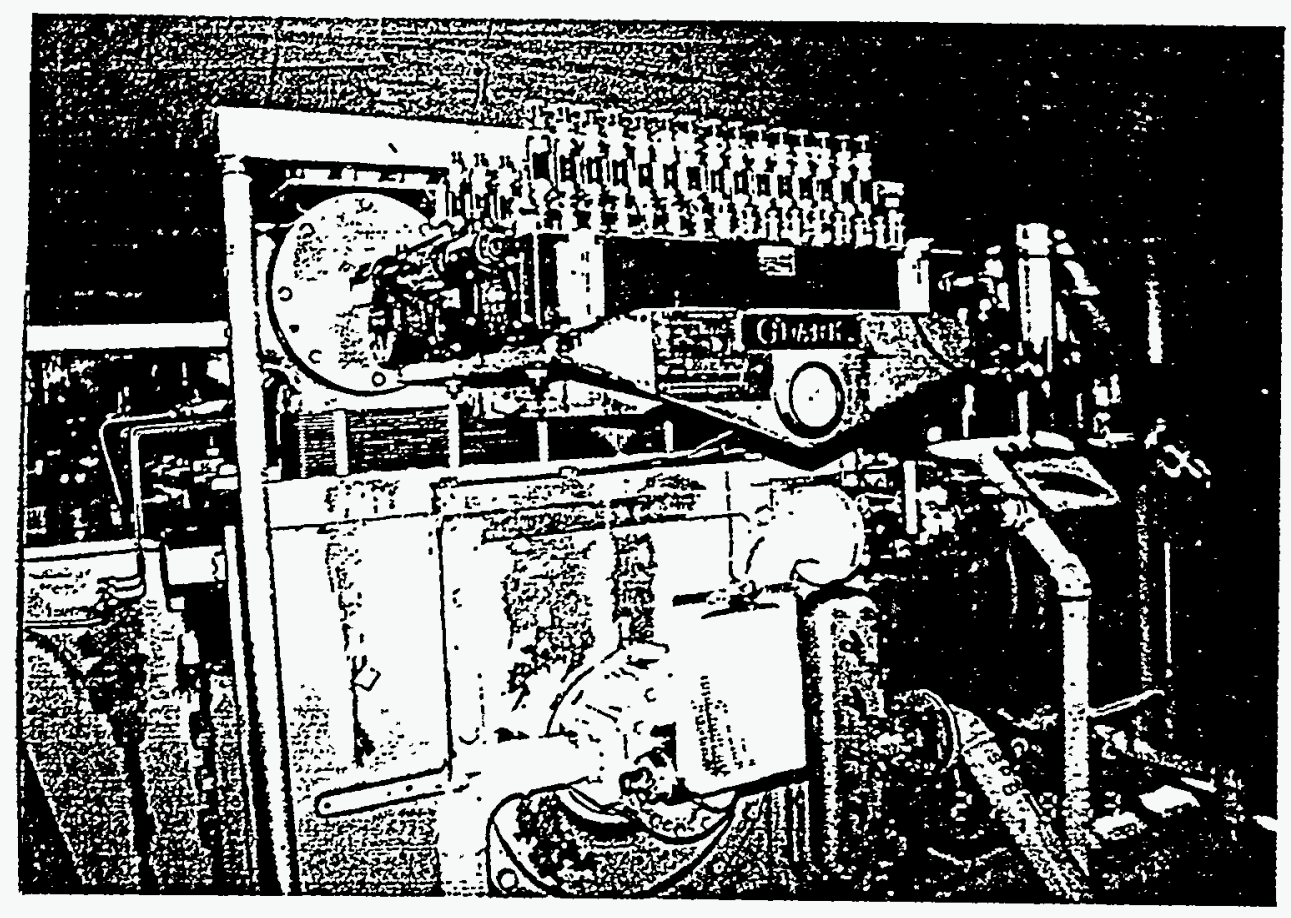

Exhibit 2.28: Photograph of TRA -643 ETR Compressor Building Compressor Actuators

Representative Oil Sample Required

(View to North) 


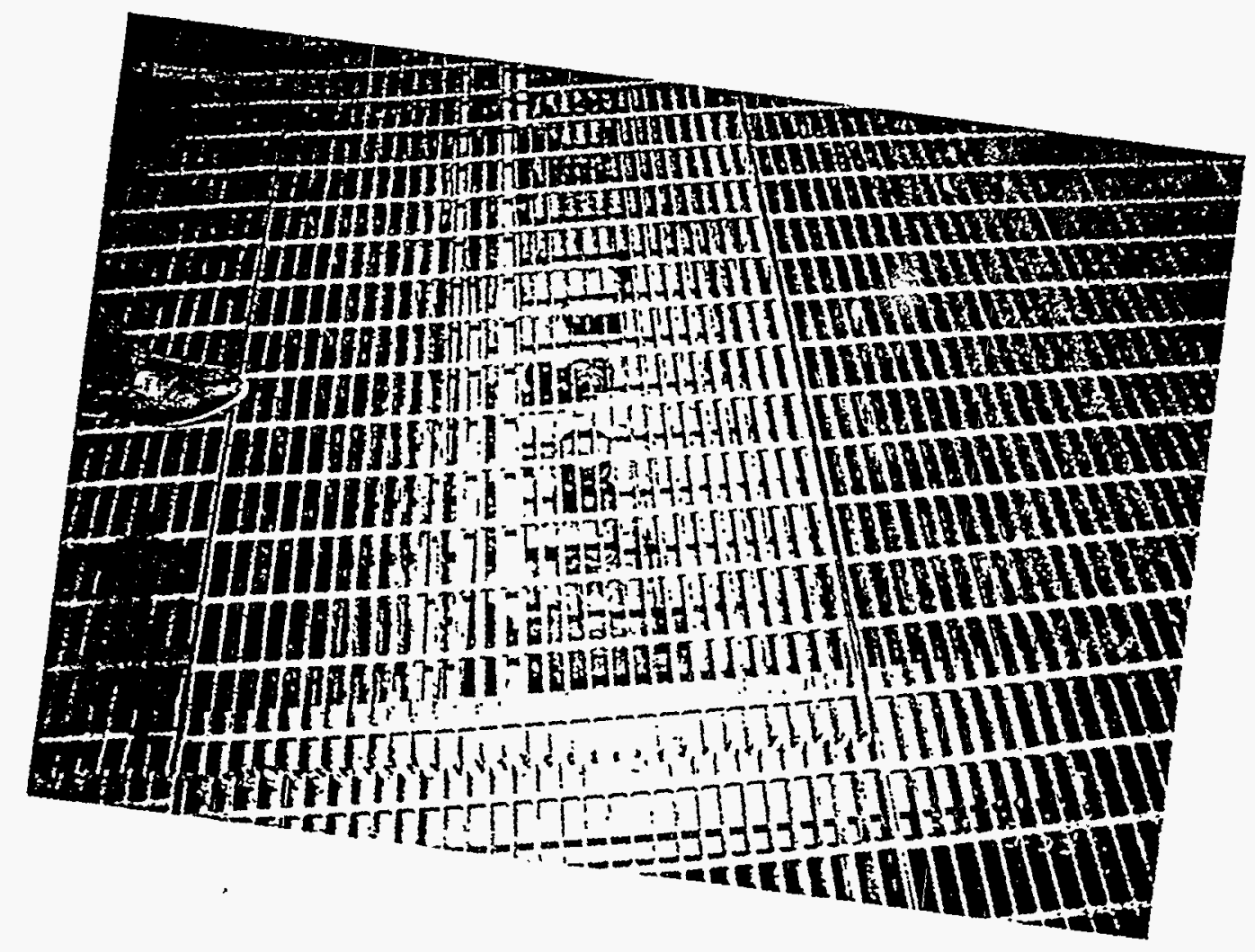

Exhibit 2.29: Photograph of TRA -643 ETR Compressor Building
Trench Below Compressors
Trench Sample Required 


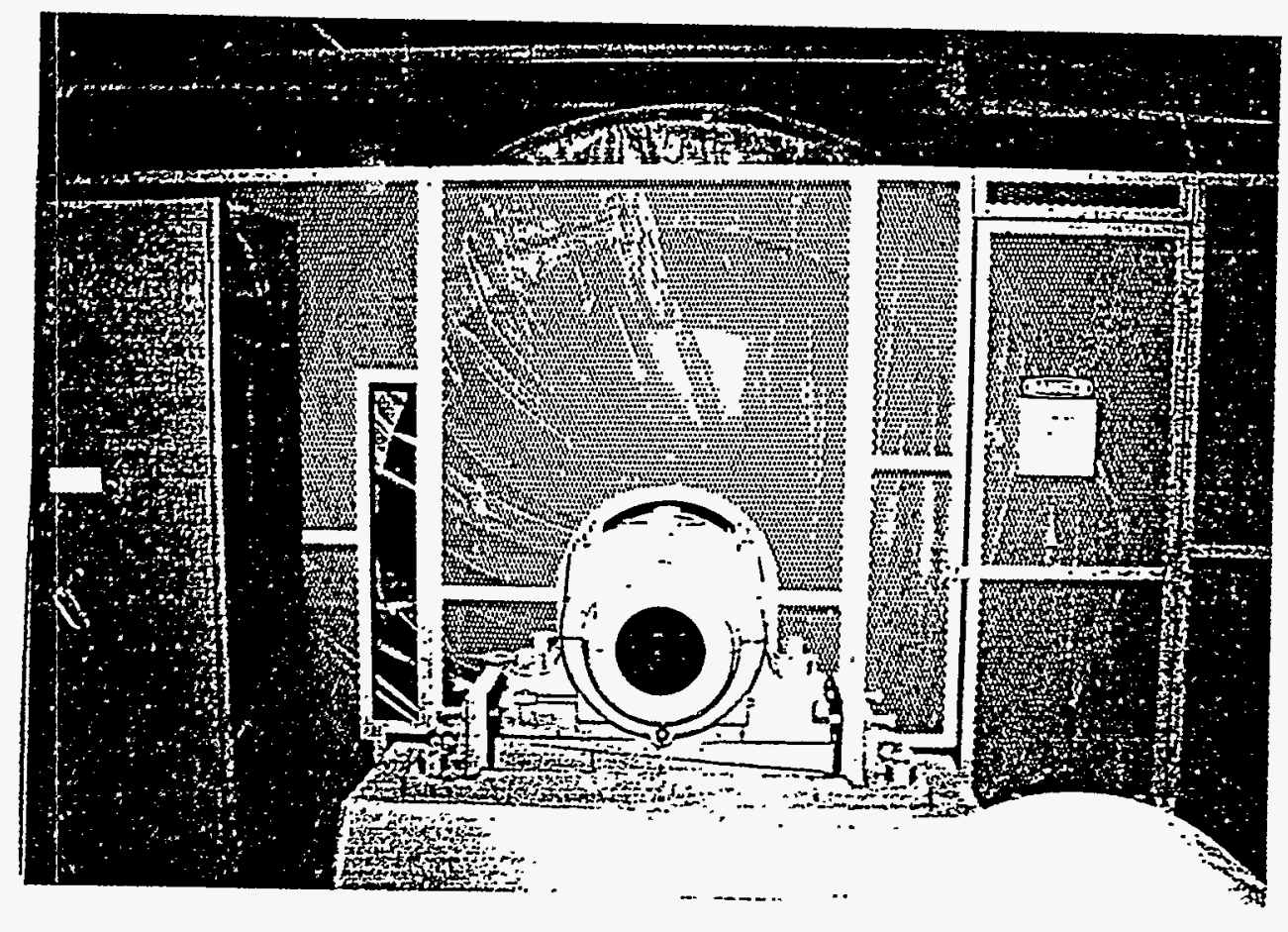

Exhibit 2.30: Photograph of TRA -643 ETR Compressor Building Compressor Motor Drive

Oil Reservoir Sample Required

(View to North) 

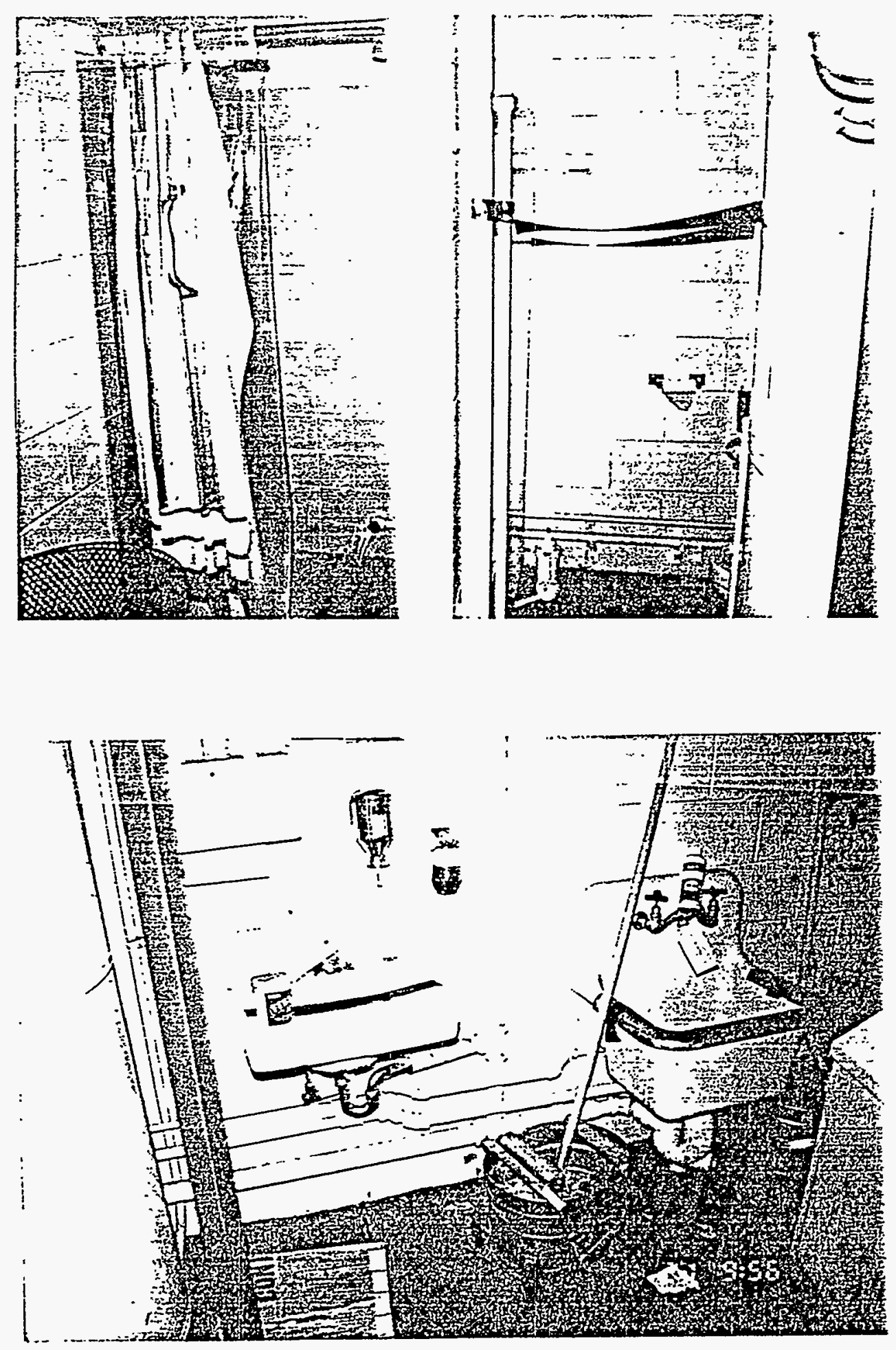

Exhibit 2.31: Photographs of TRA -643 ETR Compressor Building Decon Restroom

Samples from Shower Drain and Sinks Required

(View to West) 

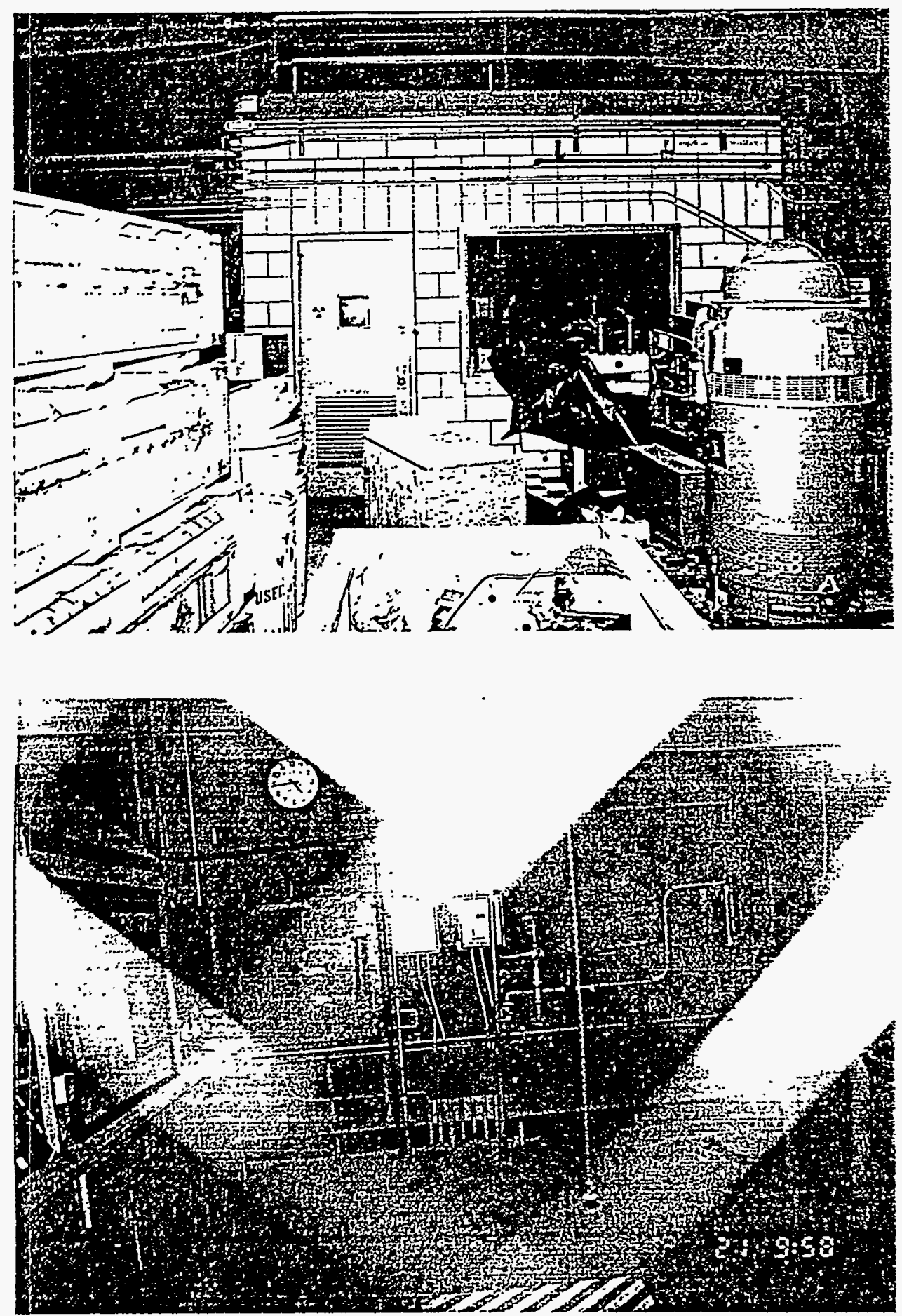

Exhibit 2.32: Photographs of TRA -643 ETR Compressor Building Chemistry Laboratory

Samples from Sink and Trench Required

(View to South) 

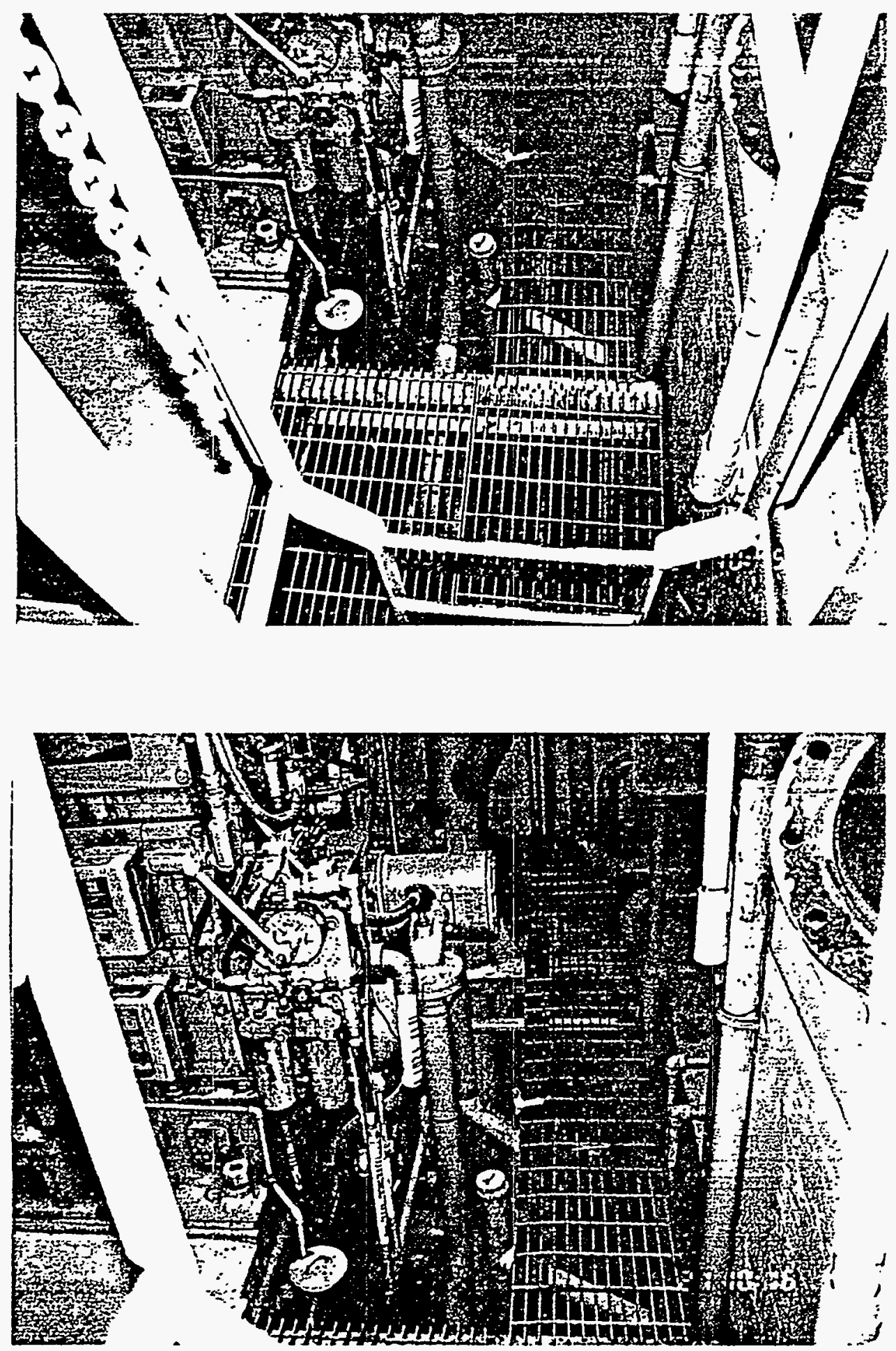

Exhibit 2.33: Photographs of TRA -648 ETR Electrical Building Diesel Generator Room Pit

Pit Samples Required

(View to West) 


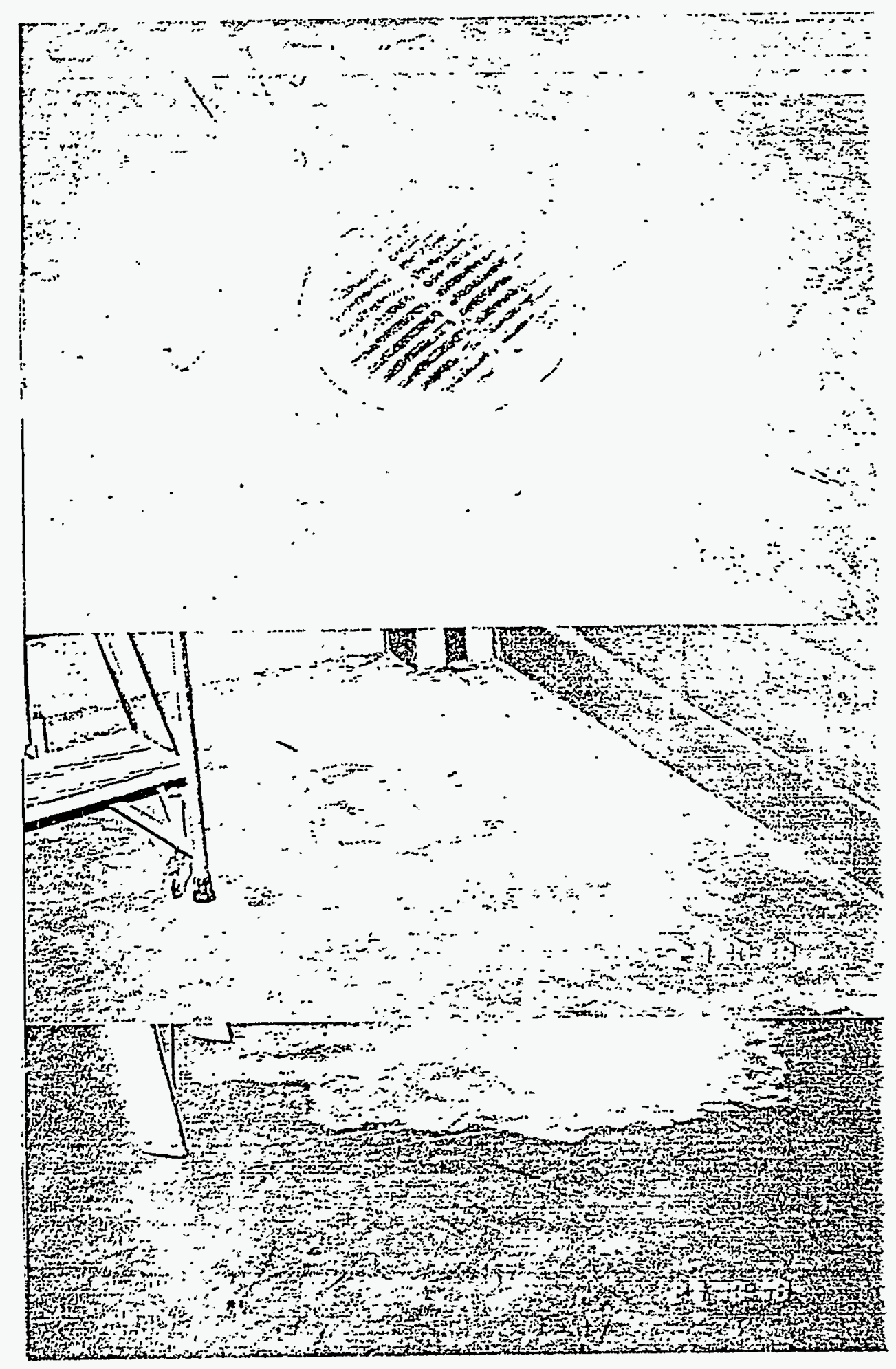

Exhibit 2.34: Photographs of TRA -648 ETR Electrical Building Battery Room

Samples of Drain and Floor Spill Areas Required

(View to Northeast)

Page 101 of 108 


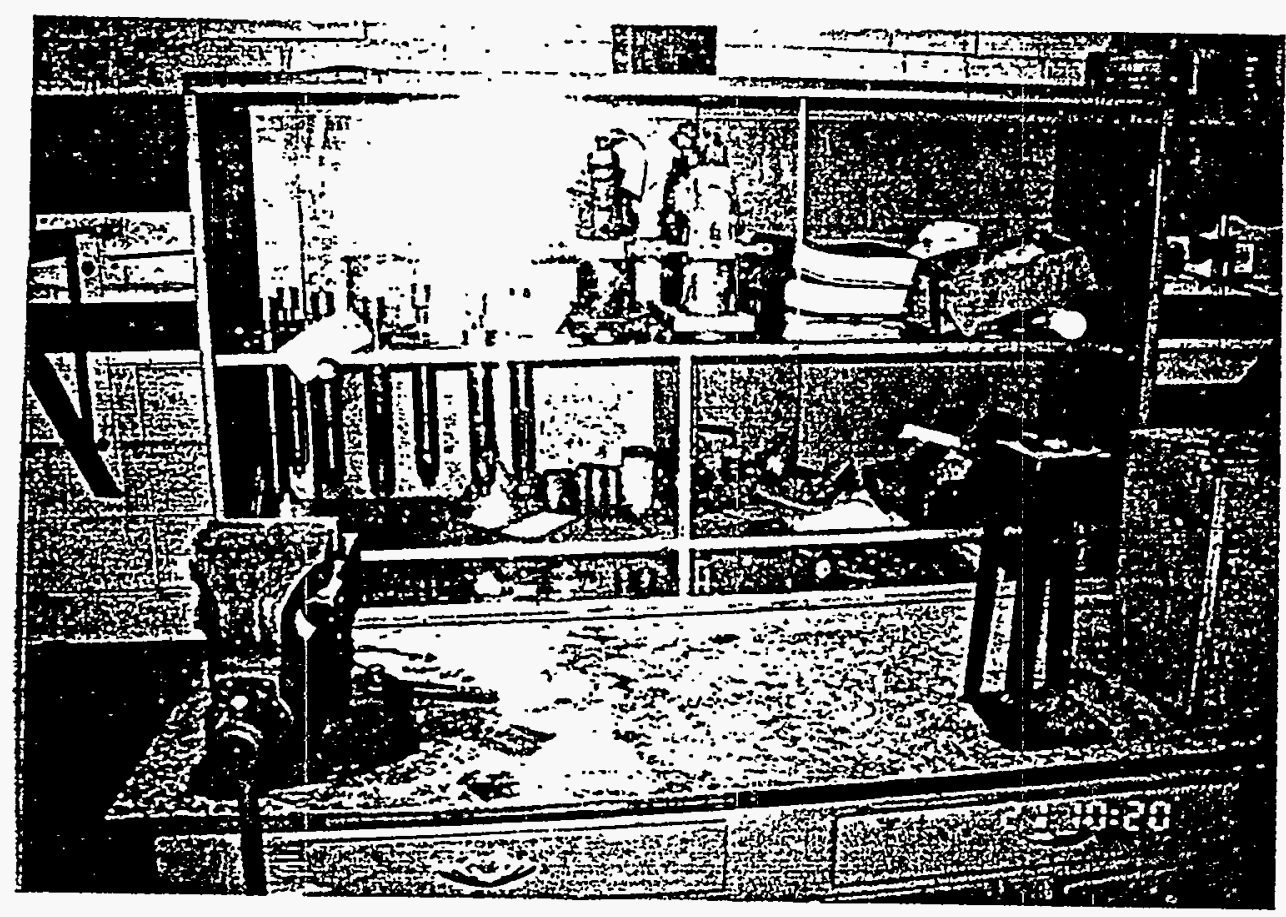

Exhibit 2.35: Photograph of TRA -663 ETR Superior Diesel Building Fuel Injector Cleaning Station

Residue Samples Required 
APPENDIX A

Page 103 of 108 
Figures A-1, A-2, and A-3 in Appendix A present examples of sample labels, chainof-custody forms, and sample log sheets that will be used for the sampling excursion. 

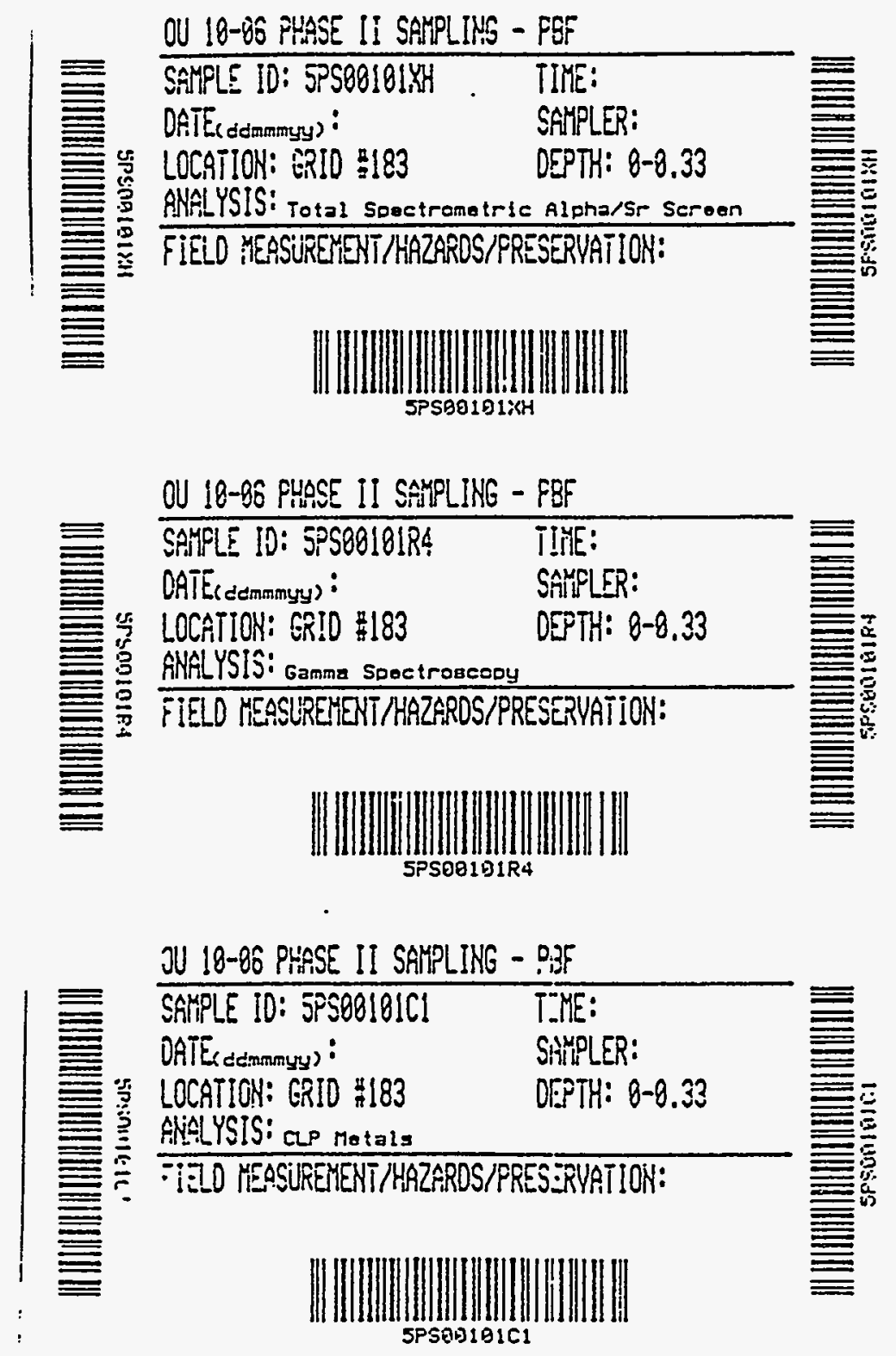

Figure A-1: Sample Label 


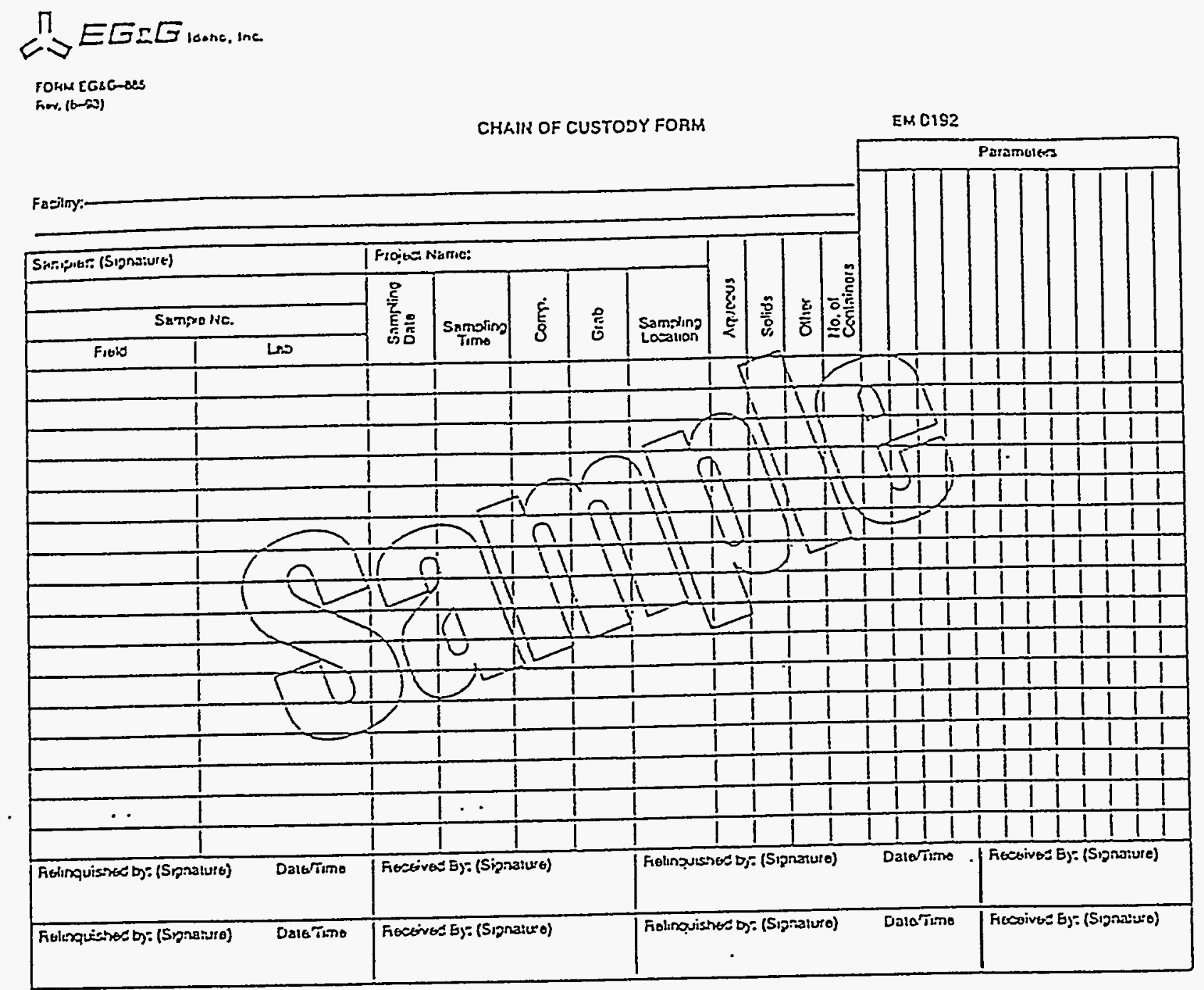

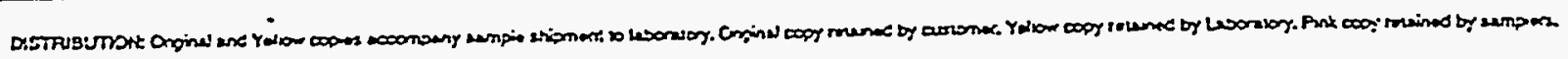

Figure A-2: Chain-of-Custody (COC) Form 


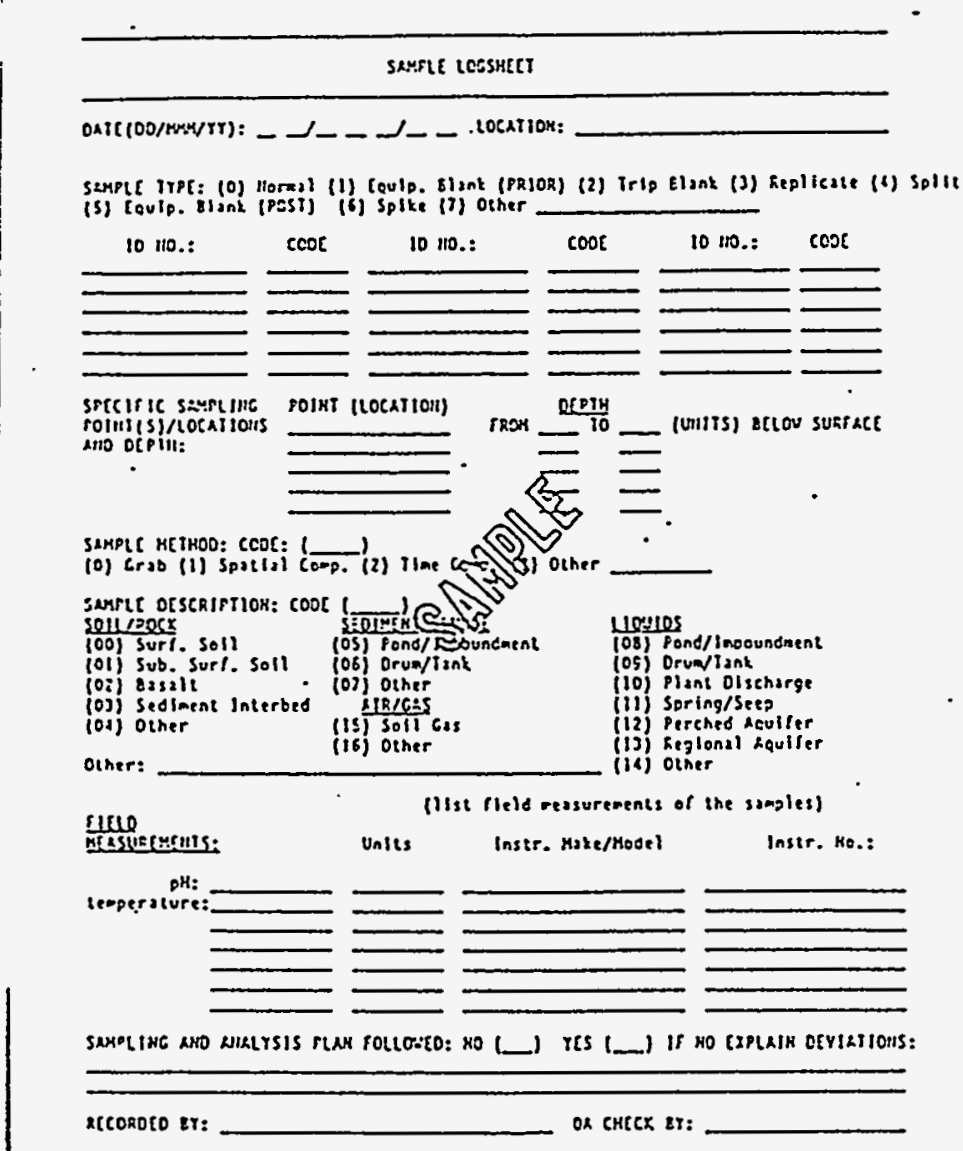

Figure A-3: Sample Logsheets 


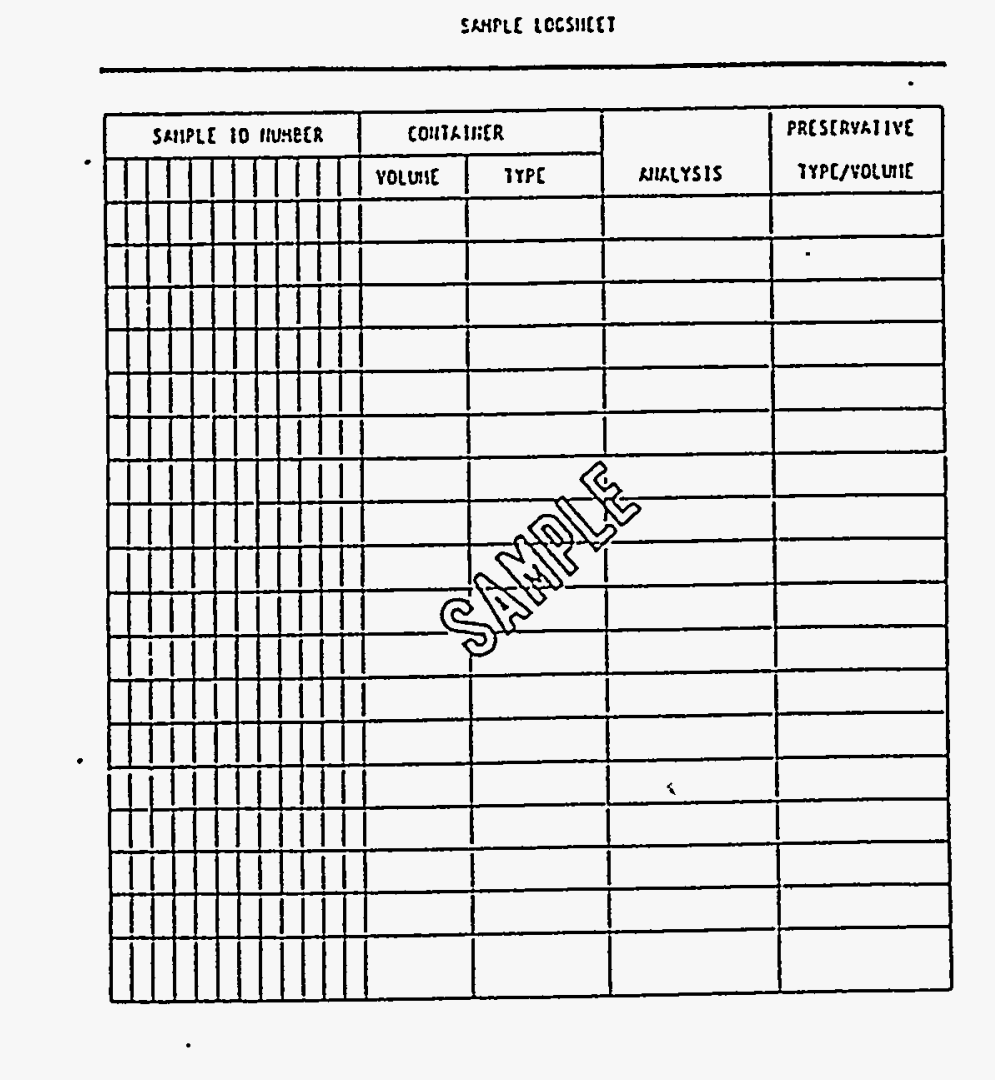

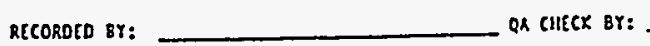

Figure A-3: Sample Logsheet (Page 2 of 2)

Page 108 of 108 